
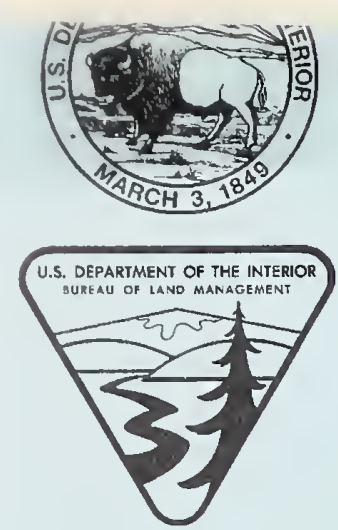

tates Department of the Interior

Bureau of Land Management

\title{
ENVIRONMENTAL ASSESSMENT FOR PREDATOR MANAGEMENT IN MONTANA
}

\author{
EA \#MT-930-93-01
}

STATE DUUNMENTS COLLETION

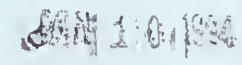

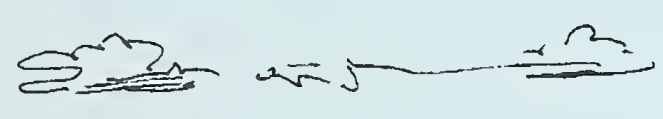

$<$
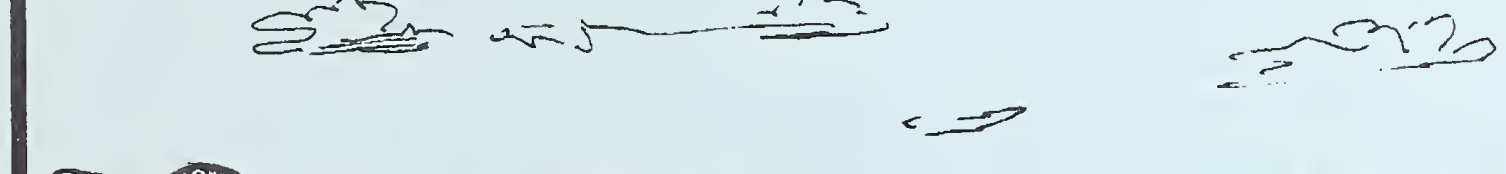

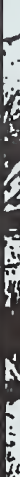
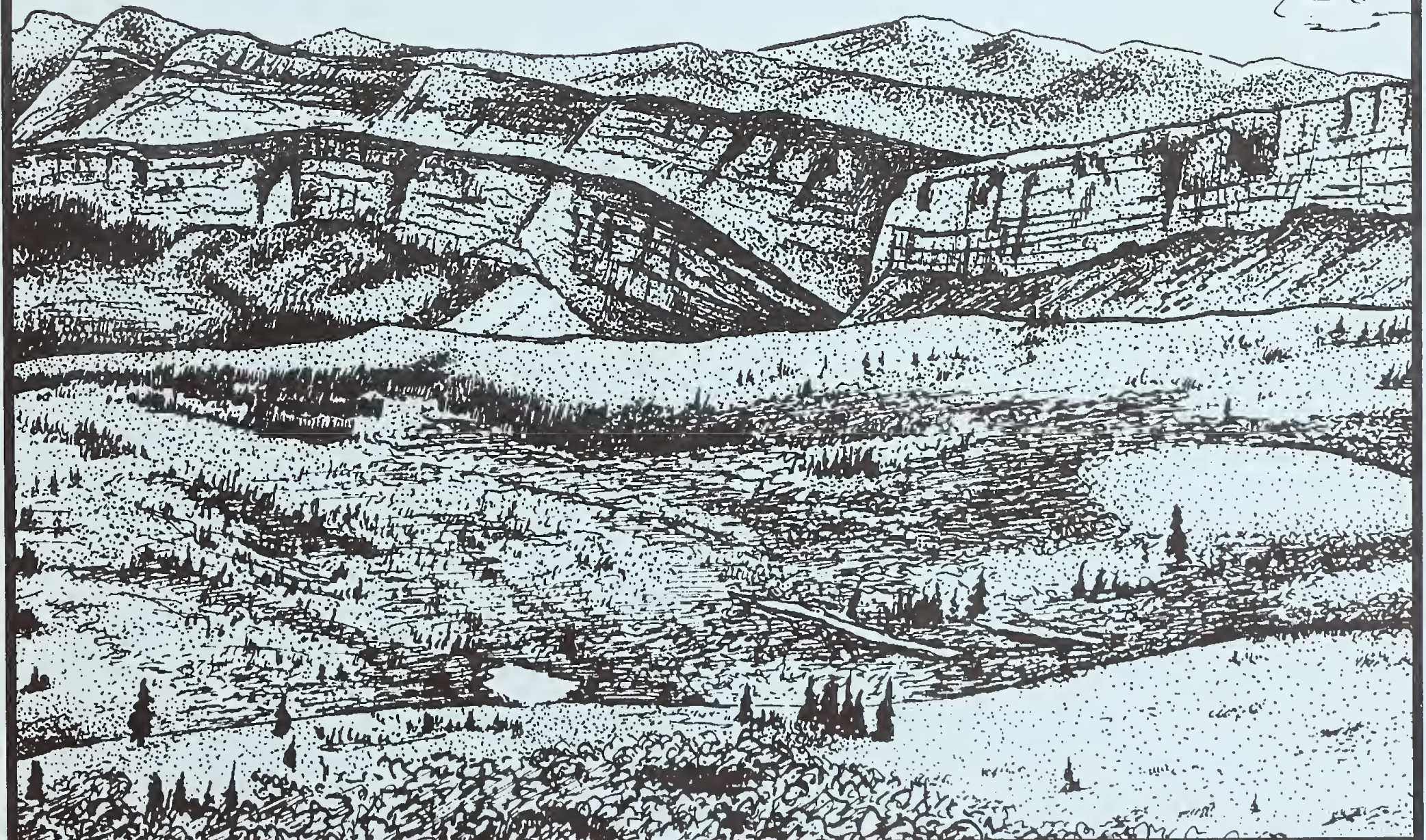


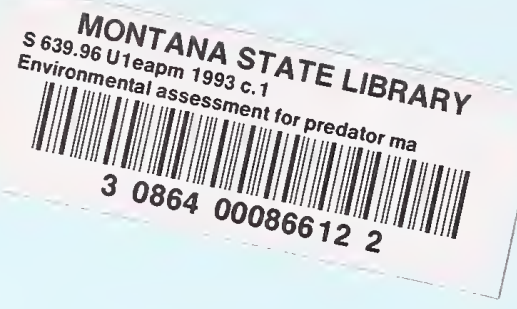

The Bureau of Land Management is responsible for the stewardship of our public lands. It is committed to manage, protect, and improve these lands in a manner to serve the needs of the American people for all times. Management is based on the principles of multiple use and sustained yield of our nation's resources within a framework of environmental responsibility and scientific technology. These resources include recreation; rangelands; timber; minerals; watershed; fish and wildlife; wilderness; air; and scenic, scientific, and cultural values. 


\section{CONTENTS}

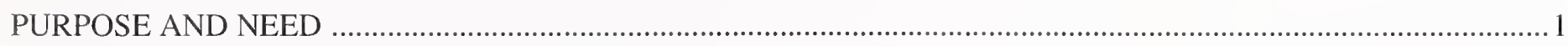

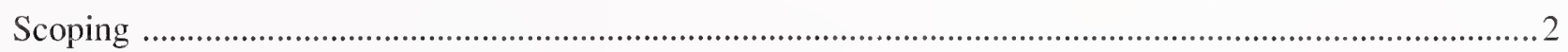

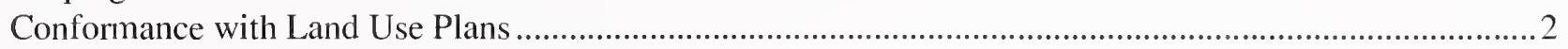

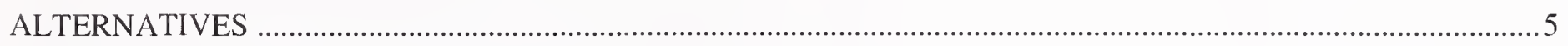

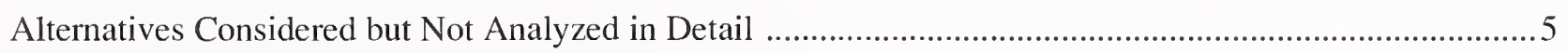

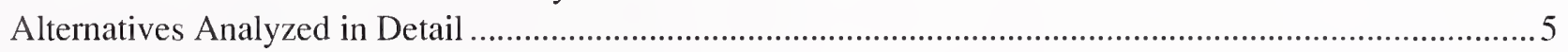

Alternative 1 - Integrated Pest Management .................................................................................... 6

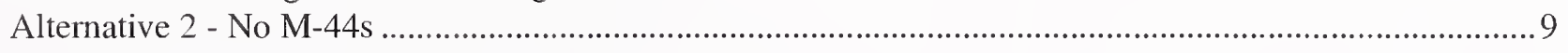

Alternative 3 - No Action (Emergency Control Only) .......................................................................

Alternative 4 - No APHIS-ADC or DOL Predator Management on BLM Lands ........................................9

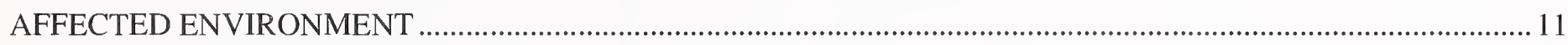

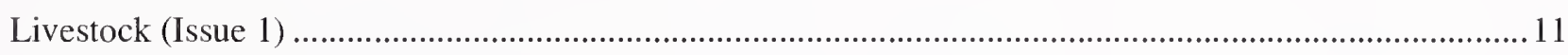

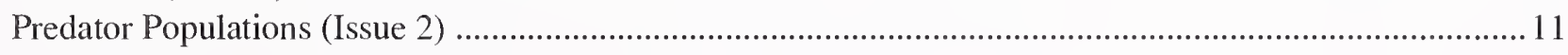

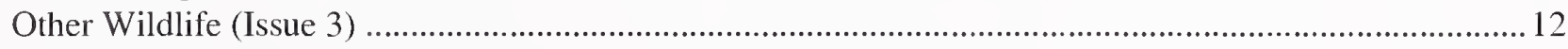

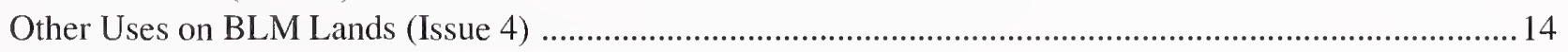

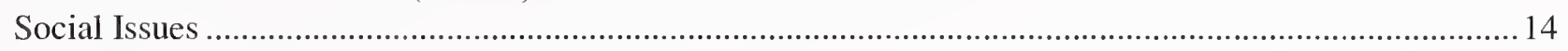

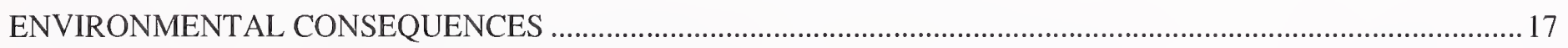

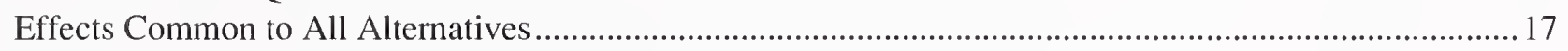

Alternative 1 (IPM - Proposed Action) ............................................................................................... 17

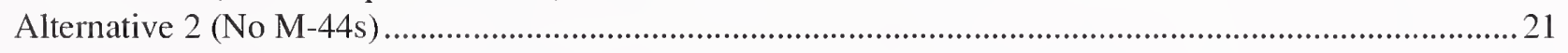

Alternative 3 (Emergency Control Only) ................................................................................................23

Alternative 4 (No APHIS-ADC or DOL Predator Management Activities on BLM Lands) ........................24

Alternative Summary - Number of Acres Affected by Activity

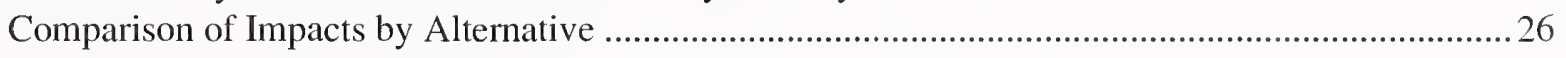

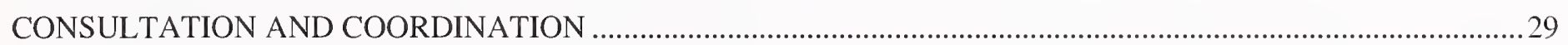

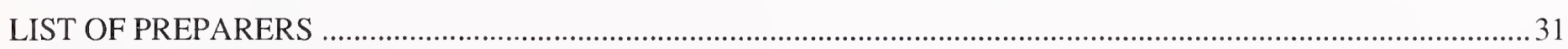

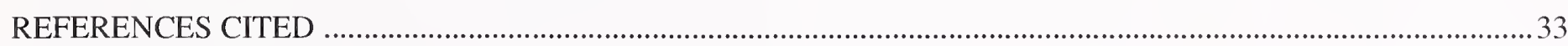

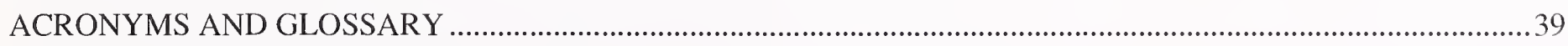

\section{APPENDICES}

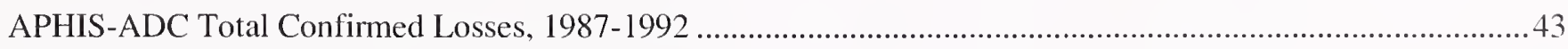

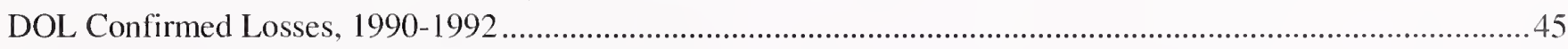

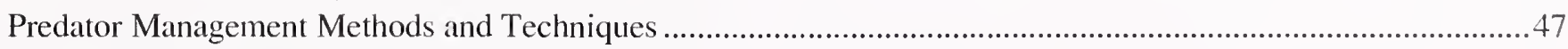

USFWS Biological Opinion/Reasonable and Prudent Measures ...................................................................49

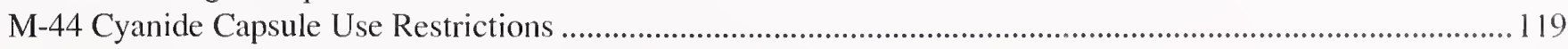

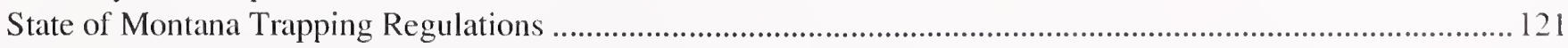

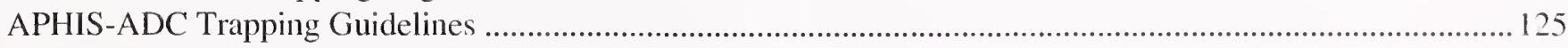

Montana Sheep/Lamb Losses, Livestock Inventory for Montana, and Cattle and Calve Losses .......................... 129

MAPS

Map \#1 - Human Safety Zones

Back of Book

Map \#2 - Designated Bird Hunting Areas

Back of Book

Map \#3 - Historical Loss Areas

Back of Book

Map \#4 - Threatened and Endangered Species Back of Book 
Digitized by the Internet Archive in 2016 


\section{PURPOSE AND NEED}

This Environmental Analysis (EA) addresses the effects of proposed predator management activities on lands managed by the Bureau of Land Management (BLM) in Montana. Such activities would be carried out in most Montana counties by the Animal and Plant Health Inspection Service (APHIS)-Animal Damage Control (ADC) of the U.S. Department of Agriculture. However, in McCone, Dawson, Richland, Carter and Powder River Counties, predator management activities would be carried out by personnel supervised by the Montana Department of Livestock (DOL). All predator management activities on BLM lands would be conducted in accordance with national and state Memoranda of Understanding (MOUs) between BLM, APHIS$\mathrm{ADC}$, and DOL. Such agreements identify the responsibilities of the respective agencies in implementing predator management activities on BLM lands, and establish general guidelines to assure a uniform statewide program.

The primary statutory authority for the predator management program is the Animal Damage Control Act of March 2, 1931, as amended (46 Stat. 1468; 7 U.S.C. 426-426b), which states:

"The Secretary of Agriculture is hereby authorized and directed to conduct investigations, experiments, and tests as he may deem necessary in order to determine, demonstrate, and promulgate the best methods of eradication, suppression, or bringing under control on national forests and other areas of public domain as well as on State, Territory, or privately owned lands of mountain lions, wolves, coyotes, bobcats, prairie dogs, gophers, ground squirrels, jackrabbits, and other animals injurious to agriculture, horticulture, forestry, animal husbandry, wild game animals, furbearing animals, and birds, and for the protection of stock and other domestic animals through suppression of rabies and tularemia in predatory or other wild animals and to conduct campaigns for the destruction or control of such animals. Provided, that in carrying out the provision of this Section the Secretary of Agriculture may cooperate with State, individuals, and public and private agencies, organizations, and institutions."

APHIS-ADC is authorized by Congress to conduct federal predator management activities relating to most wildlife damage situations. Field activities are conductcd within authorizations received from cooperating federal and state regulatory agencies.

In Montana, under the Airborne Hunting Act, Public Law 92-159, and Montana Codc Annotated Section 81-7-501, the DOL has the responsibility for control of predatory animals and is authorized to issue aerial hunting permits for the protection of livestock. The Airborne Hunting Act prohibits the killing or har asment of wildlife from aircraft. It also authorizes any state to issuc a license or permit for aerial hunting of certain wildlife for protection of livestock and for other purposes.

The BLM is responsicle for the stwwardship of our public lands. The BLM is corrmined to manage, protect, and improve these lands in a mannur to serve the needs of the American people for all times. Management is based on the principles of multiple use and sustained yield of our nation's resources within a framework of environmental responsibility and scientific technology. These resources include recreation; rangelands; timber; minerals; watersheds: fish and wildlife; wilderness; air: and scenic, scientific, and cultural values.

A comprehensive Environmental Impact Statement (EIS). "U.S. Fish and Vildlife Service"s Mammalian Predator Damage Management for Livestock Protection in the Westcrn United States," was completed in 1979 by the U.S. Fish and Wildlife Service (USFWS) to comply with the terms of the National Environmental Policy Act (NEPA). The 1979 EIS evaluated the predator management program on a nationwide basis. It discussed the USFWS proposed program and nine alternatives. The proposed program had five operational control strategies, including reducing local carnivore populations on local depredating target species populations or individual animals, using preventive control or general suppression of local populations of target species, buffer zone management, and offending animal management.

In its role as a muitiple vse manager of public lands. BLM must consider iritcrelationships of the various uses such as domestic livestock grazing, wildife and recreation. Most animal damage in Montana consists of predation on domestic livestock. Threats to human heaith and safely are infrequent but can and do occur. Prompt response to these situations could be critical.

Confirmed losses, which are livestock actually found and verified by APHIS-ADC personnel as predator hills, over the period of 1987 through 1992 on lands of all ownership in Montana ranged from 1.576 to 3.846 per yealr with a total confirmed loss of 15.006 (an average of $2,5($ ) I per year). Sec Appendix 1. The DOL confined losses for the period of 1990- 1992 raneed fron 440 to 1.003, with at total confirmed loss of 2,142 (an average of 714 per year). Sec Appendix 2. The recent historic level of prediation loss is expected to 
continue at about the same rate indefinitely. Many additional livestock losses are reported due to predators than what APHIS-ADC and DOL supervised personnel confirm. Reported user losses from predation in Montana on lands of all ownerships from the Montana Agricultural Statistics Service for 1991 was approximately 44,900 sheep and 2,100 cattle. The direct dollar value estimated for all livestock lost by predation in Montanaduring 1991 amounted to \$2.4 million (Montana Agricultural Statistics Service, 1991).

\section{SCOPING}

Consultation, coordination and public involvement has occurred throughout the scoping process with scoping letters, a Federal Register notice, news releases and meetings with state and other federal agencies. Formal scoping was initiated with a letter, dated July 15, 1993, which was distributed to over 800 organizations and individuals representing a wide range of public land users, range permittees, and others interested in projects on public lands. News articles were distributed throughout the state to notify the public of BLM's intent to prepare an EA on predator management. A Federal Register notice of intent to prepare an EA was published in July 1993. As of August 20, 1993, 83 comment letters had been received.

\section{Issues}

Four key issues were identified during scoping. These key issues guided the development of alternatives and the analysis of effects. The four issues focused the environmental analysis on site-specific, direct, indirect, and cumulative impacts that could occur under any alternative.

Key issues are:

\section{Livestock Losses on BLM Lands and Adjacent Private Lands (Issue 1)}

Concern was expressed that livestock losses resulting from predation, if left unchecked, would result in high economic losses to livestock operators. Others felt that livestock depredation on public lands is part of the "cost of doing business."

There was also concern that not allowing predator management on public lands would prevent livestock operators from adequately protecting their livestock, even on private lands. Others felt that the BLM has no obligation to adjacent private landowners and that predator management should be restricted to the private lands.

\section{Predator Populations (Issue 2)}

There was concern that existing coyote numbers would be suppressed below minimum viable populations as a result of predator management activities. There was also concern by some that past predator management activities by APHISADC, DOL, and livestock operators are partially responsible for low predator populations, and that more than just depredating predators were being taken. Some commentors believe predators should be preserved on BLM lands. Other commentors felt that coyotes or other predator species are so abundant, that predator management activities are necessary to keep the numbers at a manageable level.

\section{Other Wildlife (Issue 3)}

Respondents were concerned about the effects of predator management on other wildlife species, including threatened and endangered and candidate species. Some commentors believe that wildlife have become more abundant because of predator management.

\section{Other BLM Land Uses (Issue 4)}

Respondents were concerned about the effect predator management activities would have on recreation use, the special values of Wilderness Study Areas (WSA), and Areas of Critical Environmental Concern (ACEC).

\section{CONFORMANCE WITH LAND USE PLANS}

BLM planning decisions affecting predator management activities on public lands in Montana are contained in the following documents, listed by district. The planning decisions in these documents concerning predator management activities are briefly stated below.

\section{Miles City District:}

Big Dry Resource Management Plan (RMP) (Draft 1993) - This plan specifies that predator management activities be authorized. Aerial hunting of predators would be permitted in the planning area.

\section{Lewistown District:}

Judith/Valley/Phillips RMP (October 1992) - BLM would allow predator management within the planning area. The methods used could include predator management methodologies and techniques found in Appendix 3. Predator management would be conducted on BLM land by the U.S. Department of Agriculture, 
APHIS-ADC. Predator management would be allowed on prairie dog towns within the 7 kilometer complex with restrictions on the placement of $\mathrm{M}-44 \mathrm{~s}$, traps, and snares to avoid taking black-footed ferrets (See Environmental Consequences, Alternative 1, Issue 3).

\section{Butte District:}

Garnet RMP (May 1986) - All predator management activities would be coordinated with the USFWS, Montana Department of Fish, Wildlife and Parks (MDFWP), and in the case of aerial gunning requests, with the DOL.

Headwaters RMP (November 1983) - Predator management activities would be coordinated with the USFWS and, in the case of aerial gunning requests, with the DOL.

Dillon Management Framework Plan (September 1979) - It was decided that selective aerial predator control be the only means by which predatory animals, other than wolves be removed from BLM land between the town of Lima and Bloody Dick Creek. The rationale was that the most positive indication of gray wolf occupancy recorded at that time had been documented in the Lemhi Pass area. It further stated that the BLM would be negligent of the intent of the Endangered Species Act if it allowed steel traps or poisoning for predators to take place in the area of concern.
Since then, the USFWS has provided APHIS-ADC with their biological opinion (See Appendix 4), which states that the use of snares, steel traps and aerial shooting is not likely to jeopardize the continued existence of the gray wolf. Use of $\mathrm{M}-44 \mathrm{~s}$ is prohibited in occupied gray wolf range. In any of the alternatives, the reasonable and prudent measures provided by the USFWS would be followed. Therefore, the Dillon Management Framework Plan would be amended by the final decision made on this EA.

\section{OTHER LAND USE PLANS}

Predator management is not specifically addressed in the documents listed below. However, livestock grazing is permitted under these land use plans. Predator management would be open to consideration, in support of livestock grazing management, unless otherwise prohibited. For example, predator management would be prohibited where it would jeopardize any federally listed threatened or endangered plant or animal. All plans require Section 7 consultation with the USFWS on any specific actions which may affect a protected species.

\section{Miles City District:}

Billings RMP (November 1983)

Powder River RMP (December 1984)

\section{Lewistown District:}

West Hi-Line RMP (1988)

Headwaters RMP (November 1983) 


\section{ALTERNATIVES}

\section{ALTERNATIVES CONSIDERED BUT NOT ANALYZED IN DETAIL}

Prairic dog control should be included in this EA. Prairie dog control was specifically addressed in the Draft Big Dry RMP and the Judith, Valley, Phillips RMP. If there is a need to manage prairie dogs on BLM land in an area that has not been previously analyzed for that action, an environmental assessment would be completed at that time.

The full range of available non-lethal methods (animal husbandry, guard dogs, etc.) should be employed prior to the use of lethal control. Livestock management and other non-lethal management methods are discussed in this document, in practice, and continue to be recommended through technical assistance through APHIS-ADC as an integral part of predator management. These practices can be appropriate in certain circumstances, but cannot replace lethal methods in every case. The proposed action, Integrated Pest Management (IPM), would use a variety of practical mcthods, both lethal and non-lethal, for prevention and control of offending animals and keep animal damage to livestock or human health as low as possible. The 1979 USFWS EIS adequately discussed an alternative emphasizing non-lethal methods.

Predator management activities should not be authorized in WSAs or ACECs. Guidance issued in the "Interim Management Policy and Guidelines for Lands Under Wilderness Review" (IMP), states "Animal damage control activities directed at individual offending animals may be permitted, as long as this will not jeopardize the continued presence of any species in the area." Actions within all WSAs would meet this criteria in the alternatives discussed in the EA. Predator management activities would be restricted in two ACECs (See Environmental Consequences, Issue 4) based on recreational values. Othcr ACECs would not be affectcd by these activities based on the analyses donc in the EA.

Livestock grazing should be restricted in those areas where there has been a history of high livestock depredation. This alternative was not considered in cletail bccause it is not consistent with existing regulations. Also, by moving livestock to an area where livestock depredation has been low, the offending animal is likely to follow the livestock which could lead to accelcrated predation if therc are more offending animals in the relocated area.

A bounty program should be established. The BLM does not have the authority to establish a bounty program. Also, past bounty programs have been inadequate because individual offending animals were not taken, ecologically sound control methods were not always used, and predators were taken from outside of the local area for purposes of compensation.

\section{ALTERNATIVES ANALYZED IN DETAIL}

\section{Management Common to All Alternatives}

Certain stipulations would apply to Alternatives I - III (Control Alternatives). These common stipulations concern WSAs and Reasonable and Prudent Measures submitted by the USFWS (Washington, D.C. office) to APHIS in their Biological Opinion on the effects to threatened and endangered species by the predator management program (July 28, 1992). See Appendix 4 for USFWS Reasonable and Prudent Measures.

As stated in the "Interim Managenent Policy and Guidelines for Lands Under Wilderness Review" (IMP), predator management directed at individual offending animals may be permitted, as long as this will not jeopardize the continued presence of any species in the area. Shooting of animals from an aircraft may be allowed, only where specifically authorized by provisions of state law and upon BLM approval.

Actions within all WSAs must meet the non-impairment criteria as stated in the IMP. All vehicular traffic off existing roads and trails must be approved by the BLM authorized officer, as identified in existing travel plans.

\section{Planned Control Areas}

Planned control areas are sites on BLM land where predator management activities could occur if not restricted by designated bird hunting areas, human safety areas, or threatened and endangered species habitat.

\section{Human Health and Safety Zones}

No predator mantigement would be allowed within human safety zones als outlined on Map No. 1, exeept under emergency control procedures and BLM approval. In addi- 
tion to the designated safety zones shown on the map, no predator management would be allowed:

- within 1/4 (0.25) mile, or appropriate buffer zone of any community or residence unless the owner/occupant requests or approves control devices closer;

- within 1/4 (0.25) mile, or appropriate buffer zone of any state or federal highway;

- within $1 / 4(0.25)$ mile, or appropriate buffer zone of all developed recreation areas.

\section{Bird Hunting Areas}

Traps, snares, or M-44s that would be used in designated bird hunting areas, as outlined on Map No. 2, must be removed by APHIS-ADC personnel or DOL supervised personnel at least 2 days before the opening of all bird hunting seasons to ensure bird dogs would not be threatened by these tools. Scents used to attract predators to M-44s are also attractive to bird dogs. Traps and snares used are canid specific, which could also endanger bird dogs. During bird hunting seasons, traps, snares or M-44s would not be allowed, except on a case-by-case basis under emergency control procedures (see Alternative 3 for a description of emergency control procedures).

\section{Posting Control Areas}

APHIS-ADC and DOL must post signs to provide adequate warning of all areas where control devices would be used. Enough signs must be installed at commonly used gates, access points, or where appropriate, and at the specific device location to ensure proper public notification. Signs would be routinely checked to assure they are present, obvious, and readable. Signs would also be removed when equipment is not longer in use. Signs must also be posted directly at M-44 locations to ensure proper public notification.

\section{Checking of Control Devices}

Traps, snares, and other devices would be checked at intervals consistent with state regulations, to facilitate the release of nontarget animals. In the area west of Choteau, APHIS-ADC is not authorized to use M-44s and has special timing restrictions on checking traps due to the presence of various threatened and endangered species.

\section{Monitoring}

Under the Alternatives 1 through 3, APHIS-ADC or DOL would be required to provide data on their activities. This information is necessary for:

1. Reevaluating the use of specific control techniques,

2. Deciding on appropriate activities for the coming year at the annual meeting.

All data would be submitted to the appropriate BLM district office. Monitoring specifics could be modified as per mutual agreement between BLM and APHIS-ADC or DOL at the annual meeting.

Required data would include:

1. A table showing number and species of target and nontarget animals taken by each control technique.

2. The number of confirmed livestock losses by species on BLM lands by BLM district.

This EA and the subsequent decision records would in no way restrict actions of private individuals that would otherwise be legal under state or federal law. This includes the right of a livestock operator to use lethal force against offending predators (excluding threatened and endangered species and Golden Eagles) in the protection of their livestock.

\section{ALTERNATIVE 1 - Integrated Pest Management (APHIS-ADC, DOL and BLM Proposed Action)}

This alternative emphasizes an Integrated Pest Management (IPM) approach to reduce animal damage. IPM is the process of applying a variety of practical methods for prevention and control to minimize animal damage to livestock or human health. This is accomplished in such a manner as to minimize damage control costs, and potentially harmful effects of control measures to humans, target and non-target species and the environment. This IPM process would draw from a large array of options using techniques deemed to be essential depending on the nature of the problem. 
Predator management methods and techniques that would be used in planned control areas are decided upon at the annual meeting between BLM, APHIS-ADC, DOL, and MFWP. These methods are defined in Appendix 3 and would be applied as either a corrective (in response to actual loss or repeated harassment) or preventive (local predator population reduction based on historical losses) strategy. Management actions would be directed towards localized populations and/or individual offending predators.

\section{Management Strategies:}

1. M-44s, would be used for canid control after annual authorization or re-authorization from the Department of the Interior within the planned control areas. All EPA regulations governing their use would be followed (see Appendix 5). M-44s would not be used in designated bird hunting areas during the bird-hunting seasons or within defined human safety zones.

2. Livestock producer methods would be encouraged throughout the state. Methods that livestock producers might use include guarding animals and electronic scaring devices such as propane exploders, siren strobe devices, and tape recordings. Currently, about 35 percent (APHIS-ADC, April 1992) of the livestock producers requesting services from APHIS-ADC in the state use these measures with varying degrees of success. APHIS-ADC would continue to offer technical assistance to individuals and provide sources for dog procurement to permittees.

3. Leg-hold traps and snares would only be used within the planned control areas. Pan tension devices would be used with traps to exclude the smaller non-target animals. Signs would be posted at main access roads into planned control areas when traps or snares are used. The use of traps would conform with State Trapping Regulations (See Appendix 6) and APHISADC guidelines (See Appendix 7).

4. Calling and shooting would be used to manage ongoing depredation situations.

5. Denning, which consists of finding coyote dens and taking animals with an EPA registered fumigant, would be used in the planned control areas where predation can be attributed to food procurement for young.

6. Aerial hunting would be allowed within the planned control areas.

\section{Requests for Control}

Requests for control would come directly to APHIS-ADC from the permitree or to DOL in those counties with a DOL approved MOU. APHIS-ADC or DOL would investigate the request to verify the cause of death. Once the cause of death has been determined and if a wildlife species is responsible, appropriate action would be taken as outlined above.

\section{Predator Management Methodologies and Techniques}

The most effective approach to resolve wildlife damage problems is to integrate the use of several methods, either simultaneously or sequentially. A variety of methods are available to accomplish the objectives of the current predator management program. In selecting control techniques for specific damage situations, a wide variety of factors are considered, such as: the depredating species responsible, status of the target or potential nontarget species, season of damage, local environmental impacts, legal aspects, and relative costs of control options. In addition, various federal, state, and local statutes and regulations. MOUs, as well as APHIS-ADC program policies will also direct the selection and use of these tools.

\section{Livestock Producer Practices}

Livestock producer practices consist primarily of animal husbandry, habitat modification, and animal behavior management.

Animal husbandry practices would involve such practices as use of herders; gathering of sheep during periods when predation is most likely; use of guard dogs, burros or llamas to serve as custodians or protectors of sheep; shifting of breeding schedules to time births to coincide with the greatest availability of natural prey to predators or to avoid seasonal concentration of migrating predators such as eagles; use of sheds and pens to protect young animals cluring lambing and calving periods; removal or liming of carcasses and moving animals away from high risk areas based on experience with terrain, predator habitat and habits.

Habitat modification practices could be used where practical and feasible, based on the type and extent of the livestock operation. For example, on small ranch operations, fences (wire netting or electrical) and other physical barriers may be used. However, on most rangeland situations, these practices would be economically and ecologically impractical because fences designed to repel preda- 
tors would create barriers to movement of other wildlife species (i.e., deer, elk, and antelope).

Animal behavior modification refers to tactics which alter the behavior of the predators, including scare tactics (electronic distress sounds, propane exploders, pyrotechnics, lights, etc.) and aversive agents. These tactics used in relation to livestock predation are generally temporary and have limited application since predators tend to adapt or become accustomed to the scare tactic or aversive agent.

Livestock producers would be encouraged to use the above practices based on level of risk, need, and practical application.

\section{Corrective Damage Control}

Corrective damage control would occur when predator management activities respond to current damage problems. Corrective damage control would be authorized when the affected individual(s) has requested control services and the APHIS-ADC or DOL has verified and documented that a current (within the last 30 days) damage problem exists and is significant enough to warrant control services.

Livestock producers would be encouraged to enter into control agreements with APHIS-ADC or DOL, and rely on trained personnel to carry out predator management activities, which based on the circumstances, deemed to be necessary. Refer to Appendix 3 for a description of the predator management methods and techniques.

\section{Use of Chemical Toxicants}

M-44s would only be used in designated areas and their use would comply with the 26 EPA use restrictions (see Appendix 5). APHIS-ADC and DOL would post signs to provide adequate warning in all areas where control devices would be in use.

\section{Non-target Species}

Every precaution would be taken to prevent the capture or taking of non-target species (i.e., pan-tension devices). Captured animals would be released where consistent with public health considerations and provided they were not impaired beyond the capability of self maintenance.

\section{Emergency Animal Damage Control}

Situations may develop which warrant predator management activities in "no control" areas or "restricted control" areas. Such needs would come from operator requests and would be handled on a case-by-case basis by the BLM District Manager. Refer to Alternative 3 for a list of emergency ADC procedures.

\section{Basis for Designation of Restricted and Closed Control Areas}

Designation of corrective control areas would be determined and updated through the annual plan process, as previously outlined. Criteria considered in determining zones and level of control or any restrictions in method would include:

- Public health and safety.

- Intensity and timing of general recreation use and "sport" hunting.

- Presence of threatened, endangered, or sensitive wildlife species.

- Number and kind of livestock damaged or killed, historical losses, and the season in which the losses occurred.

- Potential for reoccurrence of loss.

- Conflicts with other uses.

\section{Preventive Damage Control}

Preventive damage control would occur when predator management activities respond to losses which have historically occurred. "Historically occurred" means that a significant problem has occurred one or more times per year. For example, in areas where livestock loss has historically occurred, predator management activities may be used prior to a current loss (within the last 30 days). Preventive damage control would be authorized through the ADC plan where the affected individual(s) has requested control services or where the APHIS-ADC or DOL has evaluated and documented that losses have occurred and will continue or recur in the absence of control activities. The historical loss areas, on Map No. 3, identify areas where preventive damage control would take place, in addition to the individual requests for control (as described above). 
By using preventive control, livestock losses could be decreased or stabilized. Coyote predation on livestock could be anticipated in advance by referring to historical loss information. Preventive damage control would then be used in historical loss areas.

\section{ALTERNATIVE 2 - No M-44S}

This alternative would be similar to Alternative 1 except that M-44s would not be authorized. All other approved methods for control would be permitted. Preventive control would be allowed in areas where historical livestock losses had been documented.

\section{ALTERNATIVE 3 - No Action (Emergency Control Only)}

Preventive control measures would not be authorized, and corrective control would be applied only where APHIS$\mathrm{ADC}$ or DOL have confirmed recent loss of livestock to predation. Emergency predator management is requested by an operator when losses are occurring. The BLM would review and approve/disapprove these requests on a caseby-case basis.

Emergency predator management needs would come from operator requests and would be handled on a case-by-case basis using the emergency control procedures outlined below.

\section{Emergency Control Procedures}

\section{Requests for control}

- Livestock permittees or affected individuals would be required to request control from APHIS-ADC or DOL.

\section{Problem Evaluation}

- APHIS-ADC or DOL supervised personnel would confirm losses and determine if emergency control would be warranted.

\section{Submission to BLM District Manager}

- APHIS-ADC or DOL supervised personnel would contact the BLM District Manager. The predator man- agement needed would be described. APHIS-ADC or DOL supervised personnel would specify the livestock permittee needing assistance and the reason for the control (losses).

\section{Authorization}

- Upon evaluation of the request, the BLM District Manager would notify APHIS-ADC or DOL if authorization would be granted and of any restrictions. APHIS-ADC or DOL may initiate measures prior to approval if immediate action is warranted. Otherwise, control would be initiated upon approval.

- APHIS-ADC or DOL would notify BLM of completion of any approved emergency control measures.

\section{ALTERNATIVE 4 - No APHIS-ADC or DOL Predator Management on BLM Lands}

Under this alternative, no APHIS-ADC or DOL predator management would be authorized on BLM land in Montana. However, private landowners could continue to conduct predator management on BLM lands and could continue to enter into agreements with APHIS-ADC or DOL to carry out predator management on private, state, and other non-BLM lands. APHIS-ADC would be available to provide technical assistance or make recommendations to operators.

A "no control" alternative was analyzed by the USFWS (EIS 1979) and was dismissed as an invalid alternative. However, due to interest in this option, an analysis of this alternative has been included. A "no control" alternative is also being evaluated in the current APHIS-ADC draft EIS.

This "no control" alternative would place the immediate burden of control work on BLM lands on livestock producers. Livestock producers, independently or cooperatively, would carry out or fund control work.

There would be less control over the kind of control device used and the manner in which animal damage control was carried out on BLM land. Illegal poisons would be used in greater quantity than in the present (Scrafford, USFWS, Personal Communication, 1993). 



\section{AFFECTED ENVIRONMENT}

This chapter describes the existing conditions within the proposed treatment areas and the environmental components that are affected by the proposed action described in Chapter I and the alternatives described in Chapter II. The discussion focuses on issues identified during the scoping process.

Cultural, historical, or paleontological resources; floodplains; prime or unique farmlands; hazardous materials; wilderness values; and wild and scenic rivers which are protected by federal law or regulation, would not be affected and, therefore, have not been addressed. In addition, it has been determined that none of the alternatives or any combination thereof would have a significant effect on regional hydrology, air quality, or wild horse management.

\section{LIVESTOCK (ISSUE 1)}

Current uses of private lands adjacent to and intermingled within BLM boundaries include ranching and farming. Ranching involves both cattle and sheep. Both types of operations range from large to small herds of livestock. Livestock production is listed as a major industry in Montana. Currently, the BLM authorizes approximately 1.2 million animal unit months (the amount of forage consumed by one cow and calf in 1 month or by five sheep in 1 month). Approximately 5 percent of this forage is authorized for sheep and approximately 95 percent for cattle.

Between 1987 and 1992 the total APHIS-ADC confirmed livestock losses due to predation in Montana averaged 2,501 animals per year. In addition, between 1990-1992, the DOL confirmed livestock losses due to predation in the five counties they operate in at an average of 714 per year. Reported losses of livestock to predators by the Montana Agricultural Statistics Service (MASS) were much higher. For example, MASS reported 44,900 sheep and lambs and 2,100 cattle and calves were lost to predators in 1991 (See Appendix 8). The estimated direct dollar value for the livestock losses during 1991 amounted to \$2.4 million (MASS, 1991). According to APHIS-ADC personnel, 16 percent of the predators taken in FY92 were taken on BLM lands (APHIS, 1993). If these figures fairly accurately reflect the livestock losses attributable to predators on BLM lands (i.e., 16 percent of livestock losses occurred because of predators on BLM lands), the annual value of livestock losses due to predators on BLM lands would be an estimated $\$ 390,000$. The total value of livestock lost to predators in Montana ( $\$ 2.4$ million) amounted to about 2 percent of the 1992 market value of calves, sheep, and lambs reported sold in Montana-\$120,900,000 (Shard, MASS. Personal Communication, 1993).

Although 4,000 livestock producers graze livestock on BLM lands, it is unknown how many suffer losses to predation. In 1992, over 200 livestock producers requested APHIS-ADC and DOL assistance while operating on BLM lands. Half of these requests were in Carter and Powder River counties in southeast Montana. It is also uncertain what the average annual value of those losses are. According to Jahnke Et al. (1987), it is likely that the "average outof-pocket indirect cost of predation increases as the size of operation increases as a result of two major factors. First, large operations are dependent on vast tracts of land, often conducive to inhabitation by predators. Second, large operators tend to lamb on the open range, which increases the susceptibility of lambs to predators."

According to APHIS, FY92 expenditures by federal, cooperative, and other funding sources (such as state and county sources) for animal damage control amounted to $\$ 1.5$ million.

\section{PREDATOR POPULATIONS (ISSUE 2)}

\section{Coyote}

Ideas of absolute densities for coyotes are obscure and frequently limited to educated guesses (Knowlton 1972). Coyotes are highly mobile animals and coyote home range (territory) size varies a great deal by sex of the animal and the age of the animal (Todd and Keith 1976, Pyrah 1984. Althoff 1978). Gese Et al. (1988) reported that resident annual coyote home ranges averaged: canyon - 2.1 square miles, hill - 2.5 square miles, pinyon-juniper-prairie -4.2 square miles, and prairie habitats - 6.3 square miles. Ozoga and Harger (1966), Edwards (1975), and Danner (1976), however, observed a wide overlap between coyote home range and did not consider coyotes territorial.

To further confound the idea of absolute coyote densities. the presence of an unusual food concentration can greatly influence spatial organization and non-breeding helpers at the den (Danner and Smith 1980). A positive relationship was established between coyote densities in mid-late winter and the availability of dead livestock (Roy and Dorrance 1985). In addition, each occupied coyote territory can have 
several non-breeding helpers at the den (Allen, Et al. 1987 and Bekoff and Wells 1982). Therefore, each defended coyote territory may have more than just a pair of coyotes. Messier and Barrette (1982) reported that during November through April, 35 percent of the coyotes were in packs of 3 to 5 animals and Gese (1988) reported that coyote groups of $2,3,4$, and 5 comprised 40,37, 10 and 6 percent of the resident population, respectively.

The total coyote population in Montana is unknown, however, population estimates can be made using scientific studies. Many authors have estimated coyote populations throughout the west and elsewhere (Pyrah 1984; Camenzind 1978; Knowlton 1972; Clark 1972; Gier 1968; and USDI 1979). By using the total land area of Montana (145,603 square miles), an estimated coyote population range can be made (USDI 1970).

Coyote populations will vary depending on the time of year, food abundance, and possibly habitat. Coyote densities range from a low of 0.39 /square mile during the time when populations are low (dispersing to other areas) to a high of $3.55 /$ square mile when populations are high (postwhelping).

Based on the total land area and the above information, Montana has a coyote population that ranges from a low of about 57,000 to a high of about 517,000 animals.

\section{Red Fox}

Red fox are the most common and well known species in the genus Vulpes, and is the most widely distributed nonspecific predator in the world (Voigt 1987). Foxes are regarded as nuisance predators almost everywhere, preying on wildlife and livestock, and have become notorious in many areas of the world as carriers of diseases (Allen and Sargeant 1993, Voigt 1987, Cowardin Et al. 1985, Pils and Martin 1978, Sargeant 1978, TullarEt al. 1976, Ables 1975, Richards 1974, Tabel Et al. 1974, Andrews Et al. 1973). Because of its importance to humans, it has been the subject of much study during the last 20 years. Investigations have revealed that red foxes are extremely adaptive with much diversity in their behavior and habitats. Voigt and Earle (1983) showed that red foxes avoided coyotes but coexisted in the same area and habitats.

The density of red fox populations is difficult to determine because of the animals secretive and elusive nature. However, the red fox has a high reproductive and dispersal capacity similar to coyotes, and are capable of withstanding high mortality within the population (Allen and Sargeant 1993, Voigt 1987, Voigt and MacDonald 1984, Harris 1979, Pils and Martin 1978, Storm Et al. 1976, Andrews Et al. 1973, and Phillips and Mech 1970). Strom Et al (1976) states that 95 percent of the females (43.6 percent were less than 1 year old) bred successfully in a population in Illinois and Iowa. Rowlands and Parkes (1935) and Creed (1960) reported that male red fox breed in their first year. Litter sizes averaged about 4.7 for 13 research studies and litters with as many as 14 and 17 offspring per litter have been reported (Strom 1976, Voigt 1987). Murie (1961), Ables (1969), and Sheldon (1950) all reported that more than one female was observed at the den, and suggest that red foxes have "helpers" at the den; a phenomenon also observed in coyotes. Reported red fox population densities have been as high as over 50/square mile (Harris 1977, MacDonald and Newdick 1982, Harris and Rayner 1986) where food was abundant; Ontario population densities are estimated at 2.6 animals/square mile (D. R. Voigt, unpub.), and Sargeant (1972) reported one fox den/3 square mile.

Based on the total land area and the above information, Montana has a red fox population of about 379,000 animals.

\section{OTHER WILDLIFE SPECIES (ISSUE 3)}

The public lands managed by BLM are home to many types of wildlife other than the previously mentioned predators.

\section{Threatened or Endangered Species}

Threatened or endangered species that could be affected by all of the alternatives are the black-footed ferret, grizzly bear, grey wolf, bald eagle, whooping crane, piping plover, Least tern and peregrine falcon. These species either occur, or have a potential to occur within the state. To date, none of these species has been affected by the APHIS-ADC or DOL predator management program on BLM lands. Some of the areas occupied by threatened, endangered and candidate species are identified on Map \#4.

\section{Black-Footed Ferret (State and Federally "endangered”)}

Black-footed ferrets were released in 1991 and 1992 in Wyoming, and there were three known litters born in the wild in 1993. There are 19 total black-footed ferrets known to live in the wild. All other known ferrets are in captive breeding facilities. One reintroduction area is located in north-central Montana in Phillips County, where large prairie dog colonies exist. There are large areas of BLM land as well as portions of the Fort Belknap Reservation, the Charles M. Russell National Wildlife Refuge (CMRNWR), and State land that could be involved. Three other potential areas in the Miles City District are currently being evaluated. 
Grizzly Bear (State game species; Federally "threatened")

Montana's grizzly bears on BLM managed lands are mainly located in the Northern Continental Divide ecosystem, with a few occurring in the Centennial Mountains. That population is healthy. Delisting information is being gathered for examination.

Gray Wolf (State and Federally "endangered")

A minimum of three packs exist in the Northern Continental Divide ecosystem, with scattered singles interspersed among them. Also, wolves occupy, intermittently, the Centennial Mountains area and a strip east of and parallel to the Beaverhead Mountains (western edge of Beaverhead County). They may use any habitat, but find greater security in remote coniferous forest types.

\section{Bald Eagle (Federally "endangered")}

Populations have increased dramatically. The USFWS is in the process of downlisting the bald eagle from endangered to threatened. In 1993, there were 160 viable nesting territories known. The bald eagle nests near rivers, lakes, and reservoirs in all but the northeastern part of the state. Many bald eagles are present during migration and winter near rivers, lakes, and reservoirs.

\section{Peregrine Falcon (State and Federally "endangered")}

Nine to eleven wild nesting pairs of peregrines are known to have bred in Montana as a result of hacking (release of captive-bred young). Central/eastern Montana is the main area of the western United States that remains to be reoccupied by peregrines. Hacking efforts will be increased significantly during 1994-96. Their habitat preference includes high cliffs adjacent to riparian and aquatic habitats.

\section{Whooping Crane (State and Federally "endangered")}

Spring and fall migrants occur very rarely in the northeastern part of the state. An occasional summer non-breeder from Grays Lake may visit the southwestern or southcentral part of the state. The whooping crane uses large open marshes or sub-irrigated meadow habitats.

Least Tern (Federally "endangered")

Least terns are known to occur along the lower Yellowstone River. Barren islands are used for nesting.

Piping Plover (Federally "threatened")

Breeding pairs are found sparingly in northeastern Montana, including portions of the Milk and lower Missouri drainages. They require barren sand or gravel bars.

\section{Candidate Species (Federal Candidates for threatened and endangered species designation)}

\section{Pygmy Rabbit}

The pygmy rabbit is known to occur in Beaverhead and Madison Counties. It occupies a riparian-sagebrush habitat.

Swift Fox

Formerly abundant in grassland habitats, there are only three specimens now known to occur in Mentana. The swift fox was recently re-introduced in Canada, with possibilities of immigration and re-establishment in Montana. There have been a number of reliable sightings north of Havre and southeast of Miles City.

\section{Wolverine}

The wolverine occurs widely in the western mountains, primarily in coniferous forest habitats. Population has grown substantially in the past 50 years, but it is still rare due to a naturally low population density.

\section{Ferruginous Hawk}

The ferruginous hawk population is much reduced from historic levels. They occur primarily in foothill areas and badland habitat types, although they were formerly found throughout grassland habitats. In 1993, 84 territories produced only 8 young in one area in southwest Montana.

\section{Mountain Plover}

The mountain plover prefers prairie dog towns or other very short grass or erosion pavement habitats for breeding. Known populations in the northcentral and central parts of the state exist. There are also a few populations scattered elsewhere.

\section{Ungulates}

Ungulates which inhabit Montana include elk, deer, moose, pronghorn, bighorn sheep and mountain goats. Ungulates often winter in areas where livestock/coyote predation occurs. Therefore, there may be some conflict with predator management due to aerial overflights. There has only been one case where an ungulate was taken by predator management activities in the last 3 years. A deer was taken by a snare in 1992. 


\section{Other Game Animals}

Mountain lions, bobcats and black bears can cause conflicts with livestock. However, none of these animal species have been taken on BLM lands as either target or non-target species in recent history for predator management.

\section{Upland Birds}

Upland game birds occurring within the area proposed for predator management activities include sharp-tailed grouse, blue grouse, spruce (Franklin) grouse, sage grouse, ruffed grouse, pheasant, mourning dove, Hungarian partridge, and wild turkey. None of these species have been affected by APHIS-ADC or DOL predator management activities in recent history.

\section{Raptors}

Raptors occurring within the area proposed for predator management activities include the golden eagle, the roughlegged hawk, the Swainson's hawk, the ferruginous hawk, the red-tailed hawk, the northern harrier, and various accipiters such as Cooper's hawk, goshawk, sharp-shinned hawk, merlin, American kestrel, turkey vulture, prairie falcon, osprey, and several species of owls. None of these species have been affected by APHIS-ADC or DOL predator management activities in recent history.

\section{Small Game}

Small game animals which have been affected in the past by APHIS-ADC and DOL predator management activities include skunks, raccoons, badgers, and porcupines. These animals can become non-target species caught in traps and snares. This problem is minimized by using pan-tension devices, which requires a minimum weight to spring the trap.

\section{OTHER USES ON BLM LANDS (ISSUE 4)}

BLM land is used for a variety of purposes. Commercial uses include, but are not limited to, oil and gas exploration and production, livestock grazing, mining, and timber. Recreational uses include, but are not limited to, hunting, fishing, camping, trapping, horseback riding, hiking, and off-road vehicle use. The land use plans for the respective resource areas define the uses and any limitations thereto on BLM lands.

\section{Special Areas (Wilderness Areas, Wilderness Study Areas and Areas of Critical Environmental Concern)}

\section{Wilderness Area}

The Bear Trap Canyon Wilderness Area is the only BLM managed wilderness in Montana. It is located in southwest Montana in Madison County where the Madison River cuts through the northwestern end of the Madison Range. It comprises approximately 6,000 acres adjacent to, or encompassing, the Madison River for approximately 9 miles. Due to the high recreation use in this area, there would be no predator management activities allowed.

\section{Wilderness Study Areas (WSAs)}

Currently, there are 40 WSAs in the state. Areas can be designated wilderness only by an act of Congress. Until Congress takes action on the BLM suitability recommendations, all of the WSAs will be managed under the "Interim Management Policy for Lands Under Wilderness Suitability." Predator management activities would be allowed in WSAs under this Interim Management Policy.

\section{Areas of Critical Environmental Concern (ACEC)}

Five ACECs administered by BLM exist in Montana. Three ACECs are located in the Lewistown District, and two are located in the Butte District. There are nine potential ACECs identified in the Judith/Valley/Phillips RMP; however, the Record of Decision has not been released. There are five cultural sites identified to be designated as ACECs in the Draft Big Dry RMP. Predator management activities would be restricted from two of the ACECs due to high recreation use (See Environmental Consequences, Alternative 1, Issue 4).

\section{SOCIAL ISSUES}

Information collected during scoping for this EA indicate two major views regarding predator management activities.

One view, expressed by organized environmental groups such as the Predator Project and the National Wildlife Federation, and some individuals indicates major concerns about predator management. The concerns are similar among 
the groups and include the following: the need for predator control; the effectiveness of control for reducing livestock losses; support for non-lethal means of control; impacts to wildlife including non-target and threatened and endangered species; the effects of predator management on recreationists; and concern about the cost of predator management. These groups also oppose use of M-44s on BLM lands, with some mentioning the danger to recreationists and pets. One group raised the issue of rancher responsibility and suggested ranchers should be mandated to use protective measures for their herds. One group suggested thresholds for livestock losses should be developed; the threshold would have to be exceeded before lethal predator management activities were initiated.

Members of the second group are direct or indirect recipients of predator management services such as ranchers, recreationists concerned about the effect of predators on game populations, and those concerned about the economic stability of their community. Ranchers, and those concerned about the economic stability of their community, feel predator management is critical for the survival of the livestock industry and the communities that depend on the livestock industry. These individuals want predator management policies to be flexible and for all legal methods (both lethal and non-lethal) to be available. Many ranchers, and some recreationists, indicated predators need to be controlled due to their effect on game populations, and said predator management activities benefit ranchers and recreationists alike. Some recreationists mentioned a concern about the use of M-44s because of danger to hunting dogs.

Residents of rural areas in Montana are experiencing varying population and social trends. Some communities, mostly in western or central Montana, are facing an influx of new people into their area in search of the lifestyle offered by a rural environment. Other communities, mostly in eastern Montana, are facing declining populations and difficulties maintaining their local businesses, services, and infrastructure. Residents of all ranching communities are concerned about preserving their communities and ranching lifestyle. Many feel their current lifestyle is being jeopardized by change coming from outside the local area, with pressure to direct resources away from livestock grazing.

In 1992, over 200 operations requested predator management services on the BLM land they leased. Fifty percent of these requests came from Custer and Powder River Counties. Historically, the operations receiving predator management services have been concentrated in eastern and southwestern Montana. 


\section{ENVIRONMENTAL CONSEQUENCES}

The following critical elements have been analyzed and would not be affected by the proposed action or alternatives.

\author{
Air Quality \\ Cultural Resources \\ Farmlands, Prime/Unique \\ Floodplains \\ Native American Religious Concerns \\ Hazardous/Solid Waste \\ Water Quality \\ Wetland/Riparian Zones \\ Wild and Scenic Rivers \\ Wilderness
}

This section describes the probable consequences of each alternative on selected environmental resources described in Chapter III, Affected Environment. This section is organized by alternative with the direct, indirect, and cumulative effects discussed for each issue, if applicable.

\section{EFFECTS COMMON TO ALL ALTERNATIVES}

Under all alternatives the Interim Management Policy And Guidelines For Lands Under Wilderness Review (IMP guidelines) would apply. Adherence to these guidelines would ensure conformance with the WSA non-impairment criteria as described in the Proposed Action and Alternatives chapters.

Under any of the alternatives, (including the Proposed Action) restrictions on the use of M-44s by APHIS-ADC and DOL and other techniques (as described in the National ADC Biological Opinion mentioned below) would virtually eliminate the probability of impacts to threatened and endangered species. Informal consultation with the USFWS is currently occurring to determine if the Endangered Species Act (ESA) Section 7 consultation is required. A formal ESA Section 7 consultation was conducted on the Animal Damage Control Program (July 28, 1992). This consultation was initiated by APHIS-ADC with the USFWS and addressed the APHIS-ADC program nationwide. The reasonable and prudent measures and accompanying terms and conditions cited by the USFWS are incorporated into BLM requirements affecting all alternatives (See Appen(dix 4).

\section{ALTERNATIVE 1 (IPM-Proposed Action)}

\section{Direct and Indirect Effects}

Livestock Losses (Issue 1) - Confirmed livestock losses on BLM and private lands would be expected to be similar to those recorded from 1987 to 1992, (which ranged from 1,576 to 3,846 per year for APHIS-ADC and 440 to 1,003 per year for DOL. In April 1993, BLM policy was issued to allow emergency control only until an adequate environmental assessment had been completed. Local fluctuations in loss levels would be expected in response to annual fluctuations in predator populations.

Coyote predation on livestock could be anticipated in advance by identifying and referring to historical loss information. By using preventive damage control strategies prior to livestock turn-out onto the BLM or adjacent pastures, livestock losses would be expected to decrease or to remain the same as in previous years.

The estimated annual value of livestock losses in Montana would be similar to those reported in recent years, approximately $\$ 2.4$ million. Of this, an estimated $\$ 390,000$ would be attributed to predators on BLM lands (based on the assumption that an estimated 16 percent of the predators causing these livestock losses are on BLM lands - refer to the affected environment section).

Depredation would continue to affect an estimated 200 livestock producers while they are operating on BLM lands. It is anticipated that the number of operators who request APHIS-ADC or DOL assistance while operating on BLM lands would remain about the same as in the past (about 200). Operators with larger operations and those who lamb on open range would continue to be most affected by predation. Predation would continue to increase the cost of the operation and decrease the revenue of the operators. The result is that personal income to these livestock producers and local agricultural income to the community would continue to be affected.

Lost revenue from depredation would affect community and state income (Jahnke Et al., 1987). A reduction in the number of sheep or cattle marketcd could reducc inflow of dollars into local communities. The amount is unknown and would vary from one community to another. The significance of this impact would depend on the size of the 
community's economy, the value of livestock losses, and the relative importance of livestock production to the local economy. Local economies like those in Powder River and Carter Counties would probably be affected by predation on BLM lands more than most areas because of their high percent of BLM lands, the importance of livestock production on the local economy, and historic predation problems. The amount and significance of this local economic impact would not be expected to change from recent years. Statewide the impact ( $\$ 2.4$ million) would amount to about 2 percent of the 1992 market value of Montana's calf, sheep, and lamb production $(\$ 120,900,000)$.

Annual expenditures for animal damage control in Montana would be remain relatively unchanged; i.e., approximately $\$ 1.5$ million.

Predator Populations (Issue 2) - The proposed action has the potential to affect predator populations on approximately 8 million acres on BLM managed lands in Montana. The actual number of acres to be treated is unknown and would vary from year to year depending on requests to APHIS-ADC and DOL by private landowners and permittees. It was stated in the affected environment section of this EA that Montana has an estimated coyote population that ranges from a low of about 57,000 animals to a high of about 517,000 animals. In 1992, 7,847 coyotes were taken by APHIS-ADC and DOL, or 1.5 to 13.7 percent of the population, depending on the current population. In 1992 , 7,432 coyotes were taken by sport hunters and trappers or 1.4 to 13 percent of the population (See Table 1). Cumulative effects on the coyote population would be from 3 up to 26.8 percent of the coyote population taken annually. Connolly and Longhurst (1975) in a modelling study determined that, "If 75 percent of the coyotes are killed each year, the population would be exterminated in slightly over 50 years". The authors further state that their, "Model suggests that coyotes through compensatory reproduction can withstand an annual control level of 70 percent. To further demonstrate the coyote's recruitment ability, if 75 percent control occurred for 20 years, coyote populations would regain precontrol densities by the end of the fifth year after control terminated." If Connolly and Longhurst's (1975) "model is accurate, there is no need for concern that the coyote may become a rare or endangered species". Based on this information, APHIS-ADC and DOL's impact on the coyote population would be minimal and would not have any long-term impacts on the coyote population in Montana.

With the proposed action, compared to the other alternatives, it is anticipated that coyote populations would decrease slightly in localized areas due to preventive control in historical loss areas.

APHIS-ADC and DOL did not take any black bear, grizzly bear, bobcat, or mountain lions on BLM lands during 19911993.

Red fox dispersal serves to replace and equalize fox densities over large areas and over a wide range of population densities. Annual harvests in localized areas in 1 or more years likely will have little impact on the overall population in subsequent years, but may reduce localized predation (Allen and Sargeant 1993). Phillips (1970) states that fox populations are resilient and in order for fox control operations by trapping to be successful, pressure on the population must be almost continuous. Phillips (1970) and Voigt (1987) further state that habitat destruction that reduces prey numbers, water and cover will impact fox populations to a greater extent than a short-term overharvest.

In 1992, 2,038 red foxes were taken by APHIS-ADC and DOL in Montana on private and BLM lands, or .5 percent of the population. In 1992, 6,935 red foxes were taken by sport hunters or trappers, or 1.8 percent of the population. The cumulative effect on the red fox population would be 2.4 percent of the red fox population taken annually.

Based on the above facts, and research findings that red fox reproductive and dispersal capabilities are similar to coyotes, applying Connolly and Longhurst's (1975) model is appropriate to determine the impact on red fox populations from depredation management. This in combination with the small area of BLM-administered lands where depredation management is conducted, and with the small number of fox taken by APHIS-ADC and DOL, the impact to the red fox population would be negligible. Voigt (1987) seems to sum up the outlook for red fox populations by stating that "the future of the red fox as a member of many ecosystems around the world seems secure." 
TABLE 1

Montana Fur Take Estimates *, **

\begin{tabular}{|l|c|c|c|c|c|c|}
\hline & $\mathbf{1 9 8 6 - 8 7}$ & $\mathbf{1 9 8 8 - 8 9}$ & $\mathbf{1 9 8 8 - 8 9}$ & $\mathbf{1 9 8 9 - 9 0}$ & $\mathbf{1 9 9 0 - 9 1}$ & $\mathbf{1 9 9 1 - 9 2}$ \\
\hline Coyote & 14,000 & 15,958 & 7,838 & 4,750 & 4,559 & 7,432 \\
Fox & 8,468 & 8,500 & 9,329 & 3,927 & 3,529 & 6,935 \\
\hline
\end{tabular}

*Information provided by MDFWP

**Fur takes on BLM-administered land is included in the statewide total

Other Wildlife Species (Issue 3) - Traps and neck snares place some individual animals at risk. APHIS-ADC and DOL traps would be equipped with pan tension devices which aid in excluding trapping of animals lighter in weight than target predators (i.e., If an animal does not weigh enough, it will not spring the trap). APHIS-ADC and DOL use methods of setting traps which are designed to minimize attraction of non-target species. Any non-target species are released whenever possible. Denning, calling/ shooting, and aerial hunting would minimize the effect on non-target species.

There would be no cumulative effects to non-target species with the proposed action based on the few non-target animals taken in the past. Non-target takes for 1992 in Montana (including both private and public lands) were as follows:

$\begin{array}{lr}\text { Species } & \text { Number Taken } \\ \text { Badgers } & 10 \\ \text { Poreupines } & 18 \\ \text { Raccoons } & 7 \\ \text { Skunks } & 2 \\ \text { Deer } & 1\end{array}$

Although the potential of affecting threatened and endangered species in association with predator control work does exist, APHIS-ADC and DOL are required to follow the reasonable and prudent alternatives listed in the formal ESA Section 7 Consultation (see Appendix 4).

In accordance with the Endangered Species Act and the Montana Bald Eagle Management Plan, no predator management activities would be allowed within $1 / 2$ mile of active bald eagle nest sites from February 1 to April 30. This may be changed for specific nest sites as site specific management plans are prepared.
No predator management activities would be allowed within $1 / 2$ mile of active ferruginous hawk nest sites from March 1 to July 31 .

Therefore, the predator management program would not be likely to jeopardize any of the listed threatened, endangered or candidate species. If other species are listed as threatened or endangered, no predator management activities would be allowed that would negatively impact those species or their habitat.

APHIS-ADC and DOL restrictions would not allow use of M-44s on prairie dog towns. Traps are not generally set on prairie dog towns, because prairie dogs will generally trip the traps. However, there is a slight chance that predator management activities near prairie dog towns could kill or injure a black-footed ferret after they are introduced. In 1991, the Black-footed Ferret Coordinating Committee approved the following mitigation for predator control on or near occupied ferret habitat:

- Predator populations may be reduced bcfore ferrets are reintroduced.

- Use selective methods of control, such as calling and shooting and aerial gunning.

- Equip snares with a stop to prevent capture of ferrets.

- Use tension springs with leg-hold traps.

These measures would be required for all predator management activities on BLM-administered land in occupied black-footed ferret habitat.

The use of aerial hunting during the spring and summer would have very little effect on ungulates. During this time period, the ungulates have begun to disperse over a larger area and move towards their summer ranges. Acrial hunting 
would be isolated and would normally be of short duration and not a daily event.

The use of aerial hunting during the winter months could cause movement of ungulates in the immediate vicinity. Nervousness of ungulates may occur, but can be reduced by avoiding groups of ungulates with the aircraft. Excessive disturbance could place additional stress and energy use by animals on their winter range. In severe winters or when animals enter the winter with low energy reserves, this disturbance could be fatal, especially if spring storms are severe and long lasting. This impact would be reduced or eliminated by avoiding low level flights directly over large ungulates on their winter range.

Predators, primarily coyotes, have been documented as having a significant impact on ungulate populations and this predation is not necessarily limited to sick or inferior animals (Pimlott 1970, Bartush 1978, U.S. Fish and Wildlife Service 1978, Hamlin Et al. 1984. Neff Et al. 1985). Neff Et al. (1985) concluded from radio tracking studies that the majority of coyotes who hunt pronghorn antelope fawns on Anderson Mesa, Arizona are residents. This means that most of the depredating coyotes were present on the fawning grounds during fawning times. Jones (1949) believed that coyote predation was the main limiting factor of pronghorn antelope in Texas. A 6-year radio telemetry study of pronghorn antelope in western Utah showed that 83 percent of all fawn mortality was attributed to predation (Beale and Smith 1980). In Arizona, Arrington and Edwards (1951) showed that intensive coyote depredation management was followed by an increase in pronghorn antelope to the point where antelope were once again huntable, whereas on areas without depredation management this increase was not noted. Similar observations of improved pronghorn fawn survival and population increase following depredation management have been reported by Riter (1941), Rosko (1948), Udy (1953), Barker (1941), and Hailey (1979). Major losses of pronghorn fawns to predators have been reported from more recent radio-telemetry studies (Barrett 1978, Beale 1978, Beale and Smith 1973, Bodie 1978, Tucker and Garner 1980, and Von Gunten 1978). After a 5 year study, Neff and Woolsey (1979, 1980) determined that coyote predation on pronghorn fawns was the primary factor causing fawn mortality and low pronghorn densities on Anderson Mesa. Coyote depredation management on Anderson Mesa increased the herd from 115 animals to 350 in 3 years, and peaking at 481 animals in 1971 . After coyote depredation management was discontinued, the pronghorn fawn survival dropped to only 14 and 7 fawns/100 does in 1973 and 1979, respectively. Initiation of another coyote depredation management program began with the removal of an estimate 22 percent of the coyote population in 1981, 28 percent in 1982, and 29 percent in 1983. Antelope populations on Anderson Mesa, during
1983 , indicated a population of 1,008 antelope, exceeding 1,000 animals for the first time since 1960 . Fawn production increased from a low of 7 fawns/100 does in 1979 to 69 and 67 fawns/100 does in 1982 and 1983, respectively.

Guthery and Beasom (1977) demonstrated that after coyote depredation management, the deer fawn production per unit area was 70 percent greater after the first year and 43 percent greater after the second year on their study area. Beasom (1974) states that predators were responsible for 74 percent and 61 percent of the fawn mortality for 2 consecutive years on his study area. Stout (1982) increased deer production on 3 areas in Oklahoma by 262 percent, 92 percent, and 167 percent the first summer following coyote depredation management and increased production 154 percent for the three areas. Garner (1976), Garner Et al. (1976), and Bartush (1978) found losses in the Wichita Mountains of Oklahoma to be 87.9-89.6 percent of radio-collared deer fawns with coyotes being responsible for 88.4-96.6 percent of the mortality.

Teer, Et al., documented that coyote diets contain nearly 90 percent deer during May and June. He concluded from the work conducted at the Welder Wildlife Foundation Refuge, Texas, that unequivocally coyotes take a large portion of the fawns each year during the first few weeks of life. Fawn remains are also common in coyote scats during the first 48 weeks of life (Steele 1969, Cook Et al. 1971, Holle 1977, Litvaitis 1978, Litvaitis and Shaw 1980).

Mule deer fawn survival was significantly increased and more consistent inside a predator-free enclosure in Arizona (LeCount 1977, Smith and LeCount 1977). Hamlin Et al. (1984) in a study of mule deer fawn mortality in Montana observed that a minimum of 90 percent summer mortality of fawns was a result of coyote predation. Other authors observed that coyotes are responsible for the majority of fawn mortality during the first few weeks of life (Knowlton 1964, White 1966, Cook Et al. 1971, Salwasser Et al. 1978, Trainer Et al. 1981). Knowles (1976) documented high winter loss of deer due to coyote predation in north-central Montana in 1975-76 and states that coyotes are the cause of most overwinter mule deer mortality.

Based on this research, it would appear that this alternative would decrease the predation on young ungulates in localized areas by decreasing the number of coyotes and red foxes in localized areas in the short-term. In the long term, predator management as described in this alternative would not impact the coyote or red fox populations, thus it would not impact predation on young ungulates.

Recreation (Issue 4) - All developed recreation sites on BLM-managed lands would have appropriate buffers of no activity by APHIS-ADC and DOL. In most cases, there 
would be no effects on recreation visitors. The National Guard Training Area, located west of Townsend, is identified as a human safety zone. However, APHIS-ADC would be allowed to conduct control work after permission is granted from the National Guard, and the BLM is notified when control work would be conducted.

Dispersed recreation is popular on BLM administered lands. Under Alternative 1, there is the potential to affect BLM users in several ways. The sounds from scare devices used by the permittees could be annoying to the dispersed recreation visitors traveling or recreating within or adjacent to areas where this technique would be used. There would be the slight potential to inadvertently trap or snare a pet accompanying a hiker, firewood gatherer, or camper. However, the possibility would be minimized by restricting predator management during bird hunting seasons.

There have been no accidental capture or death of domestic pets on BLM land from predator management activities in recent years (since 1980) nor have any complaints been received from recreationists or other users of public land.

Special Areas (Issue 4) - Predator management would be prohibited in the Bear Trap Wilderness Area based on the high number of recreationists that frequent the area. APHIS$\mathrm{ADC}$ and DOL would be allowed to perform predator management within WSAs. Actions within these areas would not make any irretrievable commitment of resources or change the characteristics of the land to hinder WSAs from being classified as wilderness.

The Outstanding Natural Area (ONA), located west of Choteau, has restrictions placed on predator management activities because of high recreation use and the presence of various threatened and endangered species. APHIS-ADC is not authorized to use toxicants (M-44s) and has special timing restrictions on checking the traps.

Two of Montana's ACECs and a special recreation management area would be identified as requiring restrictions to predator management activities based on the high number of recreationists that frequent the area. There would not be a conflict with allowing predator management activities in the remaining ACECs.

The Powder River Special Recreation Management Area (SRMA), located within the Powder River Depot area would be identified as having restrictions placed on predator management activities. Powder River SRMA is 171 acres in size and is locatcd north of the Powder River Depot.

Azure Cave is 140 acres in sizc. It is designated an ACEC because of high recreational values.
Square Butte Outstanding Natural Area is 1,947 acres in size. It is designated for high recreational values, including natural endemic systems, cultural sites, scenic qualities, rare geologic features, and key wildlife viewing sites.

\section{Social Impacts}

Under this alternative, there would be no impacts to ranchers or local communities because livestock losses would be similar to those in recent years. Ranchers would favor this alternative because a wide variety of predator management methods would be allowed. Recreationists concerned with the effects of predators on game populations, and people concerned with local community economics would also favor this alternative.

Environmental groups would not favor this alternative because they feel lethal means would be relied upon more than non-lethal means.

\section{Cumulative Effects}

Livestock losses would be similar to past years. Predator populations would not be affected in the long-term. Other wildlife species would not be affected in the long-term. Recreation and special areas would not have any long-term effects.

\section{ALTERNATIVE 2 (No M-44s)}

\section{Direct and Indirect Effects}

Livestock Losses (Issue 1) - Since M-44s are an effective method of control during winter months, livestock losses would be expected to be slightly higher during times of inclement weather. Steel traps. snares, and aerial shooting are less effective in inclement weather, whereas M-44s would remain operative and effective.

The USFWS published a study in 1978 entitled "Predator Damage in the West: A Study of Coyote Management Alternatives." In this publication, 10 field studies which analyzed the loss of sheep and lambs under various levels of predator control were reviewed. The one field study with partial control (the nature and extent of this control is unknown) reported lamb losses to predators that were three times the averagc percent of loss with control (as reported in five other studics with predator control the nature and cxtent of this control is also unknown). 
Based on this assumption, the value of annual livestock losses to predation on BLM lands would increase from $\$ 390,000$ to $\$ 1.18$ million (also based on the assumption that 16 percent of the predators causing these livestock losses are on BLM lands). The value of livestock losses on other lands is assumed to remain unchanged. Statewide, total annual value of livestock losses in Montana to predation would increase from $\$ 2.4$ million to an estimated $\$ 3.19$ million.

Depredation would continue to affect an estimated 200 livestock producers while they are operating on BLM lands. It is anticipated that the number of operators who request APHIS-ADC or DOL assistance while operating on BLM lands would remain about the same as in the past (about 200).

It is unknown if the number of operators who suffer losses to predation would change. It is also uncertain if the average value of those losses would change. The conclusions of Jahnke Et al. (1987), would also apply to this alternative (i.e., it is likely that the "average out-of-pocket indirect cost of predation increases as the size of operation increases..."). Operators with a greater dependency on BLM lands and those who operate in areas of historically high levels of predation would probably be affected the most.

If predation reduces the number of sheep or cattle marketed, the inflow of dollars into local communities would also be reduced. The amount is unknown and would vary from one community to another. The significance of this impact would depend on the size of the community's economy, the value of livestock losses, and the relative importance of livestock production to the local economy. The annual market value of livestock losses ( $\$ 3.19$ million) would amount to about 3 percent of the 1992 market value of calf, sheep, and lamb production in Montana $(\$ 120,900,000)$.

Annual expenditures for animal damage control in Montana would be remain relatively unchanged (i.e., approximately $\$ 1.5$ million).

Predation Populations (Issue 2) - It is anticipated that coyote and fox populations would remain at levels independent of what control method is used. Based on a study by Connolly and Longhurst (1975), the impact on the coyote population from control activities is minimal and would not have any long-term impacts on the coyote population in Montana. An increase in other control methods may be used to replace the $\mathrm{M}-44 \mathrm{~s}$.

Other Wildlife Species (Issue 3) - The possibility of nontarget species taken by M-44s on BLM-administered lands would be eliminated. However, traps and snares may be used more which could lead to an increase in non-target species being taken, because these tools are less selective than M-44s. In Montana, M-44s were used during predator management activities with only about $1 / 2$ of a percent of the animals taken constituting non-target species. Overall, the impact on non-target species would still be minimal (Connolly 1988).

Recreation (Issue 4) - The effects on recreation are the same as Alternative 1. However, the chance of hikers, hunters and other recreationists or their pets encountering M-44s on BLM lands would be eliminated.

Special Areas (Issue 4) - The effects on special areas are the same as Alternative 1. However, the chance of the public or their pets encountering M-44s on BLM administered land would be eliminated.

\section{Social Impacts}

Under this alternative, livestock losses would increase slightly. Those ranch operations where $\mathrm{M}-44$ s offer the best predator control methods would most likely be affected by this alternative. Ranchers would probably not favor this alternative because they prefer that APHIS-ADC and DOL retain the flexibility to use all approved methods. Both ranchers and those concerned with local community economics would be concerned about the losses in livestock income.

Environmentalists and some recreationists would favor this alternative over Alternative 1, because they oppose the use of M-44s on BLM lands. However, this alternative would not address one of the major concerns of environmental groups, that lethal means would be relied upon too heavily.

\section{Cumulative Effects}

The predator management program would be less effective during inclement weather due to the elimination of one of the most effective tools for predator control in inclement weather. As a result, livestock losses may increase. Cumulative effects on all other aspects would be the same as Alternative 1. 


\section{ALTERNATIVE 3 (Emergency Control Only)}

\section{Direct and Indirect Effects}

Livestock Losses (Issue 1) - In areas where livestock losses have historically occurred, livestock losses would increase due to no preventive damage control occurring. Most preventive damage control occurs between January and April during the lambing season. Although BLM lands are under emergency control procedures currently, emergency control did not go into effect until April 1993. Therefore, preventive damage control already occurred for 1993. Preventive damage control is not allowed under emergency control procedures. If emergency control procedures continue in the future, livestock losses would be expected to increase annually for several years, and then stabilize at a higher percentage than currently exists.

The USFWS published a study in 1978 entitled "Predator Damage in the West: A Study of Coyote Management Alternatives". In this publication, 10 field studies which analyzed the loss of sheep and lambs under various levels of predator control were reviewed. The one field study with partial control (the nature and extent of this control is unknown) reported lamb losses to predators that were three times the average percent of loss with control (as reported in five other studies with predator control the nature and extent of this control is also unknown).

Based on this assumption, the value of annual livestock losses to predation on BLM lands would increase from $\$ 390,000$ to $\$ 1.18$ million (also based on the assumption that 16 percent of the predators causing these livestock losses are on BLM lands). The value of livestock losses on other lands is assumed to remain unchanged. Statewide, total annual value of livestock losses in Montana to predation would increase from $\$ 2.4$ million to an estimated $\$ 3.19$ million.

Depredation would continue to affect an estimated 200 livestock producers while they are operating on BLM lands. It is anticipated that the number of operators who request APHIS-ADC or DOL assistance while operating on BLM lands would remain about the same as in the past (about 200).

It is unknown if the number of operators who suffer losses to predation would change. It is also uncertain if the average value of those losses would change. The conclusions of Jahnke Et al. (1987), would also apply to this alternative (i.e., it is likely that the "average out-of-pocket indirect cost of predation increases as the size of operation increases...").
Operators with a greater dependency on BLM lands and those who operate in areas of historically high levels of predation would probably be affected the most.

If predation reduces the number of sheep or cattle marketed, the inflow of dollars into local communities would also be reduced. The amount is unknown and would vary from one community to another. The significance of this impact would depend on the size of the community's economy, the value of livestock losses, and the relative importance of livestock production to the local economy. The annual market value of livestock losses ( $\$ 3.19$ million) would amount to about 3 percent of the 1992 market value of calf, sheep, and lamb production in Montana $(\$ 120,900,000)$.

Annual expenditures for animal damage control in Montana would be remain relatively unchanged (i.e., approximately $\$ 1.5$ million).

Predator Populations (Issue 2) - It is anticipated that coyote populations would remain at present levels.

Other Wildlife Species (Issue 3) - Effects would be the same as Alternative 1.

Recreation (Issue 4) - Effects would be the same as Alternative 1.

Special Areas (Issue 4) - Effects would be the same as Alternative 1.

\section{Social Impacts}

Under this alternative, livestock losses would increase slightly. Ranch operations in historical loss areas are most likely to be affected by this alternative. Ranchers would probably not favor this alternative because they prefer that APHIS-ADC and DOL retain the flexibility to control in non-emergency situations. Both ranchers and those concerned with local community economics would be concerned about the losses in livestock income.

Environmentalists may feel this alternative relies too heavily on lethal control methods.

\section{Cumulative Effects}

Livestock losses would be greater in the long-term compared to Alternative 1 and 2. Other cumulative effects would be the same as Alternative 1. 


\section{ALTERNATIVE 4 (No APHIS-ADC or DOL Predator Management Activities on BLM Lands)}

\section{Direct and Indirect Effects}

Livestock Losses (Issue 1) - Livestock losses would be expected to increase on BLM and private lands leading to greater economic effects on livestock producers. Often predators live and spend the majority of their time on BLM lands and intrude on private lands to kill livestock. The inability of APHIS-ADC and DOL supervised personnel to follow these animals onto BLM lands, and the fact that much of the BLM land pattern is scattered would make it more difficult to take the offending animal. This would result in increased livestock losses and costs. As a result, a heavier concentration of predator management would occur on private lands. As management tools are in the area longer, the risk to non-target species on private lands would increase. This increase may be offset by decreased risk to non-target species on BLM lands. Control methods that may be employed by permittees and their agents are likely to be less effective than the proposed program and may be more environmentally harmful. The restrictions placed on APHIS-ADC and DOL would not be adhered to and illegal pesticide use would likely increase by livestock producers and their agents. This would result in the death of endangered species such as the bald eagle, and other raptors such as the golden eagle, and other avian and mammalian species that eat carion. Some of these chemicals could cause chain reaction deaths and remain in the food chain for some time.

According to the USFWS study of Predator Damage in the West (1978), four field studies without predator control were reviewed for impacts on sheep and goat losses. The average annual loss to predators without control was almost four times the annual average loss reported from five studies with predator control (the nature and extent of control in these studies is unknown).

Based on this assumption, the value of annual livestock losses to predation on BLM lands would increase from an estimated $\$ 390,000$ to $\$ 1.57$ million (also based on the assumption that 16 percent of the predators causing these livestock losses are on BLM lands). The value of livestock losses on other lands is assumed to remain unchanged. Statewide, total annual value of livestock losses in Montana to predation would increase from $\$ 2.4$ million to an estimated $\$ 3.58$ million.

It is unknown if the number of operators who suffer losses to predation would change. It is also uncertain if the average value of those losses would change. The conclusions of
Jahnke Et al. (1987), would also apply to this alternative (i.e., it is likely that the "average out-of-pocket indirect cost of predation increases as the size of operation increases..."). Operators with a greater dependency on BLM lands and those who operate in areas of historically high levels of predation would probably be affected the most.

If predation reduces the number of sheep or cattle marketed, the inflow of dollars into local communities would also be reduced. The amount is unknown and would vary from one community to another. The significance of this impact would depend on the size of the community's economy, the value of livestock losses, and the relative importance of livestock production to the local economy. The annual market value of livestock losses ( $\$ 3.58$ million) would amount to about 3 percent of the 1992 market value of calf, sheep, and lamb production in Montana $(\$ 120,900,000)$.

Annual expenditures for animal damage control in Montana would be remain relatively unchanged (i.e., approximately $\$ 1.5$ million).

Predator Populations (Issue 2) - Coyote populations would be expected to increase in the short-term as methods employed by permittees would tend to be less effective and selective than those employed by the APHIS-ADC or DOL.

Other Wildlife Species (Issue 3) - The potential for unintentional losses of other wildlife species from APHIS-ADC and DOL predator management activities would be minimal. However, State law allows private individuals to control predators for the purpose of protecting livestock. Consequently, there would be more potential for impacts on non-target species from actions taken by persons other than APHIS-ADC and DOL. These private individual control efforts are generally less effective and less discriminating with regard to non-target species than APHIS-ADC and DOL programs.

Without APHIS-ADC or DOL programs, more livestock producers would take control action themselves. This could lead to the illegal use of toxicants and to an increased threat to non-target and target species. The uncontrolled or nonprofessional use of traps and snares could result in the taking of bald and golden eagles, other raptors, and gray wolves and other mammalian species.

Recreation (Issue 4) - The increased use of traps and snares by non-professionals could result in safety hazards to recreationists and their pets.

Special Areas (Issue 4) - The non-professional use of traps and snares could result in safety hazards to public land users and their pets. 
Table 2. This table summarizes a number of research papers, which compared the sheep lost to coyotes with and without predator management activities occurring.

TABLE 2

COMPARISON OF SHEEP LOSSES TO COYOTES

WITH AND WITHOUT PREDATOR MANAGEMENT

\begin{tabular}{|c|c|c|c|}
\hline \multirow[t]{2}{*}{ LOSSES WITHOUT PREDATOR MANAGEMENT * } & \multicolumn{3}{|c|}{ ( \% OF HERD KILLED) } \\
\hline & Ewes & Lambs & Herd \\
\hline W Montana 1974 (Henne 1977) & 8.4 & 29.3 & 20.8 \\
\hline W Montana 1975-76 (Munoz 1977) & 8.2 & 26.9 & 16.6 \\
\hline \multirow[t]{2}{*}{ SE New Mexico (DeLorenzo \& Howard 1977) } & 0.0 & 15.6 & \\
\hline & 0.9 & 12.1 & \\
\hline GB California (McAdoo \& Klebenow 1978) & 1.4 & 6.3 & 3.8 \\
\hline \multirow[t]{3}{*}{ W Mentana (O'Garact al 1983) } & 7.8 & 26.5 & \\
\hline & \multicolumn{3}{|c|}{ ( \% DEPREDATION BY COYOTES) } \\
\hline & Ewes & Lambs & Herd \\
\hline W Montana 1974 (Henne 1977) & $\overline{72.3}$ & 89.4 & 97.1 \\
\hline W Montana 1975-76 (Munoz 1977) & & & 99.3 \\
\hline \multirow{2}{*}{ SE New Mexico (DeLorenzo and Howard 1977) } & & 77.4 & \\
\hline & 14.0 & 67.0 & \\
\hline GB California (McAdoo \& Klebenow 1978) & & & 90 \\
\hline W Montana (O’Gara 1983) & & & 97.6 \\
\hline \multirow[t]{2}{*}{ LOSSES WITH PREDATOR MANAGEMENT } & \multicolumn{3}{|c|}{ ( \% OF HERD KILLED) } \\
\hline & Ewes & Lambs & Herd \\
\hline S Idaho (Nass 1977) & 1.1 & 1.4 & \\
\hline S Wyoming (Tigner \& Larson 1977) & 0.2 & 2.3 & \\
\hline SE New Mexico (Howard \& Shaw 1978) & 1.0 & 3.0 & \\
\hline \multirow{5}{*}{ SE New Mexico (Howard \& Booth 1981) } & 1.3 & 3.1 & \\
\hline & 1.5 & 5.2 & \\
\hline & 1.0 & 7.4 & \\
\hline & \multicolumn{3}{|c|}{ ( \% DEPREDATION BY COYOTES) } \\
\hline & Ewes & Lambs & Herd \\
\hline S Idaho (Nass 1977) & & 56.0 & \\
\hline S Wyoming (Tigner \& Larson 1977) & & & 77 \\
\hline SE New Mexico (Howard \& Shaw 1978) & & 81 & 77 \\
\hline \multirow[t]{2}{*}{ SE New Mexico (Howard \& Booth 1981) } & 20 & & \\
\hline & 20 & & \\
\hline
\end{tabular}

*Studies referenced in this EA, which were conducted "without predator management," in fact, often did have varying degrees of nonprofessional predator management, or the study was terminated because excessive livestock losses were exceeding practical budgets.

\section{Social Impacts}

Under this alternative, livestock losses would be larger than with any other alternative. Ranch operations in historical loss areas would most likely be affected by this alternative. Ranchers and those concerned with local community economics would not favor this alternative because APHISADC and DOL activities would be eliminated on BLM lands, and because some ranch income would be lost.

Some environmentalists would support this alternative while others would feel that this alternative goes too far in eliminating all APHIS-ADC and DOL activities on BLM lands.

\section{Cumulative Effects}

Livestock losses would increase. Predator populations would not be affected in the long-term. More non-target species could be taken by non-professionals in the long-term. Safety hazards to recreationists and their pets could increase due to predator management activities by nonprofessionals.

\section{Residual Impacts}

No significant residual impacts are expected to occur under any of the alternatives. 


\begin{tabular}{|c|c|c|c|c|}
\hline $\begin{array}{l}\text { U } \\
\text { 定 } \\
0\end{array}$ & 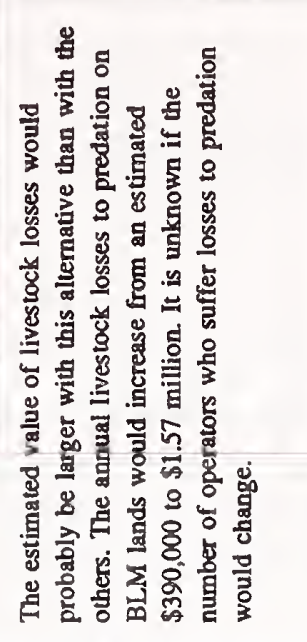 & 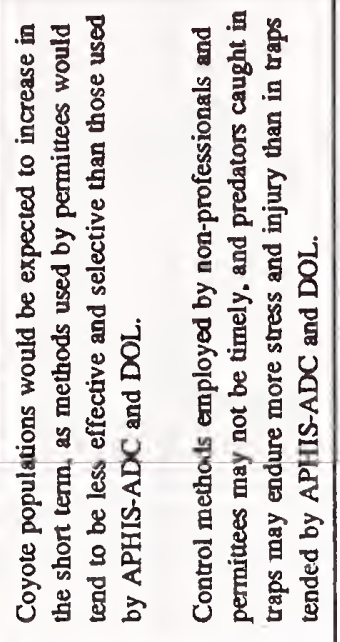 & 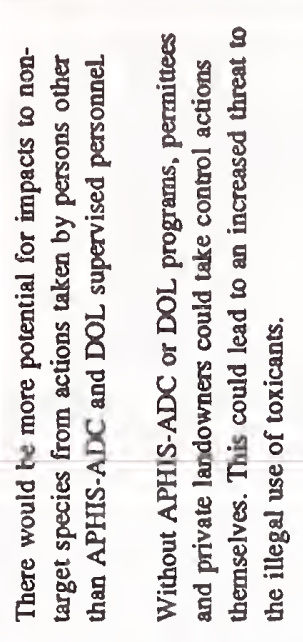 & 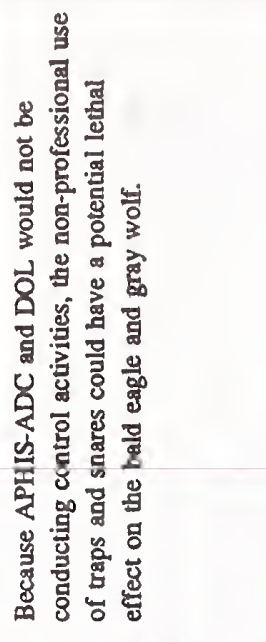 \\
\hline 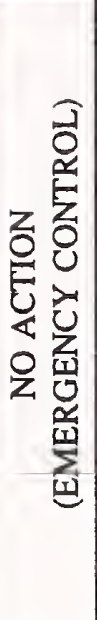 & 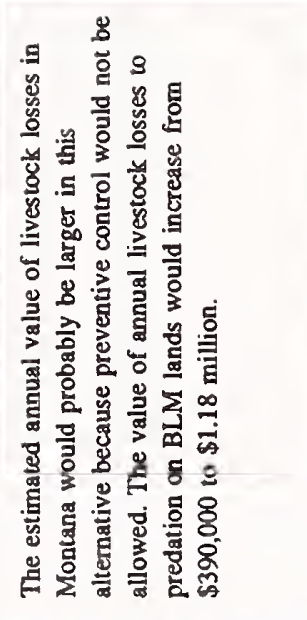 & 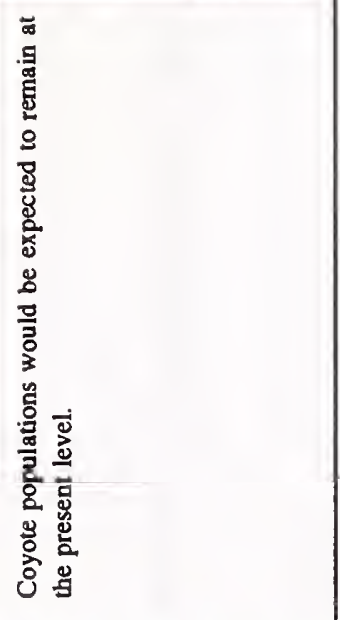 & 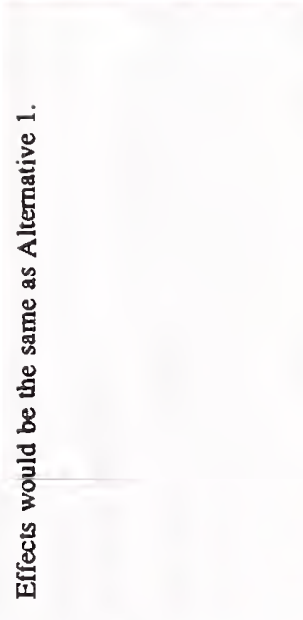 & 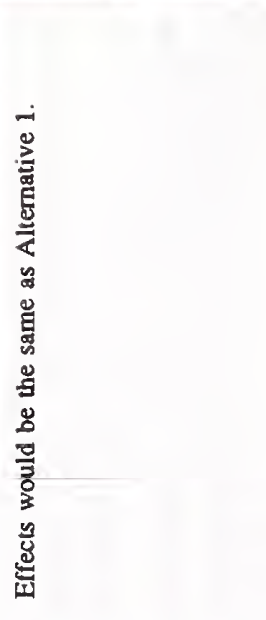 \\
\hline $\begin{array}{l}\frac{n}{j} \\
\sum_{z}^{\prime} \\
0 \\
z\end{array}$ & 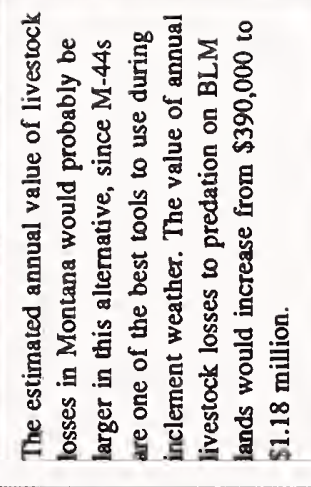 & 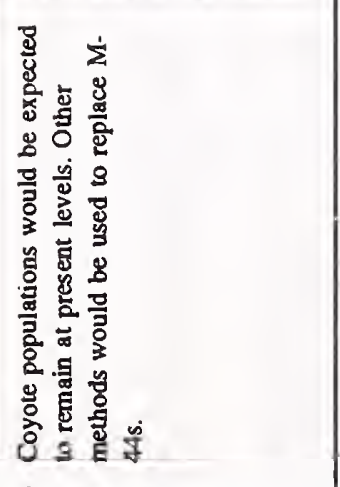 & 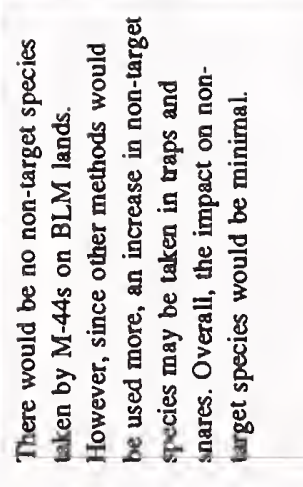 & 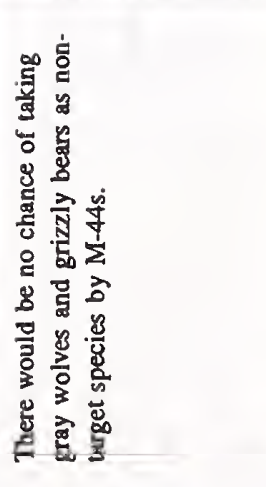 \\
\hline 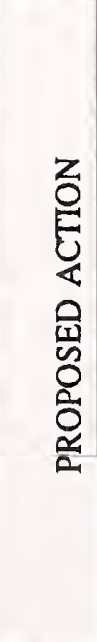 & 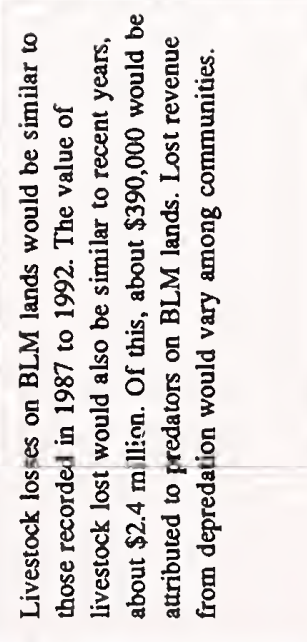 & 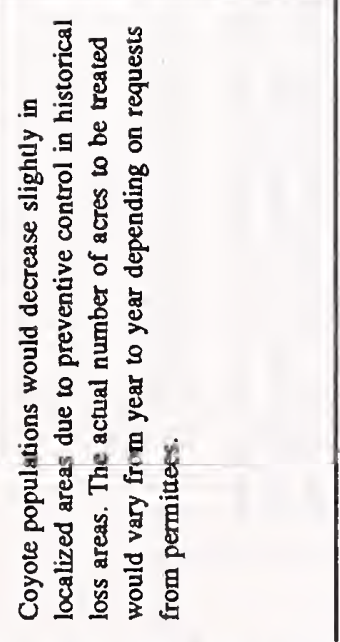 & 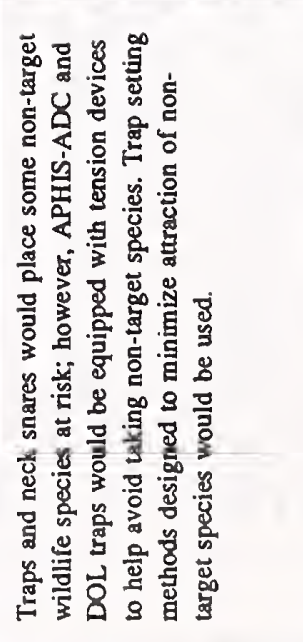 & 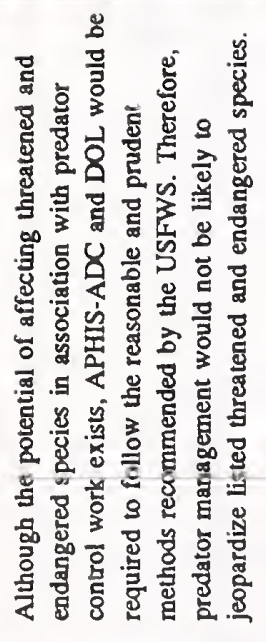 \\
\hline 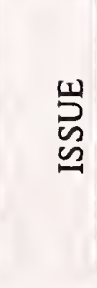 & 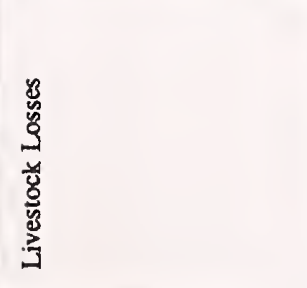 & 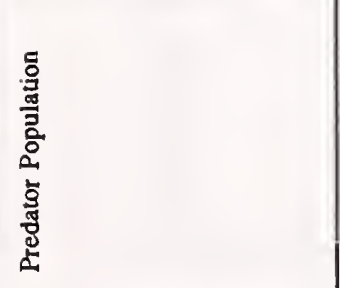 & 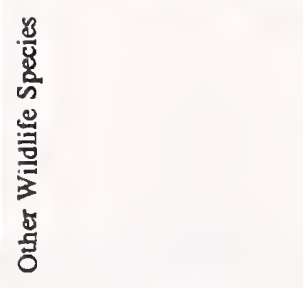 & 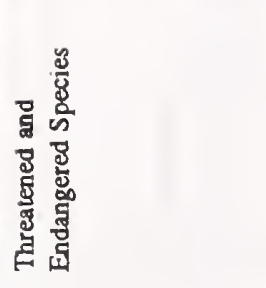 \\
\hline
\end{tabular}




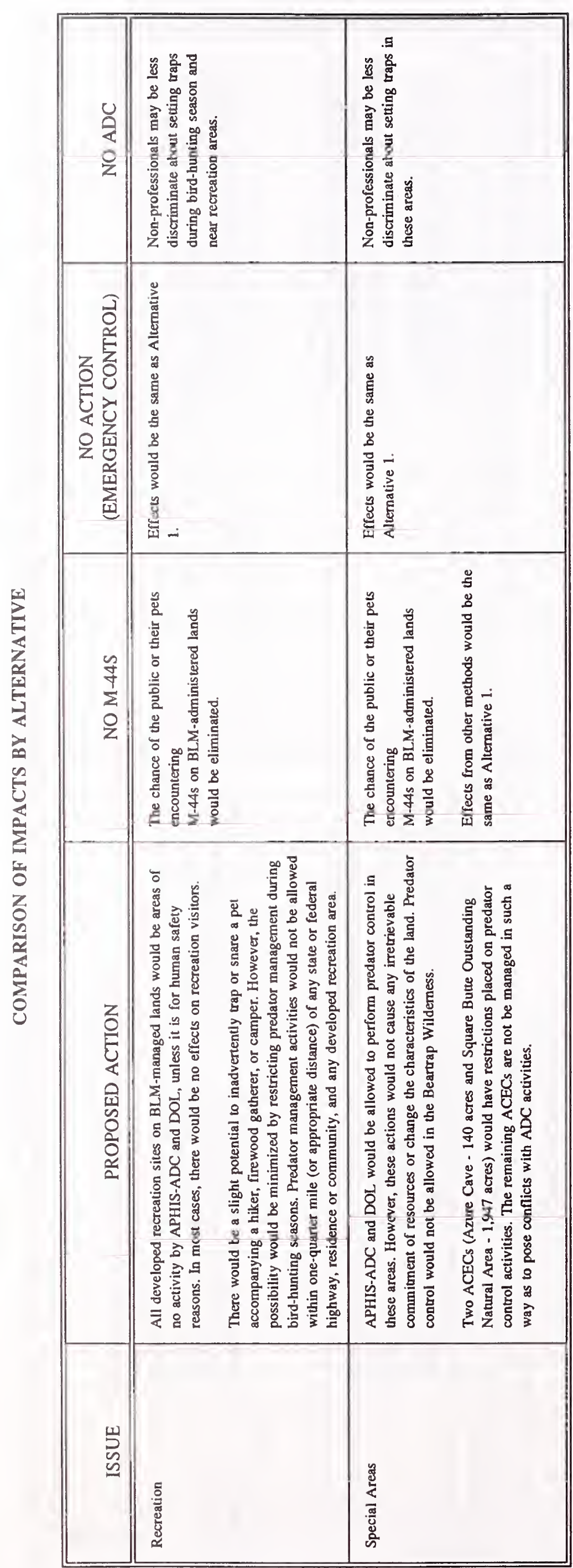




\section{CONSULTATION AND COORDINATION}

The following agencies were contacted and consulted with:

Montana Department of Fish, Wildlife and Parks (MDFWP)

U.S. Fish and Wildlife Service (USFWS)

Montana Department of Livestock (DOL)

Animal Plant and Health Inspection Service (APHIS) - ADC 


\section{LIST OF PREPARERS}

The following individuals are members of the planning team:

Sandy Brooks

Kim Okragly

John Thompson

Joan Trent

Dan Hinckley

Dan Lechefsky

Larry Handegard

Dave Hayes
Range Conservationist, Montana State Office (MSO) Social Scientist, MSO

Supervisory Planning \& Environmental Specialist, MSO

Sociologist, MSO

Wildlife Biologist, MSO

NEPA Coordinator, MSO

State Director, APHIS-ADC

Assistant State Director, APHIS-ADC

The following individuals provided technical support and review for the analysis:

\author{
Gerry Gill \\ Jody Peters \\ Dan Bricco \\ John Moorhouse \\ Jim Hoover \\ Dave Nelson
}

Land Use Specialist, Butte District Office

Wildlife Biologist, Havre Resource Area

Wildlife Biologist, Miles City District

Supervisory Natural Resource Specialist, MSO

District Supervisor, APHIS-ADC

District Supervisor, APHIS-ADC 


\section{REFERENCES CITED}

Ables, E. D. Activity Studies of Red Foxes in Southern Wisconsin. J. Wildlife Manage; 1969. 33:145-153.

. "Ecology of the Red Fox in America." In: M. W. Fox, ed. The Wild Canids: Their Systematic, Behavioral Ecology and Evolution. Van Nostrand Reinhold Co., New York, New York; 1975. Pages 216-236.

Allen, S. H., J. O. Hastings, and S. C. Kohn. Composition and Stability of Coyote Families and Territories in North Dakota. 1987. Prairie Nat. 19:107-114.

Allen, S. H., and A. B. Sargeant. Dispersal Patterns of Red Foxes Relative to Population Density. J. Wildlife Manage; 1993. 57:526-533.

Andrews, R. D., G. L. Strom, R. L. Phillips, and R. A. Bishop. Survival and Movement of Transplanted and Adopted Red Fox Pups. J. Wildlife Manage; 37:69-72.

Atlhoff, D. P. Social and Spatial Relationships of Coyote Families and Neighboring Coyotes. M.S. Thesis, University of Nebraska, Lincoln, Nebraska; 1978. 80 pp.

Andelt, W. F. and P. S. Gipson. Home Range Activity and Daily Movements of Coyotes. J. Wildlife Manage; 1979. 43:944-951.

Arrington, O. N., and A. E. Edwards. Predator Control as a Factor in Antelope Management. Trans. North American Wildlife Resource Conference; 1951. 16:179193.

Barker, E. S. Comments on Paper by K. C. Kartcher. Trans. North American Wildlife Conference; 1941. 6:273277.

Barrett, M. W. Pronghorn Fawn Mortality in Alberta. Proceedings Pronghorn Antelope Workshop; 1978. 8:429-444.

Bartush, W. S. Mortality of White-tailed Deer Fawns in the Wichita Mountains, Comanche County, Oklahoma, Part II. M.S. Thesis, Oklahoma State University, Stillwater, Oklahoma; 1978. 161 pp.

Beale, D. M. Birth Rate and Fawn Mortality Among Pronghorn Antelope in Western Utah. Proceedings Pronghorn Antelope Workshop; 1978. 8:445-448.
, and A. D. Smith. Mortality of Pronghorn Antelope Fawns in Western Utah. J. Wildlife Manage.; 1973. 38:854-859.

. Pronghom Antelope Productivity on Semidesert Range in Western Utah. Ulah Division Wildlife Resources.; 1980.

Beasom, S. L. Relationships Between Predator Removal and White-tailed Deer Net Productivity. J. Wildlife Manage.; 1974a. 38:854-359.

- Intensive Short-term Predator Removal as a Game Management Tool. Trans. North American Wildlife Conference; 1974b. 39:230-240.

Bekoff, M. and M. C. Wells. Behavioral Ecology of Coyotes: Social Organization, Rearing Patterns, Space Use, and Resource Defense. Z. Tierpsychol. 1982. 60:281-305.

Bodie, W. L. Pronghorn Fawn Mortality in the Upper Pahsimeroi River Drainage of Central Idaho. Proceeding Pronghom Antelope Workshop; 1978. 8:417428.

Camenzind, F. J. "Behavioral Ecology of Coyotes on the National Elk Refuge. Jackson, Wyoming." In M. Bekoff, Edition Coyotes: Biology, Behavior and Management. Academic Press, New York; 1978. Pages 267-294.

Clark, F. W. Influence of Jackrabbit Density on Coyote Population Change. J. Wildlife Manage; 1972. 36:343-356.

Connolly, G. E., and W. M. Longhurst. The Effects of Control on Coyote Populations. Division of Agricultural Sciences, University of California, Bulletin 1872; 1975.37 pp.

Connolly, Guy E. 1988. M-44 Sodium Cyanide Ejectors in the Animal Damage Control Program. Proceedings Vertebrate Pest Conference 1976-1986. 13:220225 .

Cook, R. S., M. White, D. O. Trainer, and W. C. Glazener. Mortality of Young White-tailed Deer Fawns in South Texas. J. Wildlife Manage.: 1971. 35:47-56. 
Cowardin, L. M., D. S. Gilmer, and C. W. Shaiffer. Mallard Recruitment in the Agricultural Environment of North Dakota. Wildlife Monogr. 92.; 1985. 37 pp.

Creed, R. F. S. Gonad Changes in the Wild Red Fox (Vulpes vulpes crucigera). J. Physiology. (London); 1960. 151:19-20.

Danner, D. A. Coyote Home Range, Social Organization, and Scent Post Visitation. M.S. Thesis, University of Arizona, Tucson, Arizona; 1976.

Danner, D. A., and N. S. Smith. Coyote Home Range, Movements, and Relative Abundance Near Cattle Feedyard. J. Wildlife Manage.; 1980. 44:484-487.

DeLorenzo, D. G., and V. W. Howard, Jr. Evaluation of Sheep Losses on a Range Lambing Operation in Southeastern New Mexico. Resource Report 341, Agricultural Experiment Station, New Mexico State University, Las Cruces, New Mexico; 1977.

Edwards, L. L. Home Range of Coyotes in Southern Idaho. M.S. Thesis, Idaho State University, Moscow, Idaho; 1975.

Flath, D. L. Personal Communication. 1993.

Garner, G. W. Mortality of White-tailed Deer Fawns in the Wichita Mountains, Comanche County, Oklahoma. $\mathrm{PhD}$. Thesis, Oklahoma State University, Stillwater, Oklahoma; 1976. 113 pp.

, J. A. Morrison, and J. C. Lewis. Mortality of Whitetailed Deer Fawns in the Wichita Mountains, Oklahoma. Proceedings Annual Conference Southeast Association of Fish and Wildlife Agencies; 1976. 13:493-506.

Gese, E. M., O. J. Rongstad, and W. R. Mytton. Homes Range and Habitat Use of Coyotes in Southeastern Colorado. J. Wildlife Manage.; 1988. 52:640-646.

Gier, H. T. Coyotes in Kansas (Revised). Kansas State College Agriculture Experiment Station. Bulletin No. $393 ; 1968.118$ pp.

Guthery, F. S., and S. L. Beasom. Responses of Game and Nongame Wildlife to Predator Control in South Texas. J. Range Manage.; 1977. 30:404-409.

Hailey, T. L. A Handbook for Pronghorn Management in Texas. F.A. Report Ser. No. 20, Texas Parks and Wildlife Dept., Austin, Texas; 1979. 59 pp.
Hamlin, K. L., S. J. Riley, D. Pyrah, A. R. Dood, and R. J. Mackie. Relationships among Mule Deer Fawn Mortality, Coyotes and Alternate Prey Species during Summer. J. Wildlife Manage.; 1984. 48:489499.

Harris, S. Distribution, Habitat Utilization and Age Structure of a Suburban Fox (Vulpes vulpes) Population. Mammal Rev.; 1977. 7:25-39.

. Age-related Fertility and Productivity in Red Fox (Vulpes vulpes) in Suburban London. J. Zool; 1979. 187:195-199.

and J. M. V. Rayner. Urban Fox (Vulpes vulpes) Population Estimates and Habitat Requirements in Several British Cities. J. Animal Ecol.; 1986. 55:575591.

Henne, D. R. "Domestic Sheep Mortality on a Western Montana Ranch." In: R. L. Phillips and C. Jonkel Eds. Proceedings 1975 Pred. Symposium. Montana Forestry and Conservation Experiment Station, School of Forestry, University of Montana, Missoula; 1977. Pages 133-146.

Holle, D. G. Diet and General Availability of Prey of the Coyote (Canis latrans) at the Wichita Mountains National Wildlife Refuge, Oklahoma. M.S. Thesis, Oklahoma State University, Stillwater, Oklahoma; 1977. 59 pp.

Howard, V. W. Jr., and R. E. Shaw. Preliminary Assessment of Predator Damage to the Sheep Industry in Southeastern New Mexico. Resource Report 356. Agricultural Experiment Station, New Mexico State University, Las Cruces, New Mexico; 1978.

Howard, V. W., and T. W. Booth. Domestic Sheep Mortality in Southeastern New Mexico. Bulletin 683. Agricultural Experiment Station, New Mexico State University, Las Cruces, New Mexico; 1981.

Jones, P. V. Jr. Antelope Management. Texas Game and Fish; 1949. 7:18-20.

Knowles, C. J. "Observations of Coyote Predation on Mule Deer and White-tailed Deer in the Missouri River Breaks, 1975-76." pp. 118-138. In: Montana Deer Studies. Montana Dept. of Fish and Game, Fed Aid Project W-120-R-7.; 1976. Pages 118-138.

Knowlton, F. F. Preliminary Interpretation of Coyote Population Mechanics With Some Management Implications. J. Wildlife Manage.; 1972. 36(2):369-382. 
LeCount, A. Causes of Fawn Mortality. Final Report, F.A. Project W-78-1, Wp-2, J-11. Arizona Game and Fish Dept., Phoenix, Arizona; 1977. 19 pp.

Litvaitis, J. A. Movements and Habitat Use of Coyotes on the Wichita Mountains National Wildlife Refuge. M.S. Thesis, Oklahoma State University, Stillwatel, Oklahoma; 1978. 70 pp.

, and J. H. Shaw. Coyote Movements, Habitat Use and Food Habits in Southwestern Oklahoma. J. Wildlife Manage.; 1980. 44:62-68.

McAdoo, J. K., and D. A. Klebenow. Predation on Sheep Range with no Predator Control. J. Range Manage.; 1978. 31(2): 111-114.

MacDonald, D. W., and M. T. Newdick. "The Distribution and Ecology of Foxes (Vulpes vulpes) (L.) in Urban Areas." In: R. Bornkamm, J. A. Lee, and M.R.D. Seaward eds. Urban Ecology. Blackwell Science Publication, Oxford, UK; 1982. Pages 123-135.

Messier, F. and C. Barrette. The Social System of the Coyote (Canis latrans) in a Forested Habitat. Can. J. Zool.; 1982. 60:1743-1753.

Montana Agricultural Statistics Services, Montana Sheep and Lamb Losses, from 1987-1992.

Montana Agricultural Statistics Service. Livestock Inventory by County, 1990-1992. 1992.

Montana Bald Eagle Working Group. Montana Bald Eagle Management Plan. USDI, Bureau of Land Management, Billings, Montana; June 1986. 61 pp.

Munoz, J. R. Causes of Sheep Mortality at the Cook Ranch, Florence, Montana, 1975-76. M.S. Thesis, University of Montana, Missoula. Montana; 1977.

Murie, A. A Naturalist in Alaska. Devin-Adair Co., New York, New York; 1961. 302 pp.

Nass, R. D. Mortality Associated With Sheep Operations in Idaho. J. Range Manage.; 1977. 30(4):253-258.

Neff, D. J., and N. G. Woolsey. Effect of Predation by Coyotes on Antelope Fawn Survival on Anderson Mesa. Special Report No. 8, Arizona Game and Fish Dept., Phoenix, Arizona; 1979. 36 pp.

Coyote Predation on Neonatal Fawns on Anderson Mesa, Arizona. Proceedings Biennial Pronghorn Antelope Workshop; 1980. 9:80-97.
, R. H. Smith, and N. G. Woolsey. Pronghorn Antelope Mortality Study. Final Report. F.A. Wildlife Restoration Project W-78-R. Arizona Game and Fish Dept., Phoenix, Arizona; 1985. 22 pp.

O'Gara, B. W., K. C. Brawley, J. R. Munoz, and D. R. Henne. Predation on Domestic Sheep on a Western Montana Ranch. Wildlife Society Bulletin No. 1 1(3):253-264. 1983.

Ozaga, J. J., and E. M. Harger. Winter Activities and Feeding Habits of Northern Michigan Coyotes. J. Wildlife Manage.; 1966. 30:809-818.

Pearson, E. W., and M. Caroline. Predator Control in Relation to Livestock Losses in Central Texas. J. Range Manage.; 1981. 34(6)435-41.

Phillips, R. L. Age Ratio of Iowa Foxes. J. Wildlife Manage.; 1970. 34:52-56.

Phillips, R. L., and L. D. Mech. Homing Behavior of a Red Fox. J. Mammal.; 1970. 51:621.

Pils, C. M., and M. A. Martin. Population Dynamics, Predator-Prey Relationships and Management of the Red Fox in Wisconsin. Wisconsin Dept. Natural Resources, Technical Bulletin No. 105; 1978.

Pimlott, D. H. Predation and Productivity of Game Populations in North America in A. G. Bannikav, ed., Trans. 9th Int. Congr. Game Biol., Moscow, USSR.; 1970. pages 63-73.

Pyrah, D. Social Distribution and Population Estimates of Coyotes in North-Central Montana. J. Wildlife Manage.; 1984. 48(3):679-690.

Richards, S. H. Canine Distemper in Wild Carnivores. North Dakota Outdoors; 1974. 36:10-11.

Riter, W. E. Predator Control and Wildlife Management. Trans. North American Wildlife Conference; 1941. 6:294-299.

Rosko, L. Preliminary Report on Antelope in the Cedar City Area, Iron County, Utah. Utah Cooperative Wildlife Resource Unit, Special Report.; 1948. 16 pp.

Rowlands, I. W., and A. S. Parkes. The Reproductive Processes of Certain Mammals VIII. Reproduction in Foxes (Vulpes spp.). Proceedings Zoological Society, London; 1935. 823-841. 
Roy, L. D. and M. J. Dorrance. Coyote Movements, Habitat Use, and Vulnerability in Central Alberta. J. Wildlife Manage.; 1985. 49:307-313.

Salwasser, H. Man, Deer and Time on the Devil's Garden. Proceedings Western Association, State Game and Fish Commission; 1976. 56:295-318.

Sargeant A. B. Red Fox Spatial Characteristics in Relation to Waterfowl Predation. J. Wildlife Manage.; 1972. $36: 225-236$.

. Red Fox Prey Demands and Implications to Prairie Duck Production. J. Wildlife Manage.; 1978. 42:520527.

Scrafford, J. Personal Communication. 1993.

Shard, T. Personal Communication. 1993.

Sheldon, W. G. Denning Habits and Home Range of Red Foxes in New York State. J. Wildlife Manage.; 1950. 14:33-42.

Smith, R. H., and A. LeCount. Factors Affecting Survival of Mule Deer Fawns. Final Report, F.A. Project W78-R, WP-2, J-4. Arizona Game and Fish Dept., Phoenix, Arizona; 1977.

Steele, J. L. Jr. An Investigation of the Comanche County Deer Herd. Oklahoma Dept. Wildlife Conservation, Fed. Aid in Fish and Wildlife, Restoration Project W-87-R; 1969. 20 pp.

Stout, G. G. Effects of Coyote Reduction on White-tailed Deer Productivity on Fort Sill, Oklahoma. Wildlife Society Bulletin; 1982. 10:329-332.

Strom, R. L., R. D. Andrews, R. L. Phillips, R. A. Bishop, D. B. Siniff, and J. R. Tester. Morphology, Reproduction, Dispersal, and Mortality of Midwestern Red Fox Populations. Wildlife Monogr. 49.; 1976. $82 \mathrm{pp}$.

Tabel, H., A. H. Corner, W. A. Webster, and C. A. Casey. History and Epizootology of Rabies in Canada. CDan. Vet. J.; 1974. 15:271-281.

Teer, J. G., D. L. Drawe, T. L. Blankenship, W. F. Andelt, R. S. Cook, J. Kie, F. F. Knowlton, and M. White. Deer and Coyotes; the Welder Experiments. Unpublished report; No date.

Tigner, J. R. and G. E. Larson. Sheep Losses on Selected Ranches in Southern Wyoming. J. Range Manage.; 1977. 30(4):244-252.
Todd, A. W. and L. B. Keith. Responses of Coyotes to Winter Reductions in Agricultural Carrion. Alberta Recreation, Parks Wildlife. Wildlife Technical Bulletin No. 5; 1976. 32 pp.

Trainer, C. E., J. C. Lemos, T. P. Kistner, W. C. Lightfoot, and D. E. Toweill. Mortality of Mule Deer Fawns in Southeastern Oregon. Oregon Dept. Fish Wildlife Resource and Development Section Wildlife Resource Report 10; 1981. 113 pp.

Tucker, R. D., and G. W. Garner. Mortality of Pronghorn Antelope Fawns in Brewster County, Texas. Proceedings Western Conference Game and Fish Commission; 1980. 60:620-631.

Tullar, B. F. Jr., L. T. Berchielli, Jr., and E. P. Saggese. Some Implications of Communal Denning and Pup Adoption Among Red Foxes in New York. New York Fish and Game J.; 1976. 23:852-857.

Udy, J. R. Effects of Predator Control on Antelope Populations. Utah Dept. Fish and Game, Salt Lake City, Utah, Publication No. 5; 1953. 48 pp.

U.S. Fish and Wildlife Service. Predator Damage in the West: A Study of Coyote Management Alternatives. U.S. Fish and Wildlife Service Report; 1978. 168 pp.

USDA, National Agricultural Statistics Service. Cattle and Calves Death Loss for 1991. 1992.

USDI, Bureau of Land Management. Final Miles City District Oil and Gas Resource Management Plan/ Environmental Impact Statement Amendment. Bureau of Land Management, Montana; 1992. Page 163.

USDI, Fish and Wildlife Service. Mammalian Predator Damage Management for Livestock Protection in the Western United States. Final Environmental Impact Statement. U.S. Fish and Wildlife Service, Washington, D.C.; 1979. 789 pp.

USDI, U.S. Geological Survey The National Atlas of the United States. 1970. p. 336

Voigt, D. R. and B. D. Earle. Avoidance of Coyotes by Red Fox Families. J. Wildlife Manage.; 1983. 47:92-95.

, and D. W. MacDonald. Variation in the Spatial and Social Behavior of the Red Fox (Vulpes vulpes). Acta. Zool. Fenn.; 1984. 171:261-265. 
. "Red Fox", pp. 378-392. In: Novak, M.; Baker, J. A.; Obbard, M. E., and Mallock, B. (Eds.) Wild Furbear Management and Conservation in North America. Ontario Ministry of Natural Resources, Toronto, Ontario, Canada; 1987. 1150 pp.
Von Gunten, B. L. Pronghorn Fawns Mortality on the National Bison Range. Proceedings Pronghom Antelope Workshop; 1978. 8:394-416.

White, M. Population Ecology of Some White-tailed Deer in South Texas. PhD. Thesis, Purdue University, Lafayette, Indiana; 1966. 215 pp. 



\section{ACRONYMS AND GLOSSARY}

\section{ACRONYMS}

$\begin{array}{ll}\text { ACEC } & \text { Area of Critical Environmental Concern } \\ \text { ADC } & \text { Animal Damage Control } \\ \text { APHIS } & \text { Animal and Plant Health Inspection Service } \\ \text { BLM } & \text { Bureau of Land Management } \\ \text { DEIS } & \text { Draft Environmental Impact Statement } \\ \text { DOL } & \text { Montana Department of Livestock } \\ \text { EA } & \text { Environmental Analysis } \\ \text { EIS } & \text { Environmental Impact Statement } \\ \text { EPA } & \text { U.S. Environmental Protection Agency } \\ \text { FR } & \text { Federal Register } \\ \text { FWP } & \text { Montana Department of Fish, Wildlife and Parks } \\ \text { IPM } & \text { Integrated Pest Management } \\ \text { MASS } & \text { Montana Agricultural Statistical Service } \\ \text { MOU } & \text { Memorandum of Understanding } \\ \text { NASS } & \text { National Agricultural Statistical Service } \\ \text { NEPA } & \text { National Environmental Policy Act } \\ \text { RMP } & \text { Resource Management Plan } \\ \text { T\&E } & \text { Threatened and Endangered Species } \\ \text { USFS } & \text { U.S. Forest Service } \\ \text { USFWS } & \text { U.S. Fish and Wildlife Service } \\ \text { USDI } & \text { U.S. Department of Interior } \\ \text { WSA } & \text { Wilderness Study Area }\end{array}$




\section{GLOSSARY}

Allotment: A specific area of public lands within which grazing use by one or more livestock operators is authorized.

Animal Damage Control Plan: An organized plan for each BLM District jointly developed by BLM, APHISADC, DOL, the Montana Department of FWP, and other interested parties specifying when, where, how, and under what constraints predator management operations would be carried out during the next 12 months. A map showing planned control, restricted control, no control, and special protection areas is part of the plan.

Animal Behavior Modification: The use of scaring tactics to deter or repel animals that cause loss or damage to resources or property. It includes the use of electronic distress sounds, propane exploders, pyrotechnics, lights, scarecrows, water spray devices and repellents.

Animal Husbandry: The use of livestock management practices, such as shed lambing, changing livestock types or breeds, altering breeding seasons, or employing herders and guard dogs, to reduce mortality due to adverse weather, predation or other causes.

Aversive Agent: A substance with taste, odor or feel that discourages a specific animal or species from using a food or place.

Candidate Species: Any species not yet officially listed but is undergoing a status review or is proposed for listing as a threatened or endangered species.

Canid: A coyote, dog, fox, wolf or other member of the dog (Canidae) family.

Confirmed Losses: Wildlife-caused losses or damages verified by APHIS-ADC or DOL. These figures usually represent only a fraction of the total losses.

Corrective Control: Predator control actions applied when damage is occurring or after it has occurred.

Denning/Den Hunting: The process of locating burrows where predators (primarily coyotes) have their young and then killing the pups. The adult predators may also be killed.

Depredating Species: An animal species causing damage to or loss of crops, livestock, other agricultural resources, or wildlife.

Endangered Species: Any species which is in danger of extinction.
Environment: The surrounding conditions, influences, or forces that affect or modify an organism or an ecological community and ultimately determine its form and survival.

Environmental Analysis (EA): An analysis of the impact of a planned action to the human environment to determine the significance of the action and whether or not an EIS is needed.

Environmental Impact Statement (EIS): A document prepared by a Federal agency to analyze the anticipated environmental effects of a planned action or development.

Eradication: Elimination of specific pest wildlife populations from designated areas.

Forage: Food for animals, especially when taken by browsing or grazing.

Furbearer: An administrative or legal grouping of mammal species that are harvested for their fur.

Habitat: An environment that provides the requirements (i.e., food, water, and shelter) essential to development and sustained existence of a species.

Habitat Modification/Management: Protection or modification of a habitat to maintain, increase, or decrease its ability to produce, support, or attract designated wildlife species.

Harvest Data: An estimation of the number of animals removed from a population.

Humaneness: The perception of compassion, sympathy, or consideration for animals.

Integrated Pest Management: The process of integrating and applying practical methods of prevention and control to keep pest situations from reaching damaging levels while minimizing potentially harmful effects of pest control measures on humans, non-target species, and the environment.

Lethal Control Methods/Techniques: Predator control methods or techniques that result in the death of animals (e.g., M-44s, aerial shooting, calling and ground shooting, and denning).

Local Population: The population within a specified geographical area causing damage to human health and safety, to other wildlife, or to forest, range, and agricultural resources.

Long-Term: An action, trend, or impact that affects the potential of a species to maintain its population through 
reproduction or immigration over an extended period of time.

Non-Lethal Control Methods/Techniques: Predatorcontrol methods or techniques that do not result in the death of target animals (e.g., live traps, repellents, fences, guard dogs, etc.).

Non-Target Species/Animal: An animal or local population that is inadvertently captured, killed, or injured during wildlife damage control activities. The same species may be either a target or non-target animal, depending on the control situation.

Offending Animal: The individual animal or local population within a specified area causing damage to human health and safety, to other wildlife, or to forest, range and agricultural resources.

Pesticide: A chemical substance used to control pest wildlife.

Pesticide Use Proposal (PUP): A pesticide that has been approved by the appropriate government agency(ies), such as the EPA, for use in a specific formulation and for a specified purpose.

Population: A group of organisms of the same species that occupies a particular area.

Predator: An animal that kills and consumes another organism.

Predator Control/Management: Control actions directed towards the offending predator (the predator(s) responsible for damage).

Prey: An animal that is killed and consumed by a predator.

Public Land: Land that is owned and controlled by a government unit (i.e., federal, state, regional, county or other municipal jurisdiction).
Pyrotechnics: Fireworks or projectiles used to frighten wildlife.

Raptors: Carnivorous bird species (e.g., owls, hawks, falcons) that prey on other birds, amphibians, reptiles, and mammals.

Short-Term: An action, trend, or impact that does not last long enough to affect the reproductive or survival capabilities of a species.

Significant Impact: An impact that will cause important positive or negative consequences to man and his environment.

Take: The capture or killing of an animal.

Target Species/Anmal/Population: An animal or local population to which wildlife damage control activities are directed to alleviate damage to agricuiture and non-agriculture resources. The same species may be either a target or non-target, depending on the situation.

Threatened Species: Any species which is likely to become an endangered species within the foreseeable future.

Toxicant: A poison or poisonous substance.

Unconfirmed Losses: Losses or damage reported by resource owners or managers, but not verified by APHIS$\mathrm{ADC}$ or DOL.

Wilderness Study Area (WSA): Undeveloped federal land retaining its primeval character and influence, without permanent improvements or human habitation, and managed to preserve its natural conditions.

Wildlife: Any wild mammal or bird. 


\title{
APPENDIX 1
}

\author{
APHIS-ADC TOTAL CONFIRMED LOSSES \\ 1987 - 1992 \\ Total Confirmed Livestock Losses, 1987 - 1992: $\quad$ 15,006 \\ Average Livestock Loss per year: 2,501 \\ Total Cattle/Calves Lost, 1987 - 1992: 837 \\ Average Lost per year: 140 \\ Total Sheep/Lambs Lost, 1987 - 1992: $\quad$ 14,169 \\ Average Lost per year: $\quad 2,362$
}

\section{APHIS/ADC CONFIRMED LOSSES BY YEAR}

SOURCE: ADC - BILLINGS, MT

\begin{tabular}{|c|c|c|}
\hline \multicolumn{3}{|c|}{1992} \\
\hline Resource & Species Responsible & \# Lost \\
\hline Cattle & Coyotes & 1 \\
\hline Cattle & Wolves, Gray/Timber & 1 \\
\hline Cattle (calves) & Bears, Black (other) & 1 \\
\hline Cattle (calves) & Bears, Grizzly & 1 \\
\hline Cattle (calves) & Coyotes & 222 \\
\hline \multirow[t]{2}{*}{ Cattle (calves) } & Lions, Mountain (cougar) & 9 \\
\hline & TOTAL: & 235 \\
\hline Sheep & Bears, Black (other) & 27 \\
\hline Sheep & Bears, Grizzly & 11 \\
\hline Sheep & Coyotes & 399 \\
\hline Sheep & Foxes, Red & 1 \\
\hline Sheep & Lion, Mountain (cougar) & 51 \\
\hline Sheep & Wolves, Gray/Timber & 1 \\
\hline Sheep (lambs) & Bears, Black (other) & 9 \\
\hline Sheep (lambs) & Bears, Grizzly & 2 \\
\hline Sheep (lambs) & Coyotes & 3,042 \\
\hline Sheep (lambs) & Eagles, Golden & 12 \\
\hline \multirow[t]{2}{*}{ Sheep (lambs) } & Foxes, Red & 56 \\
\hline & TOTAL: & 3,611 \\
\hline \multicolumn{2}{|c|}{ TOTAL LIVESTOCK LOST IN 1992: } & 3,846 \\
\hline
\end{tabular}

\section{1}

Resource Species Responsible \# Lost

Cattle Bears, Black (other) 3

Cattle Coyotes

Cattle

Wolves, Gray/Timber

3

3

Cattle (calves)

Bears, Black (other) 5

Cattle (calves)

Coyotes

200

Cattle (calves)

Eagles, Golden

TOTAL:

215

Sheep

Bears, Black (other)

43

Sheep

Bears, Grizzly

23

Sheep

Coyotes

305

Sheep

Eagles, Golden

1

Lion, Mountain (cougar)

Sheep (lambs)

Sheep (lambs)

Bears, Black (other)

14

Bears, Grizzly

4

Sheep (lambs)

Coyotes

2.435

Sheep (lambs)

Eagles, Golden

6

Foxes, Red

55

Sheep (lambs)

Lion, Mountain (cougar)

26

Sheep (lambs)

Wolves, Gray/Timber

2,928

TOTAL:

3,143 


\begin{tabular}{|llr|}
\hline & \multicolumn{1}{c|}{1990} & \\
Resource & Species Responsible & \# Lost \\
& & \\
Cattle & Bears, Grizzly & 1 \\
Cattle & Coyotes & 3 \\
& & 112 \\
Cattle (calves) & Coyote & 4 \\
Cattle (calves) & Lion, Mountain & 6 \\
Cattle (calves) & Wolf, Gray & 126 \\
& TOTAL: & 14 \\
& & 12 \\
Sheep & Bears, Black (other) & 195 \\
Sheep & Bears, Grizzly & 6 \\
Sheep & Coyotes & 6 \\
Sheep & Eagles, Golden & 7 \\
Sheep & Lion, Mountain (cougar) \\
& Bears, Black (other) & 7 \\
Sheep (lambs) & Bears, Grizzly & 2,086 \\
Sheep (lambs) & Coyotes \\
Sheep (lambs) & Foxes, Red & 50 \\
Sheep (lambs) & Lion, Mountain (cougar) & 21 \\
Sheep (lambs) & & 2,404 \\
& TOTAL: & 2,530 \\
TOTAL LIVESTOCK LOST IN 1990: & \\
\hline & & \\
\hline
\end{tabular}

1989

\begin{tabular}{|c|c|c|}
\hline \multicolumn{3}{|c|}{1989} \\
\hline Resource & Species Responsible & \# Lost \\
\hline Cattle (calves) & Coyote & 130 \\
\hline Cattle (calves) & Fox & 1 \\
\hline \multirow[t]{2}{*}{ Cattle (calves) } & Bear, Grizzly & 3 \\
\hline & TOTAL: & 134 \\
\hline Sheep & Bears, Black (other) & 45 \\
\hline Sheep & Bears, Grizzly & 11 \\
\hline Sheep & Coyotes & 199 \\
\hline Sheep & Fox & 2 \\
\hline Sheep & Lion, Mountain (cougar) & 1 \\
\hline Sheep (lambs) & Bears, Black (other) & 21 \\
\hline Sheep (lambs) & Bears, Grizzly & 12 \\
\hline Sheep (lambs) & Coyotes & 1,425 \\
\hline Sheep (lambs) & Foxes, Red & 46 \\
\hline Sheep (lambs) & Lion, Mountain (cougar) & 6 \\
\hline \multirow[t]{2}{*}{ Sheep (lambs) } & Eagle & 15 \\
\hline & TOTAL: & 1,783 \\
\hline \multicolumn{2}{|c|}{ TOTAL LIVESTOCK LOST 1989: } & 1,917 \\
\hline
\end{tabular}

\begin{tabular}{|c|c|c|}
\hline \multicolumn{3}{|c|}{1988} \\
\hline Resource & Species Responsible & \# Lost \\
\hline Cattle & Bear & 2 \\
\hline Cattle (calves) & Coyote & 60 \\
\hline Cattle (calves) & Fox & 1 \\
\hline Cattle (calves) & Bear & 3 \\
\hline Cattle (calves) & Bear, Grizzly & 3 \\
\hline \multirow[t]{2}{*}{ Cattle (calves) } & Lion, Mountain & 2 \\
\hline & TOTAL: & 71 \\
\hline Sheep & Bears & 58 \\
\hline Sheep & Coyotes & 226 \\
\hline Sheep & Fox & 2 \\
\hline Sheep & Lion, Mountain (cougar) & 11 \\
\hline Sheep (lambs) & Bears, Black (other) & 39 \\
\hline Sheep (lambs) & Coyotes & 1,517 \\
\hline Sheep (lambs) & Foxes, Red & 19 \\
\hline Sheep (lambs) & Lion, Mountain (cougar) & 47 \\
\hline \multirow[t]{2}{*}{ Sheep (lambs) } & Bobcat & 4 \\
\hline & TOTAL: & 1,923 \\
\hline \multicolumn{2}{|c|}{ TOTAL LIVESTOCK LOST IN 1988: } & 1,994 \\
\hline
\end{tabular}

\begin{tabular}{|llr|}
\hline & \multicolumn{1}{c|}{1987} & \\
Resource & Species Responsible & \# Lost \\
Cattle & Bear, Grizzly & 1 \\
Cattle & Coyote & 1 \\
& & \\
Cattle (calves) & Coyote & 49 \\
Cattle (calves) & Bear & 2 \\
Cattle (calves) & Bear, Grizzly & 2 \\
Cattle (calves) & Lion, Mountain & 1 \\
& & 56 \\
& TOTAL: & 45 \\
Sheep & Bears & 157 \\
Sheep & Coyotes & 15 \\
Sheep & Lion, Mountain & 23 \\
& & 1,178 \\
Sheep (lambs) & Bears, Black (other) \\
Sheep (lambs) & Coyotes \\
Sheep (lambs) & Foxes & 32 \\
Sheep (lambs) & Lion, Mountain & 70 \\
& TOTAL: & 1,520 \\
& & 1,576 \\
TOTAL LIVESTOCK LOST IN 1987: & \\
\hline & & \\
\hline
\end{tabular}




\section{APPENDIX 2 \\ DOL CONFIRMED LOSSES BY YEAR \\ 1990 - 1992}

\begin{tabular}{|cc|}
\hline & 1992 \\
Livestock Resource & Number Lost \\
& \\
Lambs & 629 \\
Sheep & 67 \\
Calves & 3 \\
TOTAL LIVESTOCK LOST: & 699 \\
\hline
\end{tabular}

\begin{tabular}{|cc|}
\hline & 1991 \\
Livestock Resource & \\
Lambs & Number Lost \\
Sheep & 951 \\
Calves & 48 \\
TOTAL LIVESTOCK LOST: & 4 \\
\hline
\end{tabular}

1990

Livestock Resource

Number Lost

Lambs

384

Sheep

Calves

50

6

TOTAL LIVESTOCK LOST:

440

TOTAL LIVESTOCK LOST FOR 1990 - 1992: 2,142

AVERAGE LIVESTOCK LOST PER YEAR, 1990 - 1992: 714/year 



\section{APPENDIX 3 \\ PREDATOR MANAGEMENT \\ METHODS AND TECHNIQUES}

Predator management methods could be non-lethal or lethal, depending on the management objective. When the objective is to examine or move an animal, it would be caught in a trap or snare and tranquilized and then released or moved. When shooting is involved, the decision is made to kill the animal. When chemicals are used, they are selected to achieve a specific result. The following methods would be used under Alternatives I-III, depending on the management objective, restrictions in effect, and the authorizing sanction.

\section{TRAPPING}

Traps are considered to be a nonlethal mechanical capture device since disposition of the trapped animal is left to the discretion of the individual using them.

Leghold traps would be used based on circumstances of the field and are used in a variety of situations. They are, however, difficult to keep in operation during rain, snow, or freezing weather. They can be used as "blindsets" (placed without bait) or can be placed as "baited sets". In some situations, a "draw station", such as a carcass or piece of meat is used. Traps would not be placed closer than 30 feet from the draw station, providing protection to scavenging birds.

Various pan-tension devices can be used to prevent smaller non-target animals from springing the trap. Effective placement of the trap and use of the back sets, based on professional experience also contributes to the selectivity of the trap.

\section{LIVE TRAPPING}

This technique is used primarily in the control of rabid skunks during isolated outbreaks of rabies and is considered a technique to supplement the use of leghold traps. This method incorporates the use of box-type traps to live capture target species and is very selective in application.

\section{SNARES}

Snares are generally made of small diameter cable. They are lighter weight than leghold traps and aren't as affected by inclement weather. Snares can be set to catch an animal by the neck, which is generally lethal. They may also be set to catch an animal by the foot or body. When used in this manner, they can be useful live capture devices. Snare are generally placed so as to capture the target animal during its normal movement patterns. Target animals would generally be coyotes, bears, mountain lions and beavers.

\section{SHOOTING}

Shooting is considered selective to the target animal. It is considered relatively expensive due to the staff hours required. Shooting is usually used in conjunction with calling and/or dogs. Target animals are most often coyotes, but, on occasion, may be foxes, bobcats, or bears.

Shooting from aircraft is generally associated with coyote control. Aerial hunting is:

1. Species selective,

2. Can be used for immediate control where livestock losses are severe,

3. Can be used in removing offending coyotes which are not susceptible to calling or shooting,

4. Dependent on favorable weather conditions,

5. Usually most effective in flat or rolling terrain.

Helicopters have greater utility in more mountainous, brushy or timbered terrain. Aerial hunting would be conducted in accordance with Federal and State aircraft and other related laws. Only properly training pilots and gunners would be used. 


\section{HUNTING DOGS}

Dogs are essential to successfully hunting mountain lions, bears and sometimes coyotes. Dogs trained for denning may also be used in luring adult coyotes. Trained dogs are used to locate, pursue, or decoy target animals.

\section{DENNING}

Predation problems often increase sharply during the time periods when adult coyotes are denning. Removal of pups or adults is effective in prevention or reducing predation. Denning consists of the practice of finding coyote dens and taking the animals with an EPA registered fumigant. Den hunting is often done in conjunction with calling and shooting. Denning is highly selective for the target animals.

\section{CHEMICALS}

The most commonly used chemical in Montana's predator management programs is sodium cyanide. It is used in the
M-44, a spring activated ejector device developed specifically to target coyotes or other canids. The device is baited with a bait selective to the target animal. When the target animal bites and pulls the bait, a capsule containing about 0.9 grams of powdered sodium cyanide is propelled into its mouth by a spring drive plunger. Death of the animal occurs within seconds following the discharge.

APHIS-ADC personnel or others possessing an EPA certification are the only personnel registered or authorized to use the M-44 device. Its use must be in strict conformance to the 26 EPA restrictions (see Appendix 5).

\section{FUMIGANTS}

Fumigants, as noted under "denning" are used primarily for coyotes and, on occasion, foxes. They may also be used in control of certain rodents including prairie dogs. APHISADC manufactures and uses denning cartridges especially formulated for these purposes. The cartridge is placed in an active burrow of target animals. A fuse is lit and the burrow entrance is sealed. The burning cartridge causes death by producing carbon monoxide. 


\title{
APPENDIX 4
}

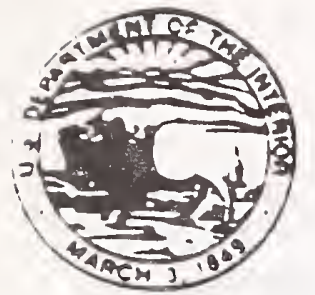

\section{Lnited States Deparment of the Interior}

\author{
FISH .LID WTLDLIFE SERITCE
}

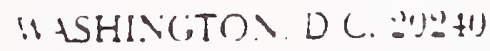

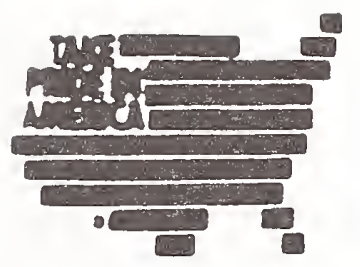

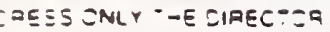

- APO NILDLIFE SEAVHCE

In Reply Refer io:

FWS/FWE/OES

$$
\therefore 28 \text { joly } 28,1992
$$

Mr. Robert Melliand

Animal \& Plant Health Inspection Service

U.S. Department of Agriculture

P.0. Box 96464

Washington, D.C. 20090-6464

Dear Mr. Melland:

This responds to Mr. James Glosser's March 15, 1990, request for reinitiation of the February 28, 1979, formai consultation with ine United States Department of Agricuiture (USDA) on its Animal Damage Control (ADC) Program as required under Section 7 of the Endangered Species Act of 1973. This consultation supersedes that initial consultation which was completed when $A D C$ was part of the U.S. Fish and Wildife Service (Service).

\section{CONSULTATION HISTORY}

In the intervening years since the February 1979 consultation, there have been substantial changes in the Endangered Species Act. There have also been a number of consultaions with the U.S. Environmental Protection Agency (EPA) on registration of chemicals used by the ADC Program and several consultations with USDA on certain specific elements of the ADC Program itself. The Section 7 regulations now require the Service to issue Incidental Take Statements for unintended taking that may occur pursuant to the otherwise legal activities conducted subsequent to a consultation. This biological opinion provides incidental take levels for cercain species along with reasonable and prudent measures to minimize or eliminate such take. Since reinitiation, the consultation period was formally extended for 60 days in July of 1990, and informally several times by mutual agreement between Service and USDA staff members. A consultation team of Regional representatives was appointed to draft the opinion. A preliminary draft was sent to the team members for input on April 19, 1991. Three drafts were prepared and circulated for formal Regional and USDA comment August 15, 1991; March 17, 1992; and a final draft on May 22, 1992.

An Aprit 11, 1988, order of the U.S. District Court for the District of Minnesota enjoined any registrations of the aboveground uses of strychnine. However, according to the EPA's Office of General Counsel and the Department of the Interior Solicitor, the current court action does not prevent an agency from seeking formal consultation nor prohibit the Service from issuing a biological opinion pertaining to strychnine. Thus, the Service is thus treating strychnine use as if the injunction has been lifted. 


\section{PROPOSED ACTIONS}

The prooosed actions consicered in this consuitation incluce the operacional, researcn. ano iecnnical assisiance fnases of the ADC Program as described in the oocument Entitled "Compliance with Section 7 Endangered Species Act of 1973, as amended." in the oderational pnase. ADC personnel carry out the controi work; in the research phase. ADC personnel conduct research to imorove widilife damage control metnods and tecnniques: and in the tecnnical assistance phase, personnel other than ADC personnel conduct the control work. Technical assistance is carried out as defined in Appendix $B$ of the Draft Environmental Impact Statement (DEIS) issued in July 1990 on the ADC Program. Examples of ADC technical assistance include, but are not limited to, providing items such as chemicals and equipment as well as providing verbal or written advice, recommendations, information, demonstrations, and training in management of wildlife damage programs. All of the methods described below are used in the conouct of the program.

ANIMAL DAMAGE CONTROL METHODS

$A O C$ empioys a number of controi tools and techniques discussed below, both chemical and non-chemical, in the implementation of its programs. These tools and techniques are diverse, situation-specific, and variable in scope, ranging from nonlethal measures to lethal control.

\section{Cultural Practices}

Cultural methods include a variety of practices that can be employed by agricultural producers to reduce resource exposure to wildife depredation and loss. Implementation of these practices is appropriate when the potential for depredation can be reduced without significantly increasing the cost of production or diminishing the resource owner's ability to achieve land management and production goals. ADC recommends changes in cultural practices when a change of this type appears to represent a means of averting losses.

Animal Husbandry - This general category includes modifications in the level of care and attention given to livestock, shifts in the timing of breeding and births, altering the selection of resource to be produced, and the introduction of livestock custodians (e.g., herders, guard dogs) to protect livestock.

Crop Selection and Planting Schedules. The choice of crops and time of planting often has a direct bearing on the potential for losses to depredation. In some cases the time of planting can be adjusted to reduce or eliminate the availability of vulnerable-crops to migratory wildlife species, and some crops are less prone to predation.

Lure Crops. Lure crops are planted or set aside for wildilife as an alternative food source to reduce the effect of depredation. To be successful, frightening techniques may be required also in the field being protected. 
Habitar Modificarions

Habitat modifications can restrict the acsess of wlidife or rencer the habitat less nospitable 0 wildlife. Habital nodifications used or recommended by $A D C$ program are described below.

Physical Barriers - Several mechanical methoos such as fences, netting, metal flasning, and spiked metal sirips are advocared for suppression of damage to i ivestock, crops, bulldings and faciitities by birds and mamals.

Two forms of physical barriers used to protect fish from foraging birds are: complete enclosures of ponds and raceways with screen or net, and partial enclosure using overnead wires, lines, net, or screen.

Habitat Management and Biological Control - Habitat can sometimes be managed not to support or attract certain wildlife species. Most of the habitat management application in the ADC program involves airport health and safety work, blackbird/starling winter roost problems. or orchards/field crop depredation complaints.

Aversive Tactics

Aversive tactics alter the behavior of the target animal to the extent that the potential for loss or damage to the property by this animal is greatly reduced or eliminated. Scaring and harassment are some of the oldest methods of combatting animal damage, and continue to be effective.

\section{Nonchemical}

Electronic Distress Sounds - Distress and alarm calls of various animals have been used independentiy and in conjunction with other scare devices to successfully scare or harass animals.

Gas Exploders - Gas exploders operate on acetylene or propane gas and are designed to scare the offending wildife by producing loud explosions at controllable intervals. The exploders are placed around the problem site in areas known to receive heavy damage.

Pyrotechnics - Shell crackers or scare cartridges are 12 -gauge shotgun shells containing a firecracker. Noise bonbs, whistle bombs, racket bombs, and rocket bombs are fired from hand-held launch guns. Noise bombs, or bird bombs, are firecrackers that travel about 75 feet before exploding. A variety of other pyrotechnic devices, including firecrackers, rockets, and Roman candles are used for dispersing animals.

Effigies, Scarecrows, and Other Scaring Techniques - Owl decoys, reflective Mylar tape, and helium-filled balloons are used as scaring devices. Their effectiveness is enhanced when they are used in conjunction with auditory scare devices. Other devices such as scarecrows, ribbons, flagging, suspended pie plans, etc., are also used in animal damage control activities. 
Liahts - A variety of lights. ncluding sirode, barricade. and revolving units have been used to frionten oirds.

Water Sprav Devices - Nater soray from rotating sprinklers piaced at strategic iocations in or arouno ponos or raceways will repei certain birds. particularly gulls.

\section{Chemical}

Chemical Repellents - Repellents are compounds which prevent use of an area or consumption of food item resources. Repellents operate by producing an undesirable taste, odor, feel, or behavior pattern. The avian frightening agent Avitrol (4-Aminopyridine) is limited for use in specific areas and for protection of specific crops. Avitrol is a toxic chemical, but is used as an area repellent by limiting the treated bait particles through dilution. Use sites are monitored to assure bait consumption is by targeted species only.

Population Management

Many capture methods employed by the ADC program can be used as either lethal or nonlethal methods depending on the management objective. When the objective is a scientific collection or relocation, or if the animal captured is a nontarget, it can be released. If the captured animal is a target species and the object is population reduction in the local area, the animal is euthanized.

\section{A. Nonlethal}

Leghold Traps - Leghold traps are frequently used to capture animals such as coyote, bobcat, fox, mink, beaver, raccoon, skunk, muskrat, nutria, and mountain lion. These traps are the most versatile and widely used tool available to $A D C$ for capturing many species.

Cage Traps - Cage traps were often used where lethal or more controversial tools would be inappropriate due to a potential hazard to pets, other wildlife, or humans. Cage traps are well suited for use in residential areas. These traps are used to capture animals ranging in size from mice to deer, but are generally impractical in capturing most large animals.

Snares - Snares, made of wire or cable, are among the oldest existing control tools. Snares can be used effectively to catch most species but are most frequently used within ADC to capture coyotes, beaver, and bears. Snares may be lethal or nonlethal.

Pole Traps - Pole traps can be effectiveiy used to capture raptors (i.e., hawks and owls) because of their behavioral tendency to perch prior to making a kill. One to several poles, 5 to 10 feet high, are erected near the area where depredations are occurring. A padded-jaw, leghold trap (usually size $1-1 / 2$ ) is set on the top of each pole. A steel wire is passed 
through the trap chain and attacned at both the tod and oase of the pole. to ailow the oira to come :0 res: on the ground after oeing captured.

3. Letnai

?. Noncnemical

Leghold Traps - When the target animal is captured, the animal is generally euthanized. The methoo of euthanasia varies, but it is ADC policy to provide the quickest, most painless death possible to the animal.

Quick-kill Traps - A number of "quick-kill" eraps are used in animal damage control work. They include Conibear-type, snap, gopher, and mole traps. The Conibear-type trap consists of a pair of rectangular wire rod frames attacned on both sides, which close in a scissor-like fastion when triggered, killing the captured animal with a quick body blow. The larger size of the Conibear trap (i.e., $\$ 330$ ) is restricted in ADC to use in shallow water or underwater and primarily to capture nutria and beaver. The smaller sizes ( $i . e ., \$ 220, \$ 115, \$ 110$ ) can be used in aquatic situations to capture nutria or muskraz, but are also used in dry land sets for trapping skunks, weasels, rats, and armadillos.

Snap traps (i.e., rat and mouse traps) are used to collect and identify rodent species that are causing damage, so that species-specific control tools can be applied.

Mole traps are used to control surface-tunneling moles (i.e., Nash moletrap and harpoon trap). Soil is pressed down in the active tunnel and the trap is placed with the trigger against the compressed area. When the mole reopens the tunnel, the trap is triggered.

Gopher traps (e.g., Macabee gopher trap) are placed in burrows to control pocket gophers. These traps are set in active burrows and are selective to the animal targeted.

Shooting

Ground Hunting - Lethal reinforcement is often necessary to ensure the continued success in bird scaring and harassment efforts.

Shooting is an integral facet of predator control. Trap-wise coyotes, while difficult to trap, are often vulnerable to calling. Shooting can be selective for offending individuals and has the advantage that it can be directed at specific damage situations.

Aerial Hunting - Shooting from aircraft is a commonly used coyote danage control method. Aerial hunting is species-selective and can be used for immediate control where livestock losses are severe, providing weather, terrain, and cover conditions are favorable. Aerial hunting can be effective in removing offending coyotes which have become "trap-wise" and/or are not susceptible to calling and shooting. 
Hunting Dogs - Dogs are essential to successful hunting of mountain lion and bear. Dogs tranned for coyote denning are also valuable in luring offending coyote adults within snooting distance.

Denning - Denning is the oractice of seeking out the dens of depreating coyotes or red fox and eliminating the young, aduits, or both to stop ongoing and/or prevent further depredations on livestock. Denning is used primarily in the Western States. The usefulness of denning as a damage control method is proven, however, since locating dens is difficult and time consuming, and den use is restricted to approximately 2 to 3 months of the year, its practical use is limited.

\section{Chemicals}

\section{a. Toxicants}

Several toxic chemicals have been developed for use in the control of animal damage. Because of their efficiency, such toxicants have been widely employed. Since toxicants are generality not species-specific, and their use may pose a hazard to some nontarget species.

The following section describes the chemicals used in the current $A D C$ program:

Zinc Phosphide - Zinc phosphide is a metallic toxicant used as a rodenticide.

Sodium Cyanide - Sodium cyanide is used in the M-44, a spring-activated ejector device developed specifically to take coyotes and other canine predators. The M-44 device consists of a capsule holder which is wrapped with fur, cloth, or wool; a spring-powered ejector mechanism; a capsule containing approximately 0.1 grams of powdered sodium cyanide (plus inert ingredients); and a 5 or 7 inch hollow stake.

Sodium cyanide is a fast-acting toxicant that, upon contact with moisture, either rapidly breaks down or is quickly metabolized. When sodium cyanide contacts water it quickly hydrolyses into hydrocyanic gas and sodium hydroxide. Cyanide which is ingested, kills the animal and is proteinbound, rendering it harmless to other animals that might scavenge the carcass.

Strychnine - Strychnine is a white, crystalline, bitter-tasting toxicant. It is very toxic to most ammals and birds. with the exception of gallinaceous birds which are relatively resistant. Strychnine is often retained in the gut of the consuming animal and consequently may pose a secondary hazard to scavengers. ADC currently restricts normal program use of strychnine to field rodent and nuisance bird control efforts. strychnine is not used as a predacide except in emergency situations involving human health and safety. 
Strychnine-treated grain is used in the concroi of damage caused by a variecy of fieid rodents. When used as a fieid rodenticide. strycnninetreated milo or oats are ininiy scattered in or near the rodent's den, burrow. or area where damage is occurring.

Anticoagulants - Several anticoagulant rocenticides are used to control commensai rocents and some field rodents. Common anticoagulants include warfarin, diphacinone, and chloropnacinone. Anticoaguiants were originally multiple-dose toxicants (i.e.. several feedings were required to achieve a lethai dose), however some recent formulations require oniy a single feeding to be effective.

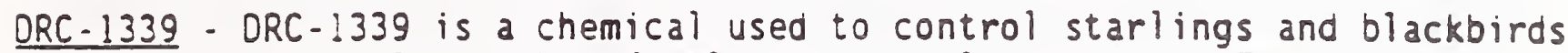
in and around cattle and hog feedlots and poultry yards. This chemical is highly toxic to starlings, generally less toxic to other birds. and relatively nontoxic to most mammals. There is minimal danger to raptors or to mammalian carnivores that might eat DRC-1339 poisoned starlings since hawks and mammais are resistant to ORC-1339. ORC-1339 causes most birds to die at the roosting site.

Compound 1080 - Currently, the only registerea, non-experimental, use of this chemical in controlling predators is as the active ingredient in the Livestock Protection Collar.

b. Fumigants

Gas Cartridges - Fumigants or gases are used to control burrowing wildife. In the ADC program, fumigants are oniy used in rodent burrows and in predator dens. The ADC program manufactures and uses den and burrow cartridges specifically formulated for both of the above-stated purposes. These cartridges are hand placed in the active burrow or den of the target animal, and the entrance is tightly sealed with soil. The burning cartridge causes death from a combination of oxygen depietion and carbon monoxide poisoning.

Aluminum phosphide. Aluminum phosphide tablets are used as a fumigant in the control of prairie dogs.

\section{c. Stressing Agents}

PA-14 - The avian stressing agent PA-14 is the only chemical registered for control of roosting blackbirds and starlings during the winter months.

PA-14 is a surfactant that lowers the surface tension of water. When PA14 solution is sprayed on birds, the chemical action of the surfactant breaks down the feathers' natural waterproofing characteristics. Feathers become soaked and matted from the PA-14 solution and lose the insulating value. When applied during low temperatures, and if the birds are sufficiently wetted, insulation loss cannot be offset by increased metabolism, and the treated birds' body temperature eventually drops to the lethal level. 
In the past, the Service has conducted numerous informai and formal consultations on specific ADC projects to consider the possible effects of those projects on endangered and threalened species in a paricuiar geograpnic area. This process will concinue in any instance where Service, $A D C$ or other Fegeral agency Dersonnei identify possible aoverse impacts to threatened or endangered species.

One major objective of this consultation is to provide for cioser routine coordination between USDA and the Service on Section 7 responsibilities.

Toward this end. the Service will provide information on newly listed species and will review possible impacts of new and existing control tectiniques. In return, $A D C$ personnel will keep the Service up-to-date on program changes, new techniques and non-target losses.

\section{FORMAT}

"May effect" determinations have been made for 22 species. The opinion will address each of those individually with status information, effects of the proposed action, and biological opinion with reasonable and prudent aiternatives as appropriate.

An incidental take statement follows the biological opinion, with its reasonable and prudent measures and implementing terms and conditions, as appropriate. Sections $4(d)$ and 9 of the Act, as amended, prohibit taking (harass, harm, pursue, hunt, shoot, wound, kill, irap, capture or collect, or attempt to engage in any such conduct) of listed species of fish or wildi ife without a special exemption. Harm is further defined to include significant habitat modification or degradation that results in death or injury to listed species by significantly impairing behavioral patterns such as breeding, feeding, or sheltering. Harass is defined as actions that create the likelihood of injury to listed species to such an extent as to significantly disrupt normal behavior patterns which include, but are not limited to, breeding, feeding, or sheltering. Under the terms of $\xi 7(b)(4)$ and $\xi 7(0)(2)$, taking that is incidental to and not intended as part of the agency action is not considered a prohibited taking provided that such taking is in compliance with the.terms and conditions of this incidental take statement. The measures described in the incidental take statement are nondiscretionary, and must be implemented by the agency so that they become binding conditions of any grant or permit issued to the applicant, as appropriate, in order for the exemption in $\xi 7(0)(2)$ to apply.

The Federal agency has a continuing duty to regulate the activity that is covered by the incidental take statement. If the agency fails to adhere to the terms and conditions of the incidental take statement through enforceable terms that are added to the permit or grant document, the protective coverage of $\xi 7(0)(2)$ may lapse.

The biological evaluation submitted by USDA contained 144 species (Enclosure 1). 
The Service does not believe that any of the following species will be adverseiy affected by any aspect or ine AOC Program:

\section{Mammais}

1. Listed bats: Ozark and Virginia big-eared, gray, and Indiana. Habitat modifications mentioned in the evaluation are so minor in nacure that the Service has determined 'no affect'.

2. Ungulates: Columbian white-tailed deer and woodland caribou. Although $A D C$ suggested that leghold traps and neck snares may affect these two cervids, the Service is unaware of any such occurrences in the past. The limited overlap between the ranges of the species and the area of operational ADC activity further reduces the likelihood of exposure.

3. Sonoran pronghorn: There have been no $A O C$ activities in the range of this species since 1968. Any new activity may require consultation at that time.

4. Eastern cougar: This subspecies is believed to be extirpated.

5. Florida panther: The panther occurs outside the operational area of the ADC program. Leghold traps or snares are not recommended by $A D C$ within the species' range.

6. Northern flying squirrels: The high country distribution of these squirrels in Virginia and North Carolina results in little opportunity for exposure. In addition, $A D C$ does not use or recommend rodenticides within the species' ranges.

7. Delmarva fox squirrel: There is virtually no field rodent control conducted in the range of the fox squirrel and. ADC would not recommend use of toxicants within the species' range.

8. Red wolf: Limited distribution in the wild (eastern North Carolina) precludes the likelihood of exposure. If further releases are successful, it will be necessary to review $A D C$ activities to insure continued protection.

9. Mt. Graham red squirrel: $A D C$ does not use or recommend toxicants within the species' limited range.

10. Hualapai vole: $A D C$ does not use or recommend toxicants within the species' limited range.

11. Listed mice: Alabama beach mouse, Anastacia Island beach mouse, Choctowatchee beach mouse, Perdido Key beach mouse, Key Largo cotton mouse, southeastern beach mouse, salt marsh harvest mouse. $A D C$ does not use or recommend toxicants within these species' ranges. 
12. Other listed rodents: Fresno kangaroo rat, Morro Bay kangaroo rat, Tipton kangaroo rat, giant kangaroo rat, Key Largo wooorat. ADC does not use or recomend rodenticices within inese species ranges.

\section{Birds}

13. Masked bobwhite: $A D C$ does not use or recommend use of chemrcais within the limited range of this species.

14. Puerto Rican species: Puerto Rican nightjar, Puerto Rican parrot, Puerto Rican piain pigeon and yellow-shouldered blackbird. There is no registered use for zinc phosphide, strychnine, ORC-1339 or avitrol in Puerto Rico.

15. Brown pelican: Pelicans nest and feed in estuarine and marine habitats, so there is no opportunity for exposure.

16. Pacific Island birds: Hawaiian common moorhen, Hawaiian coot, Hawaiian duck, Hawaiian goose. Hawailan stilt, Newell's Townsend's snearwater, large Kauai thrush, small Kaual thrush, Molokai thrusn, Laysan finch, Nihoa fincn, and Nihoa milleroird. ADC does not use or recommend use of toxicants in areas where these species might be exposed to them.

17. California least tern and California clapper rail: Impact would likely be beneficial for predator control for skunks, raccoons and red foxes.

18. Eskimo curlew: Species is so rare, if it exists at all, that neither adverse nor beneficial impact is anticipated.

19. Interior least tern: Species aquatic feeding habits preclude exposure.

20. Light-footed clapper rail: Species aquatic feeding habits and wetland habitat preference preclude the likelihood of exposure.

21. Piping plover: Impacts would likely be beneficial as gull control could reduce competition for nesting space.

22. Black-capped vireo: Impacts would $\cdot$ - $^{2} y$ be beneficial as control of cowbirds would reduce nest parac,l ...

23. Roseate tern: Impacts would likely be beneficial as gull control could reduce competition for nesting space.

24. Wood stork: Aquatic feeding habits preclude the likelihood of exposure.

\section{Reptiles}

25. Alabama red-bellied turtle and flattened musk turtle: The red-bellied turtle is an herbivore and the musk turtle feeds on mollusks. Thus, 
the feeding haoits of the turites freciude the likelihood of exposure to toxicants.

26. American crocodile and American ailigator: The limiced range of the American crocodile (exireme souchern fiorida) ano nadicat preference (saltwater estuaries) preclude i ikelihooo of exposure io any aspect of the ADC Program. The American alligator is listed only as similar in appearance in order to protect the American crocodile.

27. Sea turtles - green, loggerhead, leacherback, Kemp's ridley and hawksbill: Control activities to protect turtle nests from predation would be beneficial.

28. Mona boa. Mona ground iguana, and Monito gecko: No toxicants are registered for use in Puerto Rico. Other predator control activities are beneficial.

29. Fish, clams, crustaceans, and plants: ADC evaluation describes possible impacts from use of PA-14 on bird roosts with subsequent runoff of this material. The Service does not believe this will occur. The low toxicity of these toxicants, combined with the unilkely possibility of much material getting into aquatic habitat, minimizes the chances of exposure. 


\section{AFFECTED SPECIES}

The Service concurs with ADC that ine joliowing threacened or endargered species will be aqverseiy iffecteo oy some aspect or the AOC Proyram:

Mammals (7)

PAGE

1. Black-footed ferret (Mustela niarioes) . . . . . . . . 13

2. Grizzly bear (Ursus aresos). . . . . . . . . . . . . . . 16

3. Gray woif (Canis lupus). . . . . . . . . . . . . . . . 20

4. San Joaquin kit fox (Vulpes macrotis mutica). . . . . . . . . 25

5. Ocelot (Felis pardalis)................. . . 27

6. Jaguarundi (Felis yaqouaroundi). . . . . . . . . . . . . . . . . . 27

7. Utah prairie dog ( Cynomys parvidens) . . . . . . . . . . . . 28

Birds (8)

1. Aleutian Canada goose (Branta canadensis leucopareia). . . . 29

2. Bald eagle (Haliaeetus leucocephalus). . . . . . . . . . 32

3. Peregrine falcon (Falco peregrinus). . . . . . . . . . . . 37

4. Northern aplomado falcon (falco femoralis septentrionalis). . 38

5. Attwater's greater prairie chicken (Iympanuchus cupido

attwateri). . . . . . . . . . . . . . . 39

6. Whooping crane (Grus americana). . . . . . . . . . . . . . 40

7. Mississippi sandhill crane (Grus canadensis pulla). . . . . 41

8. California condor (Gymnogyps californianus). . . . . . . . 43

Reptiles (5)

1. Desert tortoise (Gopherus agassizii) . . . . . . . . . . 4 45

2. Gopher tortoise (Gopherus polyphemus). . . . . . . . . . . . . 47

3. Blunt-nosed leopard lizard (Gamoelia silus). . . . . . . . . 50

4. Eastern indigo snake (Drymarchon corias couperi) . . . . . . . 52

5. San Francisco garter snake (Thamnophis sirtalis tetrataenia). 54

Amphibians (1)

1. Wyoming toad (Bufo hemioghrys baxteri) . . . . . . . . . 56 


\title{
BLACK-FOOTED FERRET (Hustela nigripes) - E
}

\author{
3IOLOGICAL JPINION
}

Status of the species

The biack-footed ferret is a large, buckskin-coiored weasel with black face mask, black tipped tail and black feet, and can weign up to 3 pounds. They depend upon prairie dogs for both food and sheiter and have never been found where prairie dogs do not exist. Today, at least partly due to the extensive prairie dog poisoning campaions of the 1930's, the black-footed ferret is one of the rarest native mammals in North America.

Since the turn of the century, the ierret's habitat (prairie dog colonies) decreased by as much as 95 percent, primarily as a result of land-use changes and practices that include prairie dog control (Choate et al. 1982, Anderson et al. 1986, Flath and Clark 1986). From over 100 million acres in the late $1800^{\prime} \mathrm{s}$, prairie dog colonies are estimated to be reduced to about 2 million acres; only a portion of which may be suitable for ferret survival and recovery.

The last known wild black-footed ferrets were found in Meeteetse, Wyoming, but this species once ranged from the great plains of Canada to intermontane regions of the interior Rocky Mountains and Southwest.

The likelihood of other populations of ferrets being found in the wild is considered low, and if some remain, the probability of their continued survival and viability in the wild for long periods of time is considered low by population biologists. However, the occurrence of ferrets within the historic range of the species must still be considered possible by the Service.

There are currentiy nearly 300 captive ferrets managed cooperatively by the Wyoming Game and Fish Department and the Fish and Wildiife Service in facilities at: Wyoming Game and Fish Department's Sybille Wildife Research and Conservation Education Unit, Wheatland, Wyoming; Henry Doorly 200 in Omaha, Nebraska; and the Conservation and Research Center near Front Royal, Virginia; the Louisville Zoological Park in Louisville, Kentucky; and the Cheyenne Mountain 200 in Colorado Springs, Colorado; the Phoenix Zoo in Arizona; and Toronto Metropolitan 200, Canada. In the spring of 1991. forty-nine ferrets were released in the Shirley Basin. Wyoming. As of November, 1991, ten or fewer were considered likely to be alive. The Service, States, and other Federal agencies have begun to identify prairie dog complexes approximately 10,000 acres in size and of sufficient quality to be considered for ferret reintroductions. This requires mapping prairie dog colonies in each state and selecting complexes of prairie dog colonies to evaluate and rank nationally for reintroductions of black-footed ferrets. Once the final sites have been selected, areas considered not suitable for recovery of the species can be cleared by the Service under the proposed "Block Clearance" Program and, after review, can be rewoved from areas with currently recommended control restrictions. 
Appendix $F$ of the DEIS on the ADC Program identifies a potential adverse impact on the black-footed ferret from the use of aiuminum pnosonide, gas cartridges, and zinc pnospnide io controi orairie dogs, and leghold traps to control coyotes. Appendix $F$ also identifies a potential positive impact for ferrets from the use of $M-44 \mathrm{~s}$ and legnold traps for coyote control. $A D C$ personnel believe that if coyotes and other predators are controlled, there will be less cnance of their killing a ferret or prairie dog, the ferret's primary food source, altnough coyotes probably would not kill enough prairie dogs to negatively affect black-footed ferret numbers. Predator control (primarily of coyotes) in and around prairie dog towns also would decrease the possibility of introducing diseases which may negatively impact blackfooted ferrets.

The DEIS states that the preferred prairie dog control tool in areas where ferrets may exist is zinc phosphide rather than strychnine grain baits. Use of zinc phosphide in areas where ferrets may exist would occur only after ferret surveys were conducted and no evidence of ferrets was found. The DEIS also states that any impact on ferrets from the loss or reduction of the availability of prey is speculative.

Primary and secondary poisoning of ferrets combined with the cumulative impact of control programs on their primary habitat (prairie dog colonies) will have an adverse impact on the survival and recovery of this species. As prairie dog colonies become smaller and their spacing more distant, it can be theorized that ferret populations would suffer the following consequences: (1) reduced gene flow; (2) decreased ability to disperse to new colonies; and (3) lowered mating success.

\section{BIOLOGICAL OPINION}

Even with ferret surveys and successful reproduction in captivity, the survival and recovery of the species is unlikely with a large annual rate of habitat loss. Loss of a single black-footed ferret in the wild would constitute jeopardy to the species. It is, therefore, my biological opinion that those components of the ADC Program described above are likely to jeopardize the continued existence of the black-footed ferret, because of the possible mortality that could result.

\section{REASONABLE AND PRUDENT ALTERMATIVES}

The Section 7 regulations have defined reasonable and prudent alternatives as alternative actions, identified during formal consultation, that can be implemented in a manner consistent with intended purpose of the action, that can be implemented consistent with the scope of the Federal agency's legal authority and jurisdiction, that are economically and technologically feasible, and that the Service believes would avoid the likelihood of jeopardizing the continued existence of listed species or result in the destruction or adverse modification of critical habitat. 
The reasonable and prudent aiternative to preclude jeopardy during prairie dog control is for ADC personnel to l) work with the States, landowner, and/or land agency to map prairie dog colonies in the vicinity of each colony that is proposed for controi. ano 2 ) Ensure that orairie gog control snall not occur in any prairie oog comoiex iarger than i, 000 acres. unless the area has been block cleared by the Service's block clearance process. A prairie dog comolex consists of two or more neighboring prairie dog towns, each less than 7 kilometers $(4.34$ miles) from eacn other. Once the area of proposed action is mapped, the following criteria shall be applied to preclude jeopardy to the black-footed ferret as a result of the use of toxicants by $A D C$ personnel:

1. A black-tailed prairie dog colony or complex of less than 80 acres having no neighboring black-tailed prairie dog towns may be treated without a ferret survey. A midrange of 102 acres (61 to 294 acres) of occupied black-tailed prairie dog habitat is believed necessary to support a single ferret. so it is highly unilikely that a ferret would be found in an isolated colony of less than 80 acres. A neighboring prairie dog town is defined as a colony less ihan 7 kilometers from the town to be ireated. based on the longest distance that the ferret has been observed to travel during the night (Biggins et al. 1985, Richardson et al. 1987).

2. A white-tailed prairie dog colony or complex of less than 200 acres having no neighboring white-tailed prairie dog towns may be treated without a survey. It is estimated to require between 195 and 475 acres of white. tailed prairie dogs to support a single ferret.

3. Urban situations (e.g., playgrounds, golf courses, etc.) may be treated without conducting ferret surveys. The approoriate Service office shouid be contacted in advance of any ireatment to determine whether an "urban situation" exists.

4. For black-tailed prairie dog colonies or complexes over 80 acres but less than 1,000 acres, and white-tailed prairie dog colonies or complexes over 200 acres but less than 1,000 acres, prairie dog control may be allowed after completing a black-footed ferret survey within 30 days of proposed treatments provided no ferrets or their sign are found. If all colonies in the complex are surveyed without sign of ferrets, no future survey for ferrets would be required. These surveys will be coordinated with the appropriate Service office.

5., For prairie dog complexes over 1,000 acres, no control shall be allowed until the complex has been evaluated by appropriate State and/or federal agencies (those agencies participating on state working groups for ferret recovery) for its potential as a recovery site and until the complex has been block cleared. One thousand acres would be a ainimum complex size for consideration as a black-footed ferret reintroduction site and would likely require intensive management of habitat for a ferret population (USFWS 1988). The Black-footed Ferret Recovery Plan calls for the establishment of at least 10 populations with no fewer than 30 breeding adults in each population by the year 2020 . 
o. $A D C$ personnel snall maintain recoras of the number of acres of prairie dog towns or compiexes controlled and the type of chemicals used for the controi. These recoras snall de provideo to the Service and EPA on an annuai basis.

7. Surveys should be supervised by biologists trained in ferret survey techniques and ferret biology at a Service-approved training workshop. Currently, only the University of Wyoming conducts such a course. Ferret surveys should be reviewed by the Service for compliance with survey standards and Section 7 of the Endangered Species Act. The Service will work with $A D C$ personnel to determine or evaluate the possibilities of developing a core in-house training program for $A D C$ personnel to ensure that proper and appropriate ferret surveys are carried out.

Because the Service finds jeopardy to the ferret, the Agency is reauired to notify the Service of its final decision whether the reasonable and prudent alternative will be implemented.

\title{
INCIDENTAL TAKE STATEMENT
}

Assuming the implementation of the reasonable and prudent alternatives described above, the Service does not anticipate that the proposed action will result in any incidental take of the black-footed ferret.

\section{GRIZZLY BEAR (Ursus arctos horribilis) - T}

\author{
BIOLOGICAL OPINION
}

\section{Status of the Species}

Grizzly bear populations in the conterminous United States are restricted to northcentral and northeastern Washington, northern and eastern Idaho, western Montana, and northwestern Wyoming. Only six areas are known to sustain either self-perpetuating or remnant populations, exciuding southern Colorado, where a grizzly bear was killed in the fall of 1979 in a remote section of the San Juan National Forest. These areas-include the Yellowstone Grizzly Bear Ecosystem (YGBE), the Northern Continental Divide Grizzly Bear Ecosystem (NCOGBE), the Cabinet-Yaak Grizzly Bear Ecosystem (CYGBE), the Selkirk Mountains Grizzly Bear Ecosystem (SMGBE), the SelwayBitterroot Grizzly Bear Ecosystem (SBGBE), and the North Cascades Grizzly Bear Ecosystea (NCGBE).

The primary components of the grizzly bear habitat include food, cover, and denning habitat. Grizzly bears are successfül omnivores, and in some areas may be entirely herbivorous. Grizzly bears must avail themselves of large quantities of food in order to survive denning and post-denning periods. They are opportunistic feeders and will prey or scavenge on almost any available food including ground squirrels, ungulates, carrion, and garbage. This search for food is a prime influence on movements. Upon emergence from 
the den, they seek the lower elevations. drainage bottoms, avalanche chutes. and ungulate winter ranges. where their food requirements can de met.

Limited reproductive capacity of grizzly bears orecludes any raoid increase in the population. Mating appears to occur from late May tnrough mid-July, with a peak in mid-June. The age of first reproduction and litter size varies and may be reiated to the nutritional state of the bear. Litter sizes range from 1 to 4 with the mean of aoout 2.

The current population of grizzly bears is estimated at between 800 and 1,000 bears (USFWS 1982a). The YGBE population is estimated between 200 and 350, while the NCGBE population is believed to be between 440 and 680 bears (USFWS 1982a). In the US, the CYGBE population is estimated at less than 15 individuals. The decline in the bear populations has been related to habitat loss and indirect human-caused mortality. Most of the actions adversely impacting the grizzly bear occur on Federal lands. Some nonFederal actions that would adversely impact the grizzly bear include habitat destruction and direct human-caused mortality (e.g., both legal and illegal shooting of bears) on privare iands.

\section{Effects of the Proposed Action}

Secondary poisoning of grizzly bears by aboveground use of strychnine baits is possible if enough rodent carcasses containing strychnine are consumed following rodent control. In an April 1, 1980, biological opinion, the Service concluded that below ground use of strychnine-treated grain for pocket gopher control was not likely to jeopardize the continued existence of the grizzly bear. Aboveground use of strychnine is presently prevented by a court injunction issued April 11, 1988. Further action is required by the EPA before the injunction can be lifted.

In Montana, Columbian ground squirrel control using strychnine baits may occur in or adjacent to grizzly recovery areas if the court injunction is lifted. Aboveground use of strychnine inside grizzly recovery areas in Wyoming and eastern Idaho (Yellowstone ecosystem) would be low since the recovery area is primarily on public lands where aboveground use of strychnine would be restricted to case-by-case evaluations by the forest Service or National Park Service and/or used below ground in conifer plantations for pocket gophers.

Existing label restrictions (prior to the injunction) prohibit the aboveground use of strychnine baits in the geographic range of the grizzly bear except under programs and procedures specifically approved by the EPA. Where feasible, the user is required to pick up and burn or bury all visible carcasses of ground squirrels in or near treated areas. The aboveground use of strychnine for porcupine control is specifically prohibited in areas known to be occupied by the grizzly bear and lastly, the user is advised by label to contact the Service or state fish and game office for specific information on the presence of endangered species. 
The M-44 is cadable of killing a grizzly bear if a grizzly bear pulls the M-44 and receives sodium cyanide orally. Grizzly bears might kill sheep or lambs wearing 1080 coillars or feed on carrion of dead collared sheep.

Although compound 1080 is nigniy toxic to some warm blooded animals, there is no information on the toxicity of compound 1080 to grizzly bears. There is a reported LDSO for other bears of 0.5 to $1.0 \mathrm{mg} / \mathrm{kg}$, suggesting that both a iarge collar $(60 \mathrm{ml})$ and a smail collar $(30 \mathrm{mi})$ could be toxic to even a large grizzly bear.

$A D C$ Program policy is not to use M-44s or toxic collars containing compound 1080 in areas occupied by grizzlies. In addition, the EPA label use restrictions on $M-445$ state that these devices shall not be used in areas where federally listed threatened and endangered species might be adversely affected. Label restrictions for the 1080 livestock protection collar also require the Service to be contacted prior to its possible use in certain areas of Idaho, Montana, Washington, and Wyoming. If it is determined by the Service or the user that the use of the collar may adversely affect a grizzly bear, the collar cannot be used in those specific areas.

The ADC Program includes the live capture of grizzly bears (in accordance with the Interagency Grizzly Bear Guidelines) and other species with leghold traps, cage traps, foot snares, and tranquilizing drugs/guns. In some cases, a problem bear that meets the criteria for removal outlined in the Interagency Grizzly Bear Guidelines may have to be killed. Grizzly bears a) so may be caught in traps set for other species (e.g., coyote and wolf). Capture of a grizzly in any of these devices could result in injury or death to the bear. A grizzly bear cub could be caught and held by a leghold trap or a snare set for coyotes. However, a review of 20 years of Montana data indicates no non-target grizzly bear has been taken by traps or snares. An adult or juvenile grizzly bear could be killed in a neck snare set to capture a coyote, black bear, or mountain lion. Grizzly bears also have been accidentally killed from overdoses of drugs while attempting relocation. Based on past records, loss of a non-target grizzly bear appears to be rare. In our review of $A D C$ records and other data compiled on grizzly bear mortality for all ecosystems, there has been no accidental mortality of non-target grizzly bears during the past five years as a result of the ADC Program.

\section{BIOLOGICAL OPINIOH}

It is my biological opinion that the ADC Program is not likely to jeopardize the continued existence of the grizzly bear, except for the Cabinet-Yak Grizzly Bear Ecosystem, where take of one bear would represent joepardy to that recovery unit.

\section{REASORABLE AND PRUDENT ALTERMATIVES - CYGBE Recovery Unit}

The Section 7 regulations have defined reasonable and prudent alternatives as alternative actions, identified during formal consultation, that can be implemented in a manner consistent with intended purpose of the action, that can be implemented consistent with the scope of the Federal agency's legal 
authority and jurisdiction, :hat are economically and tecnnologicaily feasible, and that the Service delieves would avoid the likelihood of jeopardizing the continued existence of listed species or result in the destruction or adverse modification of critical haditat.

The reasonable and prudent alternative necessary to preclude jeopardy to this recovery unit is:

1. All cage (culvert) traps ano foot snares set for black bears in areas occupied by grizzly bears snail be checked at least once a day;

2. Neck snares (for coyotes) without break-away locks shall not be used in areas occupied by grizzly bears; and

3. Neck snares shall not be used for black bears or mountain lions in areas occupied by grizzly bears.

\section{INCIDENTAL TAKE STATEMENT}

There is the possibility of incidental take of grizzly bears as a result of leghold traps, snares (legs and neck), and use of tranquilizing guns. Records show eight grizzly bears have been accidentally killed in the last five-year period by various agencies while capturing and handing grizzlies. Due to the potential to accidently kill a grizzly bear during legitimate control operations, the anticipated level of incidental take as a result of the ADC Program is one grizzly bear in Wyoming and the Northern Continental Divide area (ecosystem) of Montana. Any incidental take should be reported within 5 working days to the Helena Field Office, U.S. Fish and Hildlife Service, P.O. Box 10023, Federal Building \& U.S. Courthouse, 301 S. Park, Room 494, Helena, Montana 59626-0023.

The Service has determined that this level of impact is not likely to result in jeopardy to the species, except that no take can be authorized for the CYGBE recovery unit, as take of one bear would represent jeopardy to that recovery unit.

\section{REASOMABLE AND PRUDENT MEASURES}

The Service believes the following reasonable and prudent measures are necessary and appropriate to minimize incidental take of the grizzly bear:

1. ADC personnel shall take all precautions possible to reduce any possible incidental take, including training on the use of drugs for animal immobilization and restraint.

2. $A D C$ personnel shall monitor incidental take to ensure compliance with anticipated take levels. 
Terms and Conations

In order to de exemot from the pronibitions of section $g$ of the ict. the uSDA nust comoly with the jollowing cerms and conditions. wnicn imoiement the reasonale and prudent measures descrided adove.

1. All cage (cuivert). traps and foot snares set for black bears in areas occupied by grizzly bears shali be cnecked at least once a day.

2. Neck snares (for coyotes) without break-away locks shall not be used in areas occupied by grizziy bears.

3. Neck snares shall not be used for black bears or mountain lions in areas occupied by grizziy bears.

4. The Service Fish and Wildife Enhancement Office, in the Regions of the species occurrence, should be notified within 5 days of the finding of any dead or injured grizzly bears in or adjacent to an ADC Program work area. Cause of death, injury, or iliness, if known. also shouid be conveyed to those offices.

\section{GRAY HOLF (Canis lupus) - E}

\section{BIOLOGICAL OPINION}

\section{Status of the Species}

The gray wolf inhabits the northeastern third of Minnesota, portions of the northern third of Wisconsin, and portions of the Upper Peninsula and Isle Royale of Michigan (USFWS 1992). The gray wolf also occurs, as a result of ongoing natural recolonization, in Idaho, north-central Washington, and northwestern Montana. Successful reproduction of wolves has been recorded in southeast British Columbia, Canada, along the North Fork of the Flathead River, Glacier National Park, and other areas in northwest Montana, and the north Cascades of Washington.

The key components of wolf habitat include: (1) a sufficient, year-around prey base of ungulates and alternate prey, (2) suitable and somewhat secluded denning and rendezvous sites, and (3) sufficient space with minimal exposure to humans. The primary prey for wolves in Minnesota, Wisconsin, and Michigan include deer, moose, and beaver. Wolves in the Rocky Mountains feed on elk, bison, ground squirrels, snowshöe hare, and grouse. On a biomass basis, ungulates comprise the bulk (more than 90 percent) of the wolves' diet during summer and fall in the Rocky Mountains.

In the Northern Rockies, wolf pups are born any time from late March to late April or possibly early may. Most wolves appear particularly sensitive to human activity near den sites and may abandon them if disturbed. Critical 
Habitat for the northeastern Dopulation comprises 9.845 square miles in Beltrami, Itasca. Koocniching, Lake. Lake of the woods. Roseau. and St. Louis Counties. Minnesota. and isle Royai ilationai Park in Michigan.

As of March 1991. The wolf pooulation in and adjacent to Montana is estimated to be about 50 woives in 5 packs. No more than 15 wolves were believed to be present in central idaho as of August 1987. There are no recent population figures for the gray woif (eastern timber wolf) but it is estimated that there are approximately 1.200 to 1.300 of these wolves occurring in Minnesora, Wisconsin, and Michigan. The population decline of the easter timoer wolf was a result of (1) intensive human settlement, (2) direct conflict with domestic livestock, (3) a lack of understanding of the animal's ecology and habits, (4) fears and superstitions concerning wolves, and (5) the extreme control programs designed to eradicate the wolf (Young and Goldman 1944). These same factors apply to the decline in all wolf populations in the United States. Reasons for the decline of the Northern Rocky Mountain wolf also are given as land development. loss of habitat, poisoning, trapping, and hunting. Non-Federal actions adversely impacting the wolf primarily include hunting and traoping of woives on non-Federal lanos.

\section{Effects of the Proposed Action}

According to the DEIS on the ADC Program, the use of M-44s to control coyotes, the aboveground use of strychnine to control rodents and rabbits, and the 1080 toxic collar to control coyotes could adversely affect the gray wolf. In addition, leghold traps for beaver, raccoon, and problem wolves and coyotes, and neck snares to control problem wolves and coyotes also may affect the gray wolf. An accidental shooting of a wolf while hunting coyotes is an extremely remote possibility because wolves are distinguishable from the air, and because ADC uses trained and experienced gunners in areas where wolves are known or suspected, but such incidents have occurred. Wolf relocation will occasionally cause the accidental death of or injury to wolves (e.g., accidental overdose of drugs while tranquilizing wolves, or injury from traps).

The Service believes that the Interim Wolf Control Plan (Plan) approved in August 1988, will promote the conservation of the species. The Plan, amended in December 1989, now includes Idaho, Montana, Hyoming and northeast Washington. Control plans are nearing completion for Morth and South Dakota and Hashington. A Federal or State agency or Indian Tribe that has a pereit frow the Service under Section 10 of the Endangered Species Act may conduct wolf control actions in accordance with the Plan. These control actions include: (1) capturing problem wolves ca public or private 1 ands and relocating them to remote areas of public lands: (2) placing problem wolves in captivity; or (3) killing problem wolves. Verbal approval followed by written authorization from the Service is required prior to killing a wolf.

The Northern Rocky Mountain Holf Recovery Plan clearly states that efficient and professional control of problem wolves will promote conservation of the 
species (USFWS 1987). The Service deveioped the Interim Wolf Control Plan and authorized (permitted) $A O C$ personnel to conduct wolf control in accoraance with this pian. specifically to help ensure the survival and recovery of the species. While the issue of the ADC Program participation in woif control in the Northern Rocky Mountains was temporarily resolved in FY 1991 by a Congressional appropriation to the Service to contract ADC personnel to control problem wolves, the underlining issue of funding remains unresolved.

Poisoning from aboveground use of strychnine may exist if the court injunction is lifted and if dead or dying species affected by the control programs are consumed. The aboveground use of strychnine on private lands in Idaho or Washington should have little effect on wolf numbers, since there is very little private range or cropland in gray wolf areas of these two States. Primary use of strychnine aboveground in Montana will be for Columbian ground squirrel control. The gray wolf is likely to consume any strychnine-poisoned animals encountered. Outdoor, aboveground strychnine use in wolf range in Minnesota would be extremely. unlikely even if the court injunction is ifted. In Minnesoca, where conflicts between wolves and livestock growers are most frequent, there are no known cases of wolf mortality resulting from the legal uses of strychnine in the last decade. Furthermore, there are only two suspected cases of wolf mortality from illegal strychnine use; both of these cases involved sheep carcasses laced with strychnine near farms where wolf depredation was alleged to be a problem.

Use of M-44s and 1080 toxic livestock collars is prohibited in occupied gray wolf range. Direct mortality to the gray wolf could occur as a result of using neck snares or shooting. Toxicants and neck snares are nonselective and could kill animals not intended to be killed (e.g., a nonproblem wolf). The ADC Program does not use snares or leghold traps to control coyotes in Minnesota (Wetzel, pers. comm. 1990). The live-capture of problem wolves by leghold traps and other methods may cause stress to the animals. Leghold traps in sizes No. $3 N$ or smaller are not likely to adversely affect adult wolves, but may pose a threat to juvenile wolves. Aerial hunting for coyotes by a trained and experienced aerial gunner has recently resulted in death of a wolf in North Dakota. This incident occurred in an area not occupied by wolves for many years.

"Occupied gray wolf range" will be defined as (1) an area in which gray wolf presence has been confirmed by State or Federal biologists through interagency wolf monitoring programs, and the Fish and Wildiffe Service has concurred with the conclusion of wolf presence, or (2) an area from which multiple reports judged likely to be valid by the Fish and Wildife Service have been received, but adequate interagency surveys have not yet been conducted to confirm presence or absence of wolves.

The Forest Service and Bureau of Land Management must evaluate each application for strychnine use. An environmental assessment is normally prepared with opportunity for public review. The Service reviews the 
assessment and. if necessary, conducts sedarace formal consultation. Thus. the Service has additionai ooportunities to restrict the aboveground use of strychnine ano other coxic cnemicals within ine nabitats of the gray woif on Federal lanas.

In accordance with the existing iabel, strycnnine baits should not be used in the geograptic range of the gray wolf exced uncer programs and procedures approved by the EPA. Before baiting, the user is advised to contact the Fish and Wildiife Service or tre local Stace fish and wildife office for specific information on endangered species. EPA label and use restrictions do not allow the $M-44$ device to be used in areas where federally listed endangered and threatened animal species may be adversely affected. Therefore, the use of M-44s is prohibited in areas known to be occupied by gray wolves. The use of M-44s in any other areas identified by the Service as gray wolf range will not be allowed without prior consultation with and approvai by the Servica.

A biological opinion issued to EPA on June 14. 1985. concluded that use of the 1080 toxic livestock collar was not likely to jeopardize the subspecies Canis lupus ivcaon (eastern timoer wolf) but likely to jeopardize the subspecies Canis Iupus irremotus (northern Rocky Mountain wolf). Reasonable and prudent alternatives also were given to the EPA, which in turn provided label restrictions to preclude jeopardy. Those label restrictions also require that the livestock coilar not be used in areas where gray wolves may occur.

\section{BIOLOGICAL OPINION}

Based on the above information, it is my biologieal opinion that the use of snares, steel traps and aerial shooting in the ADC Program is not likely to jeopardize the continued existence of the gray wolf nor adversely modify its critical habitat.

\section{INCIDENTAL TAKE STATEMENT}

Incidental take of gray wolves may result from use of leghold traps, snares (legs and neck) and tranquilizing guns, and from accidental shooting by aerial coyote hunters. Records show one wolf has been accidentally killed by $A D C$ personnel in the last five-year period. In view of the potential to accidentally kill of a gray wolf during legitimate control operations, the anticipated level of incidental take as a result of implementing the $A D C$ Program is one wolf in each of the State occupied by the eastern and Rocky Mountain subspecies per year.

The Service has determined that this level of impact is not likely to result in jeopardy to the species.

\section{REASONABLE AND PRUDENT MEASURES}

The Service believes the following reasonable and prudent measures are necessary and appropriate to minimize incidental take of the gray wolf: 
1. $A D C$ personnel shall take all possible precautions to reduce incidental take, including training on the use of drugs for animal immobilization and restraint.

2. AOC personnel shall monitor incidental :ake to ensure compliance with anticipated take levels.

3. Non-target wolves inadvertently captured alive must be immediately released.

\section{Terms and Conditions}

In order to be exempt from the protibitions of section 9 of the Act, the USDA must comply with the following terms and conditions, which implement the reasonable and prudent measures described above.

1. An incidental take in excess of one wolf in any state (in a given calendar year) will result in cessation of the activity causing take and reinitiation of consultation between the Fish and Wildiife State Office, the $A D C$ State office, and the involved land manager.

2. All leghoid traps shall be checked at least once a day in areas known to be occupied by gray wolves.

3. Neck snares shall not be used in areas known to be occupied by gray wolves except for areas where wolves may be a target species.

4. Number $3 N$ or smaller traps may pose a threat to juvenile woives and therefore should not be used in proximity to occupied dens and rendezvous sites. Upon documentation of wolf pups in the vicinity of control areas, the use of leghold traps shall be in coordination with the Fish and Wildife Service.

5. The Service's Fish and Wildlife Enhancement Office, in the Regions of the species' occurrence, shall be notified within 5 days of the finding of any dead or injured gray wolf. Cause of death, injury, or illness, if known, also shall be conveyed to those offices. Addresses are:

(Region 1 - Washington, Idaho)

U.S. Fish and Hildi ife Service

Lloyd 500 Building, Suite 1692

500 N.E. Multnomah Street

Portland, OR 97232

(503) $429-6150$

(Region 3 - Minnesota, Michigan, Wiscons in)

U.S. Fish and Wildlife Service

Federal Building, Fort Snelling

Twin Cities, MN 55111

(612) $231-3276$ 
(Region 6 - Montana, Wyoming)

U.S. Fish and Wildi ife Service

P.0. Box 25486

Denver Federal Center

Denver, CO 80225

(303) $236-8166$

6. ADC personnel snall participate rully in interagency wolf monitoring programs.

7. ADC personnel also shall informally consult on an annual basis with the State offices of the Fish and Wildife Service on the current status of the wolf in areas where recolonization is occurring.

\section{SAN JOAQUIN KIT FOX (Vulpes macrotis autica) - E}

\section{BIOLOGICAL OPINION}

Status of the Soecies (1argely from USFWS 1991g)

The San Joaquin kit fox is a small canid that weighs approximately 5 pounds (Hall and Kelson 1959). This subspecies was historically distributed within an 8,700 square mile area in central California, extending in the north from the vicinity of Tracy in the upper San Joaquin Valley, south to the general vicinity of Bakersfield. Intensive agriculture, urbanization, and other land-modifying actions have eliminated extensive portions of this habitat. Kit foxes currently are limited to the remaining grassland, saltbush, open woodland, alkaline sink valley floor habitats, and similar habitats located along eastern and western bordering foothills and adjacent valleys and plains (0'Farrell 1983). Foraging for a variety of rodents and lagomorphs typically occurs at night, although animals have been observed stalking California ground squirrels (Spermophilus beecheyi) during daylight hours, and pups may be observed during the day at den sites. Dens are usually constructed on gentle slopes or level areas. As few as one or as many as 32 or more entrances may be excavated at each site. Kit foxes will also opportunistically utilize man-made structures such as culverts or pipes, or may enlarge abandoned ground squirrel burrows as denning sites (0'Farrell 1983).

Remaining kit fox populations are represented by family groups that have been isolated from other groups by fragmentation of their habitat. This makes this subspecies subject to local extirpation and genetic loss from activities that would impact these family groups (Knudson, per. comm. 1992).

This species is imminently in danger of extinction because of continuing rapid loss of habitat. Aithough agricultural conditions and oil and gas development are by far the greatest source of loss, urban expansion, predation, and road kills also contribute substantially to the vulnerability of this species. Two other wild canids, the introduced red fox and coyote compete for food resources with the smaller kit fox. This 
competition for food resources increases during drought periods when the food resources these species reiy on decline to low population leveis.

The kit fox is also preyed uson by the coyotes and red fox. Expanding red fox populations througnout the San joaquin Valley present a serious threat to the kit fox. Coyoze control programs are being implemented in the San Joaquin kit fox' range and red fox control programs are being pursued in other areas where they are posing a threat to listed species.

Effects of the Proposed Action

Adverse impacts to the San Joaquin kit fox from ADC activities could occur. Leg-hold traps, snares and M-44 devices, shooting, and denning, which are commonly used to control coyotes can pose risks to kit fox because of the possibility of inadvertently capturing or killing individual kit foxes.

Rodent control agents such as anticoaguiants and fumigants. also pose risks to kit foxes because of the dangers of primary or secondary poisoning.

\section{BIOLOGICAL OPINION}

Because of the potential for rodent control activities to take the fox, it is my biological opinion that the ADC Program is likely to jeopardize the continued existence of the San Joaquin kit fox.

\section{REASOHABLE AND PRUDENT ALTERNATIVES}

The Section 7 regulations have defined reasonable and prudent alternatives as alternative actions, identified during formal consultation, that can be implemented in a manner consistent with intended purpose of the action, that can be implemented consistent with the scope of the Federal agency's legal authority and jurisdiction, that are economically and technologically feasible, and that the Service believes would avoid the likelihood of jeopardizing the continued existence of listed species or result in the destruction or adverse modification of critical habitat.

The reasonable and prudent alternative to preclude jeopardy during coyote and rodent controi is as follows:

1. Snares, M-44 devices, toxicants and fumigants shall not be used to control predator species within the recognized occupied range of the San Joaquin kit fox.

2. Leghold traps used within the kit fox range shall be equipped with built-in pan tensioning devices such that at least 4.5 pounds of pressure is required to spring the-trap. Tensioning devices shall be permanently attached, either by the manufacturer or by $\bar{A} D C$ personnel, in such a manner that they are unlikely to become inadvertently detached during use. Easily detachable tensioning devices shall not be permitted.

3. Shooting shall be conducted only by ADC personnel trained and experienced in canine identification to prevent inadvertent shooting of San Joaquin kit foxes. 
4. Use of chemical agents to control rocents within the range of ine San joaquin kit fox snall be suoject :o the following restrictions:

3. All methoos of rodent control üilizing Epa registereo comoounds must be appited with sirict odservance of EPA approveo ladei restrictions.

b. Zinc phosphide. a compound known to be minimally toxic to kit foxes, shall be the only chemical utilized for rodent control within the occupied range of the San Joaquin kit fox.

and

5. Any take of kit foxes is to be reported immediately to the Sacramento Field Office.

U.S. Fish and Wildlife Service

2800 Cottage Way, Room E-1803

Sacramento, CA 95825

(916) $978-4613$

Because the Service finds jeopardy to the ferret, the Agency is required to notify the Service of its final decision whether the reasonable and prudent alternative will be implemented.

\section{INCIDENTAL TAKE STATEMENT}

Assuming implementation of the reasonable and prudent alternative, the Service does not anticipates that any kit foxes will be taken as a result of this action.

\section{JAGUARURDI (Felis yagouaroundi cacomitili) - E OCELOT (Felis pardalis) - E}

Because the ADC Program's-operations in Texas may affect the jaguarundi and ocelot, the ADC office in San Antonio. Texas, initiated formal Section 7 consultation with the Service's Corpus Christi Field Office on August 10 , 1989. That consultation involves the use of leghold traps, snares, and $M$ $44 \mathrm{~s}$ in south Texas (the only area in the United States within which ocelot and jaguarundi occur). These predator control tools appear to be the only $A D C$ measures used in this area that may adversely affect these two cats. The Corpus Christi field office is currently working on a biological opinion that will be issued sometime during 1992. In view of that pending opinion, we will not address those two species here. 
UTAH PRAIRIE DOG (CYnomys parvidens) - T

\author{
BICLOGICAL SPINICH
}

\title{
Status of the Species
}

The Utan prairie dog is a burrowing rooent in the squirrel family. This species is confined to disjunct areas in southwest Utah including Beaver. Garfield, Iron, Kane, Piute, Sevier, and Wayne Counties. There is a positive correlation between available moisture and prairie dog abundance and density. Prairie dogs appear to prefer swale type formations where moist herbage is availabie even during drought periods. A well-drained area is necessary for home burrows. Prairie dogs must be able to inhibit a burrow system approximately 3.3 feet underground without becoming wet. The vegetative height within the colony must be low enough to allow standing prairie dogs to scan their environment for predators.

Prairie dogs are predominantly herbivores. Grasses are preferred food items during all seasons. The flowers and seeds of forbs al so are preferred. Although forbs other than alfalfa are not aiways highly preferred items, they may be critical to a prairie dog town's survival during drought. cicada (insects) are a preferred animal food item and are readily taken when available. In colonies at low elevations where moist herbage is available, breeding occurs in the early spring and lactation continues into June. Females are capable of giving birth annually to litters that average three to four young usually born in April USFWS 1991f).

The Utah prairie dog population was estimated to be about 95,000 in the 1920 s (Heggen and Hassenyager 1977), declining to a 1976 spring count of 2,160 adult animals (Turner 1979). Overall numbers have increased during the period $1976-1989$ with the 1989 spring count of 7,377 .

The decline of the Utah prairie dog was caused by human-related aiteration and by poisoning, which resulted from the belief that prairie dogs compete with domestic livestock for forage. At present, the Utah prairie dog is still threatened by the loss of habitat over much of its range. In addition, the damage caused by local concentrations of prairie dogs has provoked farmers in some areas to kill them illegally to protect crops and cropland.

\section{Effects of the Proposed Action}

A May 25, 1988, biologicai opinion issued to the EPA concluded that no jeopardy to the Utah prairie dog would occur as a result of the aboveground use of strychnine. Label restrictions require that strychnine not be used aboveground for jackrabbit, prairie dog, ground squirrel, kangaroo rat, and vole control in areas occupied by the Utah prairie dog in Garfield, Iron, Kane, Piute, Sevier, and Wayne Counties, Utah. These restrictions should extend also to Beaver County, Utah, which has suitable but currently unoccupied Utah prairie dog habitat. 
Zinc phosphide. aluminum pnosphide, ano Durrow fumigants al so couid adverseiy affect the Utah prairie oog. rowever. ADC personnei co not conduct nor recommend prairie dog controi within the range of the Utah srairie cog. The control method most iikeiy to iake Utah prairie oogs is the steel irap depioyed for coyote controi. Pan cension devices are used for legnold traps placed in Utah prairie oog habizat for coyote control.

\title{
BIOLOGICAL OPINION
}

Given the above restrictions, it is my biological opinion that use of zinc phosphide, aluminum phosphide burrow iumigants and steel traps will not jeopardize the continued existence of the Utah prairie dog.

\section{INCIOENTAL TAKE STATEMENT}

The Service does not anticipate the proposed action will result in any incidentai take of the Utah prairie dog.

\section{ALEUTIAN CANADA GOOSE (Branta canadensis leucopareia) - T}

\author{
BIOLOGICAL OPINION
}

\section{Status of the Species}

Historically, the Aleutian Canada goose, a small subspecies of the Canada goose, was known to breed on most of the larger islands in the Aleutian Islands and in the Commander and northern Kuril Island chains (USFWS 1991e). When the species was listed as endangered in March 1967, its only known nesting site was Buldir Island in the western Aleutian Islands, Alaska. Subsequently, remant flocks have been found on Chagulak 1 sland in the eastern Aleutians (Bailey and Trapp 1984), and Kaliktagik in the Semidi Islands (Hatch and Hatch 1983). The decline of this subspecies is largely attributed to predation resulting from the introduction of foxes and other small mammals to the Aleutian Islands during the period 1836 to 1930 (USFWS 1991e).

Historically, recreational and subsistence take of this subspecies in the Pacific Flyway was a significant factor preventing the rennant breeding segments from recovering. The actual wintering areas were not known until the recovery of the first banded birds was reported in late 1974 in California. The wintering habitat for this subspecies has been the focus of study from 1974 to the present (Byrd and Woolington 1983). Areas in California and Oregon, essential to winter survival, have been identified and partially protected by inclusion of the lands used in the National Hildlife Refuge System or California's Department of Fish and Game Wildife Area and State Park systems. Additionally, staging and wigration areas, and additional wintering areas in Alaska, Washington and Oregon have been closed to the hunting of this and/or other subspecies of Canada goose, offering further protection. 
On the principal wintering grounds in California, hunting closure zones have been in effect since 1975. in oroer to protect these geese. These closure zones have been largely responsible for allowing the wild population to increase from 790 birds in 1975 to as many as 7.800 birds in January of 1992. The Aleutian Canada goose was first listed as "endangered" in March 11. 1969. On December 12, 1990. the Aleutian Canada goose was reclassified as "threatened." This reclassification has not changed the level of protection afforded it under the Enoangered Species Act (USFWS 1991e).

Extensive recovery efforts have concentrated primarily on the western Aleutians flock (Buldir, Agattu, and Nizki) because the eastern Aleutian and Semidi island flocks were unknown when the first recovery plan was developed. A revised plan has been prepared. The recovery team currentiy considers the three island group flocks to be separate "breeding segments." Each breeding segment has its own recovery agenda and target population levels in the revised recovery plan. The recovery team considers the three breeding segments to constitute a single population of the Aleutian Canada goose subspecies (USFWS 199le).

With the continued growth of the Aleutian Canada goose numbers there is likely to be an expansion of its range, primarily in and about the current use areas in California, namely the northern coast, the Sacramento Valley, and the San Joaquin Valley and, secondarily, into parts of western Oregon and southwestern Washington. Aleutian Canada geese are regularly reported in the Willamette Valley of Oregon in September and early October. The greatly reduced goose hunting required for protection of the Dusky Canada goose and the abundance of winter pasture, makes this area a likely spot for range expansion by Aleutians (Bartonek 1990).

\section{Effects of the Proposed Action}

Avitrol, used in bird control, and zinc phosphide and aboveground strychnine grain baits used for rodent control, could adversely affect this species if ingested. However, recent mortalities diagnosed by the National Wildlife Health Research Center at Madison. Wisconsin were attributable to cholera, lead poisoning or shooting. No poisonings from the above chemicals have been reported.

\section{BIOLOGICAL OPINIOM}

It is my biological opinion, based on the continuing recovery of the species, that the ADC Program will not jeopardize the continued existence of the Aleutian Canada goose.

\section{IMCIDENTAL TAKE STATEMENT}

The Service anticipates that one Aleutian Canada goose could be taken as a result of the proposed action. This take will be in the form of kill. The continued expansion of the population will increase potential for exposure to these chemicals. 
The Service nas determined that this ievei of impact is not iikeiy to result in jeodardy to the species.

\section{REASONABLE AMD PRUDENT MEASURES}

The Service delieves that the following reasonable and prudent measures are necessary and appropriate to minumize incidental take of the Aleutian Canada goose:

1. Measures shail be taken to prevent use of avitrol, zinc phosphide and strychnine on the wintering grounds.

2. Measures will be taken to coordinate with the Fish and Wild ife Service prior to any use off these chemicals on the breeding grounds.

\section{Terms and Conditions}

In order to be exempt from the prohibitions of Section 9 of the Endangered Species ACt. ADC personnel must comply with the following terms and conditions which implement the reasonable and prudent measures described above:

1. The chemicals listed above shall not be used when Aleutian geese are present in known or likely habitats in Butte, Sutter, Colusa, Gienn, Stanislaus, Merced, Contra Coast, Humboldt and Del Morte Counties, California, as well as Tillamook, Coos, and Cupry counties, Oregon unless proposals for use are first reviewed and approved by the Fish and Wildiife Service, Office of Fish and Wildlife Enhancement, Sacramento, California; Incidental take on the wintering grounds shall be reported to that office within 5 days.

2. Proposals to use any of these chemicals on the species' breeding grounds shall first be reviewed and approved by the Fish and Wildlife Service Regional Office. Anchorage, Alaska, and any incidental take should be reported to that office within 5 days.

U.S. Fish and Wildife Service Anchorage Fish and Wild ife Enhancement

411 Hest 4th Avenue

Anchorage, AK 99501

(907) $271-4575$

The incidental take statement provided in this opinion satisfies the requirements of the Endangered Species Act, as amended. This statement does not constitute an authorization for take of listed migratory birds under the more restricted provisions of the Migratory Bird Treaty Act. The Service is developing a program to address incidental take under the Migratory Bird Treaty Act. 


\section{BALD EAGLE (Haliaeetus leucoceohalus) - E BALO EAGLE - T (5 STATES)

\author{
SIOLOGICAL OPINION
}

\section{Status of the Species}

The bald eagle is a wide ranging species. found in all of the 48 contiguous states at some point in its life cycle. Currently, bald eagles are federally listed as endangered in 43 states and threatened in 5 states (Washington, Oregon, Minnesota, Wisconsin and Michigan). Breeding concentrations occur in the Pacific Northwest, Great Lakes States, Maine, the Chesapeake Bay, and Florida. A unique, desert-nesting population is found in Arizona (USFWS 1982C).

The locations of wintering concentrations of bald eagles are predictable but more loosely defined. and usually occur in response to prey availability (ice-free areas affording fishing opportunities, waterfowl concentrations, etc.) and favorable habitat conditions (roost sites, etc.).

The Service has identified five bald eagle populations for recovery purposes: the Pacific states, Northern states, Southwest, Southeast, and Chesapeake Bay. Since the cancellation of DOT by the EPA in 1972, bald eagle breeding populations in all of these areas have been increasing. On February 7. 1990, the Service published a Notice of Intent (55 FR 4209) to reclassify the bald eagle from endangered to threatened throughout all or portions of its range, but to date no formal reclassification proposal has been published. The nesting population in the contiguous states for 1990 was 3,014 pairs estimated at 3,014 pairs (Kjos 1992).

\section{Effects of the Proposed Action}

Bald eagles may be taken as a result of both chemical and nonchemical methods of control.

\section{Chemical Contro! Methods}

\section{Strychnine}

Baid eagles are both predators and scavengers, with fish being a primary food item. They also feed on carcasses of nearly any vertebrate, making the species vulnerabie to poisoning following consumption of animals killed by cherical control methods.

According to the ADC Biological Evaluation, "the aboveground use of strychnine to control rodents, rabbits and "nuisance birds" may affect bald eagles. Aboveground use of strychnine may result in poisoning bald eagles if dead or dying animals are consumed. Strychnine is very toxic to most mammals and birds, (except gallinaceous birds which are relatively resistant). The main hazard to bald eagles comes from consuming cheek pouches or intestinal parts of animals containing high amounts of 
strychnine. The possibility of bald eagles picking up a poisoned animal exists because many poisoned rodents and ail birds die aboveground.

In its May 25, 1988, Jiological opinion to the EPA on the adoveground uses of strycnnine, the Service cited reports indicating that 28 bald eagles were known to have been poisoned or killed by aboveground use of strychnine between 1964 and 1986. While many of these strycnnine poisonings may have been due to improper or inappropriate application methods, at least six deaths were the result of approved use of strychnine for ground squirrel control.

ADC non-target kill records indicate that no bald eagles have been taken by any program use of strychnine during the past five years.

Strychnine labels advise users to contact the Regional Office of the U.S. Fish and Wildife Service or the siate Fish and Wildlife Office for specific information on endangered species. In addition, current labels for strychnine grain baits contain restrictions which, if followed, should help protect eagles from secondary uptake of strychnine. Users are required to pick up carcasses of rodents, etc., that are found aboveground and dispose of them properly. However, bald eagles may be attracted to dying as well as dead rodents and birds, and the requirement that carcasses be removed may not totally eliminate the hazard at a control site.

ADC personnel currently restrict use of strychnine to field rodent and nuisance bird control efforts.

\section{BIOLOGICAL OPIMION}

\section{Bald Eagie Recovery Units (except Southwest)}

Assuming that $A D C$ personnel follow current label restrictions, it is my biological opinion that aboveground use of strychnine is not likely to jeopardize the continued existence of this species, except the southwest recovery unit as outlined below.

\section{Baid eagle (Southwest Recovery Unit)}

As stated earlier, necropsies on baid eagle carcasses between 1964 and 1986 revealed that 28 mortalities were attributable to strychnine poisoning. Some of the eagle carcasses were recovered near rodent control areas. Three of the 28 eagle carcasses were collected in Arizona.

The threat of strychnine poisoning exists in the Southwest, especially if the toxicant is applied near bald eagle nesting and roost sites. The small number of breeding territories in the region renders this population particularly vulnerable to the adverse effects of aboveground use of strychnine. Currentiy there are 24 occupied territories in Arizona and two in New Mexico (USFUS, Region 2, file data. 1992). Any losses of breeding bald eagles from this region constitute a significant threat to the continued existence of the species. 
Therefore, it is my biological opinion that the aboveground use of strychnine in Arizona and New Mexico from mid-November througn mid-July (approximate nesting perioa), is i ikely to jeopardize the continued existence of the Southwestern population of bald eagles.

REASONABLE AND PRUDENT ALTERMATIVES - Southwest baid eagle recovery unit

The Section 7 regulations nave defined reasonable and prudent alternatives as alternative actions, idencified during formal consultation, that can be implemented in a manner consistent with intended purpose of the action, that can be implemented consistent with the scope of the Federal agency's legal authority and jurisdiction, that are economically and technologically feasible, and that the Service believes would avoid the likelihood of jeopardizing the continued existence of listed species or result in the destruction or adverse mooification of critical habitat.

1. In concert with the EPA, AOC personnel must develop new label and use restrictions that would prohibit the aboveground use of strychnine within a 10-mile radius of known bald eagle nest sites in Arizona and New Mexico during the aforementioneo nesting period and at known roost sites year. around or:

2. ADC personnel must contact the Service's Albuquerque and New Mexico Field offices for specific bald eagle habitat locations and nesting periods. If the proposed application is within eagle habitat when the birds may be nesting or roosting, the use of strychnine shall be prohibited. If it is determined that the use is outside of the delineated habitat, the chemical could be applied.

Because this biological opinion has found jeopardy, the USDA is required to notify the Service of its final decision on the implementation of either reasonable and prudent alternative.

\section{Nonchemical Control Methods - All populations}

\section{Leghold Traps}

Leghold traps are frequentiy used to capture mammals such as coyote, bobcat, fox, mink, beaver, raccoon, skunk, muskrat, nutria, wolves, and mountain lion. In some situations a carcass or a large piece of meat (i.e., a draw station) is used to attract target animals into an area where traps are set. It is ADC Program policy to set leghold traps no closer than 30 feet from a draw station to prevent the capture of non-target aniwals.

Exceptions to this policy are made for trapping mountain lions where traps are set at lion food cache sites that are usually in timbered areas. The trap can be set under a wide variety of conditions, and pan tension devices are used to prevent smaller animals from springing the trap, thus allowing a degree of selectivity not available with many other methods.

The leghold trap often permits the release of non-target animals. However, some bald eagles incidentally captured in leghold traps may die or require 
removal from the wild. Personnel at the University of Minnesota's Raptor Center indicate that legnold trap injuries comprise approximately 19 percent of the bald eagle injuries ireated at the Center each year. Gang or multiple set leghold traps pose aditionai proolems for baid eagles. Eagles captured in one trap will struggle or flail ineir wings, often resulting in a wing being caught in a second trap. Thus the trapped bird may sustain both leg and wing injuries. In addition. target species captured in multiple trap sets may attract opportunistic bald eagles intent on feeding on the captured animal. During feeding activity, the eagle may be trapped in a second trap.

\section{BIOLOGICAL OPINIOH - AII pOPUIations}

Despite the foregoing, there is no evidence to indicate that ADC trapping activities are having significant adverse effects on bald eagles. Bald eagle populations are increasing throughout the United States. ADC personnel have reported one loss of eagles from leghold traps used as part of their Program in the last five years. Therefore, it is my biological opinion that the ADC trapping program will not jeopardize the continued existence of the bald eagle.

\section{Snares}

Snares are among the oldest existing control tools. Snares can be used to catch a variety of target species, but are most frequently used within the $A D C$ Program to capture coyotes, beaver, bear, and mountain lion. Snares can be used effectively wherever an animal moves through a restricted lane of travel. As snares are typically deployed in this manner, there is normally minimal risk to bald eagles. The Service has been informed of the killing of two bald eagles by snares in the State of Maine in February, 1989. The birds were taken by Haine Department of Inland Fisheries and Wildi ife personnel engaged in coyote trapping activities. The use of bait was the principal factor for attracting these eagles, and the snares were set so close to clearings that bait was visible to these birds from the ground. These incidents demonstrate that snares may pose a risk to bald eagles under certain circumstances. However, they are the only occurrences known. ADC Progra policy is not to set snares within 30 feet of exposed bait.

\section{BIOLOGICAL OPINIOA - all populations}

It is my biological opinion that the use of snares will not jeopardize the continued existence of the bald eagle in the United States.

\section{INCIDENTAL TAKE STATEMENT}

(all populations)

Assuming implementation of the reasonable and prudent alternatives described above, the Service does not anticipate that the proposed action will result in an incidental take of bald eagles in the Southwest population. The 
Service anticipates that no more tnan two oaid eagies per year could be taken in the remaining four copulations as a result of strycnnine use. This take is expected in the jorm or kill.

The Service has determined that this ievel of impact is not likely to result in jeoparay to the species.

\section{REASONABLE AND PRUDENT MEASURES}

The Service believes the following reasonable and prudent measures are necessary and appropriate to minimize incidental take of the bald eagle:

1. Strychnine shall not be used within five miles (except Southwest population which is 10 miles) of an active nest, active winter or summer roost, or hack site.

2. When bald eagles are in the immediate vicinity of a proposed control program. ADC personnel must conduct daily checks for carcasses or trapped individuals. Carcasses of target animals iaken with any chemical that may pose a secondary poisoning nazard must be immediately removed and disposed of in a manner that prevents scavenging by any non-target species.

\section{Terms and Conditions}

In order to be exempt from the prohibitions of section 9 of the Act, the USDA must comply with the following terms and conditions which implement the reasonable and prudent measures described above.

1. ADC personnel shall contact either the local State fish and game agency or the appropriate regional or field office of the Service to determine nest and roost locations.

2. If a bald eagle is incidentally taken in the Southwest population, use of the control method will be halted immediately, and $A D C$ must reinitiate consultation.

3. The appropriate U.S. Fish and Wildlife Service office shall be notified within 5 days of the finding of any dead or injured bald eagle. Cause of death, injury, or iliness, if known, should be provided to those offices.

4. Leghoid traps (except those used to trap mountain lions) shall be placed a minimum of 30 feet from aboveground bait sets.

The incidental take statement provided in this opinion satisfies the requirements of the Endangered Species Act, as amended. This statement does not constitute an authorization for take of 1 isted migratory birds under the more restricted provisions of the Migratory Bird Treaty Act or the Bald and Golden Eagle Protection Act. The Service is developing a program to address incidental take under the Migratory Bird Treaty Act. 
PEREGRINE FALCOA (Falco peregrinus anatum) - E ARCTIC PEREGRINE (Falco peregrinus tundrius) - T

OIOLOGICAL OPINION

Status of the Species

The peregrine faicon is a medium-sized raotor. The anatum subspecies breeds in the boreal forest regions of Alaska and the Yukon Territory, and south of the tree line in northern and eastern Canada to northern Mexico. American peregrine falcons winter from southern United States to South America, with northern populations tending to winter farther south. The Arctic subspecies breeds in the tundra regions of Alaska, Canada, and Greenland, and winters in South America. Limited critical habitat has been designated in Lake, Napa and Sonoma Counties, California.

Extensive use of organochlorine pesticides is considered the primary reason for the decline of peregrine faicons (USFWS 1991d). Since restrictions were placed on the use of DOT in the early 1970s, populations stabilized. and in 1978 began to increase. Based on recent literature (1990), there are approximately 670 anatum pairs in the western United States (Burnham and Cade 1992). Peregrine falcons in the eastern United States were extirpated by the late 1970s, and a captive release program resulted in the establishment of over 100 breeding pairs by 1990 (USFWS 1991d). Population increases continue to the present in nearly all areas. American peregrine falcons, especially those at higher latitudes are highly migratory as is much of their prey. As a resuit, both peregrines and their prey spend a large portion of the year outside the boundaries of the United States.

\section{Effects of the Proposed Action}

As peregrine populations continue to increase throughout the United States, more breeding pairs and more wintering birds are occupying large cities. This increases the likelihood of their feeding on pigeons poisoned by aboveground use of strychnine during routine control operations. Such poisoning has occurred in the past in Baltimore. Maryland and Norfolk. Virginia, and at least four peregrines succumbed to strychnine during the early 1980s. These deaths were not related to the ADC Program, and the Service is not aware of any recent deaths. ADC personnel recognize the hazards of aboveground use of strychnine and restrict the aboveground use to strictly regulated field rodent and nuisance bird control. Most control activities would likely be in urban areas, feedlots, grain storage facilities, and around bridges.

\section{BIOLOGICAL OPIHION}

It is my biological opinion that the use of strychnine in the ADC Program will not jeopardize the continued existence of the peregrine falcon or adversely modify its critical habitat. 
The Service does not anticioate that the proposed action will result in incidental take of the peregrine faicon.

\title{
MORTHERN APLOMADO FALCON (Falco femoral is septentrional is) - E
}

\author{
BIOLOGICAL OPINION
}

\section{Status of the Species}

Habitat of this endangered species includes open terrain with scattered trees or shrubs. In the United States, this falcon may be found almost year-around (June through February) on the Laguna Atascosa National Wildiife Refuge, Cameron County, Texas. Between 1986 and 1989, 18 northern aplomado falcons (falcons) were successfully hacked on this Refuge. Texas has had some scattered sightings of wild falcons in the recent past (Frio County, 1980; Laguna Atascosa National Wildlife Refuge, 1983 and 1986; and Sabal Palm Grove, Cameron County, 1989). Individual falcons have also been sighted on the Gabrielson and Paimview Units of the Rio Grande Valley National Wildlife Refuge, Hidalgo County, and in the vicinity of Brownsville, Fafurrias and Valentine, Texas. The Laguna Atascosa National Wildife Refuge and some adjoining private land was the only area in the United States categorized as habitat occupied by northern aplomado falcons in 1990. In June 1991, this falcon was confirmed in Otero County, New Mexico. Modification of this falcon's grassland habitat as a result of agricultural development and pesticide use, and brush invasion are the causes of this bird's decline (USFWS 1990b).

The northern aplomado falcon feeds upon birds, insects, rodents, and reptiles. Most of its hunting occurs before noon or during late afternoon within approximately $1 / 2$ mile of its nest, though hunts may also occur up to $21 / 2$ miles from the nest (USFWS 1990b).

\section{Effects of the Prooosed Action}

A] though the ADC Program could affect the northern aplomado falcon prey base by reducing the number of available blackbirds and small rodents through the use of avicides and rodenticides, the possibility is considered remote because the species feeds on such a variety of prey. The rodenticides used do not pose secondary poisoning hazards.

\section{BIOLOGICAL OPINION}

It is my biological opinion that the $A D C$ Program is not likely to jeopardize the continued existence of the northern aplomado falcon. 


\section{INCIDENTAL TAKE STATEMENT}

The Service does not anticioate that the ADC ?rogram wil result in any
:ncidental take of the nortrern Đoiomado =icon.

\section{ATTHATER'S PRAIRIE CHICKEN (TYmpanuchus cupido attwateri) - E}

\section{BIOLOGICAL OPINION}

\section{Status of the Species}

This endangered Gulf coastal prairie subspecies once inhaoited an area from southwestern Louisiana to the Nueces River, Texas. It is now restricted to Texas and numbers approximately 456 birds. Its distribution is also significantly reduced, and individual isolated populations located in various counties have dropped to as few as two Attwater's prairie chickens in one of the seven counties inhabited by this bird. Current (USFHS, Region 2. file data 1992) distribution of the Attwater's prairie chicken is as follows:

\begin{tabular}{lc} 
County & Population \\
\cline { 2 - 2 } Austin & 48 \\
Colorado & 50 \\
Victoria & 2 \\
Galveston & 26 \\
Refugio & 330 \\
Goliad & 2 (incidental)
\end{tabular}

The Attwater's prairie chicken inhabits both cultivated and uncultivated lands, including areas grazed by livestock. It is largely an herbivorous bird, though it also eats some insects. Coastal prairie is essential for nesting cover, but the prairie chicken also utilizes cultivated areas of corn, cotton, milo, peanuts, rice, sorghum, and soybeans. The Attwater's prairie chicken is found in various types of vegetative cover depending on the season. Light to little cover may be used for courtship, while heavier cover is used for roosting. Medium to heavy cover is important for nesting, loafing, and escape. Feeding occurs in all types of cover (USFWS 1983).

\section{Effects of the Proposed Action}

Chemicals used by the ADC Program such as zinc phosphide coated grain to control rodents could kill prairie chickens, but this chemical's pesticide registration prohibits such use within Attwater's prairie chicken habitat. The use of leghold traps for predator control within the habitat of this bird is the only apparent part of the ADC Program that could adversely affect this species. Predators of the prairie chicken include armadillos, coyotes, house cats, dogs, various raptors, opossums, raccoons, and skunks. Trapping predators could have a beneficial effect upon prairie chicken nest depredation and individual birds. Conversely, leghold traps set for 
some of these animals could catch prairie chickens, resulting in their death or injury.

\section{BIOLOGICAL OPINION}

ADC leghold trapping potentially occurs within prairie chicken habitat. Though the probability of these traps catching a prairie chicken is low, loss of one or more of these birds could be devastating to distribution and genetic makeup of the population, therefore, it is my biological opinion that the use of leghold traps by the ADC Program is likely to jeopardize the continued existence of Attwater's prairie chicken.

\section{REASONABLE AND PRUDENT ALTERRATIVES}

The Section 7 regulations have defined reasonable and prudent alternatives as alternative actions, identified during formal consultation, that can be implemented in a manner consistent with intended purpose of the action, that can be implemented consistent with the scope of the Federal agency's legal authority and jurisdiction, that are economically and technologically feasible, and that the Service delieves would avoid the likel ihood of jeopardizing the continued existence of listed species or result in the destruction or adverse modification of critical habitat.

A reasonable and prudent alternative to preclude jeopardy is to use tensioning devices on the leghold traps in prairie chicken habitat to prevent prairie chickens from tripping the trap.

Because this biological opinion has found jeopardy, the USOA is required to notify the Service of its final decision on the implementation of the reasonable and prudent alternatives.

\section{INCIDENTAL TAKE STATEMENT}

The Service does not anticipate that the proposed action will result in the incidental take of the Attwater's prairie chicken if the reasonable and prudent alternative is implemented.

\section{HHOOPIMG CRANE (Grus americana) - E}

BIOLOGICAL OPINION

\section{Status of the Species}

The wild whooping crane populations consist of the major Aransas-Wood Buffalo whooping crane flock and a much smaller Rocky Mountain flock developed by cross-fostering into sandhill crane nests. The former migrates 2,500 miles in the spring (April), from the Texas Gulf Coast to Wood Buffalo National Park, Northwest Territories, Canada (Smith et al. 1986). Their fall migration through the Dakotas, eastern Montana, Nebraska, Kansas, western Oklahoma and central Texas, begins in September and is largely 
complete by November, with some straggiers arriving in December. The Rocky Mountain flock migrates in March and April from New Mexico and passes through Colorado and Wyoming and summers in Wyoming, :taho. ano Montana. The fall migracion of the Rocky Mountain podulation occurs from midSeptemoer through early Novemoer, reversing the spring route.

This crane's habitat includes a broad range of natural and man-influenced wetlands, croplands, and pasture. This omnivorous bird eats natural foods (insects, frogs, fish, plant tubers, acorns, berries, clams, crayfish, aquatic insects, etc.) and cultivated grains (barley, corn, milo, sorghum, wheat) left after harvest (Lewis 1980).

Cranes using the migration habitat are most likely to be exposed to chemicals used in the ADC Program. Data from the Hood Buffalo flock indicates individuals do not always use the same stopovers for roosting and feeding. Evidence indicates that repeated use of sites is primarily a random happening. Two major United States staging areas are the Platte River, Nebraska, and the San Luis Valley, Colorado. Critical habitat for the migration route and wintering areas has been designated in Colorado, Idaho, Kansas, Nebraska, Oklahoma, and Texas.

\section{Effects of the Proposed Action}

ADC personnel restrict their own use of and do not recomend use of Avitrol, DRC-1339, zinc phosphide rodent baits, or strychnine grain baits where whooping cranes are known or believed to be present. Therefore, the ADC Program's use of these chenicals limits the possibility of adverse effects upon the whooping crane.

\section{BIOLOGICAL OPINION}

It is my biological opinion that the toxicants used in the ADC Program are not likely to jeopardize the continued existence of the whooping crane or adversely modify its critical habitat.

\section{INCIDENTAL TAKE STATEMENT}

The Service does not anticipate that the ADC Program will result in any incidental take of the whooping cane.

\section{MISSISSIPPI SAMHILL CRAME (Grus canadensis pulla) - E}

\section{BIOLOGICAL OPINION}

\section{Status of the Species}

Most Mississippi sandhill cranes (Grus canadensis pulla) survive on the Mississippi Sandhill Crane National Hildlife Refuge in Jackson County, Mississippi. This bird's present range is from the Pascagoula River (east), to the Jackson County line (west), to the vicinity of Simmons Bayou (south), 
to 4 miles north of the town of Vancleave (north). The entire population has been estimated at less inan 100 biras every year since 1929 (USFWS $19916)$.

Savannas are the preferred habitat of the Mississippi sandhill crane and are inhabited year-around. Crane feeding habitats vary with the season. In the sumer the birds feed upon the natural foods found in swamps, savannas, and open forests including insects, earthworms, crayfish, smail reptiles, frogs and other amphibians that can be captured on the ground. During the other three seasons the birds eat small corn and chufa (introduced plants). Although some nesting occurs in forested areas, most takes place in open savannas and swamp openings. Nesting territories are generally used for more than 1 year, some for 10 to 17 years (USFWS 1991b). Critical habitat has been designated in Jackson County, Mississippi.

In the mid-1970s, a captive population of Mississippi sandhill cranes was established at the Patuxent Wildlife Research Center in Laurel, Maryland. Developed with wild Mississippi sandhill crane eggs, the captive population numbered 32 adults in 1989. Captive releases to the Mississippi Sandhill Crane Refuge began in 1981, and by 1983 there were 13 free-flying captive-raised cranes on the Refuge. A total of 96 captive-raised cranes had been released by 1989, and 53 of these have survived. By 1990, eight captive-raised cranes had attempted to nest (USFWS 1991b).

In response to predation by canids at the Mississippi Sandhill Crane National Wildlife Refuge, M-44 predator control devices were used on the Refuge by Service personnel. Subsequently, crane No. 646, a Patuxent captive-reared immature bird released onto the Refuge in late 1984, was killed when it set off a sodium cyanide loaded M-44 device in November 1985. Use of M-44's was immediately discontinued within the Refuge (Pers. Comm., Refuge Manager 1992).

Also two captive-reared cranes (Nos. 857 and 861 ) were accidentally caught in leghold traps in 1987 on the Refuge. Both birds were taken to the Louisiana State University Veterinary School where they later died. The cause of death of crane No. 857 was capture myopathy and aspergillus. The cause of death for crane No. 861 was not listed. Consequently, the use of leghold traps on the Refuge has been discontinued (Pers. Comm., Refuge Manager 1992).

\section{Effects of the Proposed Action}

Because Mississippi sandhill cranes frequently forage off the Refuge within Jackson County, Mississippi, there may be potential for the cranes to come in contact with predator control devices. An M-44 device placed in a foraging area could kill any crane coming in contact with it. Leg-hold traps would also pose a risk of injury or death in crane foraging habitat. 


\section{BIOLOGICAL OPINION}

Oue to the Mississippi sandhill crane's limited population and precarious status, the ioss of any individual wouid pose a serious threat to the survival and recovery of the species. Therefore, it is my biological opinion that the use of M-44s and steel traps in the ADC Program is likely to jeopardize the continued existence of the Mississippi sandhill crane. Critical habitat will not be adversely modified.

\section{REASONABLE AWD PRLDENT ALTERMATIVES}

The Section 7 regulations have defined reasonable and prudent alternatives as alternative actions, identified during formal consultation, that can be implemented in a manner consistent with intended purpose of the action, that can be implemented consistent with the scope of the Federal agency's legal authority and jurisdiction, that are economically and technologically feasible, and that the Service believes would avoid the likelihood of jeopardizing the continued existence of listed species or result in the destruction or adverse modification of critical habitat.

As a reasonable and prudent alternative to preclude jeopardy to the Mississippi sandhill crane, the ADC Program shall not use $M-44$ devices or leghold traps in designated Critical Habitat and other known nesting, roosting and foraging habitat used by this species: The Fish and Wildife Service (Refuge Manager, Mississippi Sandhill Crane National Wildlife, 7200 Crane Lane, Gautier. MS 39553, telephone 601/497-6322) shall be contacted prior to any $A D C$ work involving the use of these predator control methods in Jackson County. Mississippi to determine if the Mississippi sandhill crane occurs in the work area.

Because this biological opinion has found jeopardy, the USDA is required to notffy the Service of its final decision on the implementation of the reasonable and prudent alternatives.

\section{INCIDENTAL TAKE STATEMENT}

Assuming the impleantation of the reasonable and prudent alternatives described above, the Service does not anticipate that the proposed action will result in any incidental take of the Mississippi sandhill crane.

\section{CALIFOPHIA CONDOR (GMnogyos californianus) - E}

BIOLOGICAL OPINION

\section{Status of the Soecies}

This large, formerly widespread vulture has an historic range that includes the California Coastal Ranges, Central Transverse Range, Southern Sierra Nevada Mountains, to Arizona, New Mexico and Texas. California condor habitat includes rocky cliffs and trees for roosting, open grasslands and 
oak woodlands for foraging (Koford 1953). keproduction occurs at a years of age. with a low reprocuctive rate. A nesting pair only raises one chick/year and 6 months is required for young to fledge (Snyder :983).

Only 52 birds remain including 50 in captivity at the San Diego and Los Angeles Zoos. During January 1992. iwo California condors were reintroduced into a portion of their former range in southern California. Decline of the species has occurred as a result of shooting, lead poisoning, secondary poisoning from coyote control. loss of foraging areas due to urbanization, and agriculturai development (Wilbur 1980). Critical habitat has been designated in Ventura. Los Angeles. Santa Barbara. San Luis Obispo, Kern and Tulare Counties, California.

\section{Effects of the Proposed Action}

In California, strychnine is registered for rodent control. Condors can be exposed to strychnine by consuming poisoned rodents. M-44 devices loaded with sodium cyanide are used to control coyotes. A condor could accidentally trigger an M-44 during foraging, and be poisoned by cyanide. An immature femaie California condor was apparentiy killed by an $M-44$ on November 23, 1983 in Kern Councy, California.

\section{BIOLOGICAL OPIMION}

It is my biological opinion that the ADC Program's use of sodium cyanide for coyote control and strychnine for rodent control is likely to jeopardize the continued existence of the California condor. Critical habitat will not be adversely modified.

\section{REASOMABLE AND PRUDENT ALTERYATIVES}

The Section 7 regulations have defined reasonable and prudent alternatives as alternative actions, identified during formal consultation, that can be implemented in a manner consistent with intended purpose of the action, that can be implemented consistent with the scope of the Federal agency's legal authority and jurisdiction, that are economically and technologically feasible, and that the Service believes would avoid the likelihood of jeopardizing the continued existence of listed species or result in the destruction or adverse modification of critical habitat.

The following reasonable and prudent alternative would preclude jeopardy to the California condor:

1. M-44s should be used in single sets (not closer than 1000 feet from one another). The sets shall be placed so that they do not protrude above the ground level, and shall be covered or capped so they are not visible, and

2. Serychnine use will not be permitted in condor foraging habitat. 
These reasonable and prudent alternatives apply to California condor foraging habitat witnin Ventura. Kern. Santa Baroara, and San Luis Obispo Counties.

Because this biological opinion has found jeopardy, the USDA is required to notify the Service of its final decision on the impiementation of the reasonable and prudent alternatives.

\section{INCIDENTAL TAKE STATEMENT}

The Service does not anticipate the action will result in incidental take if the reasonabie and prudent alternatives are implemented.

\section{DESERT TORTOISE (Gopherus agassizii) - T}

\section{IOLOGICAL OPINION}

\section{Status of the Soecies}

The desert tortoise is a large terrestrial turtle which has ranged historically over most of the southern California deserts, in Arizona and the southern part of Utah (USFHS 1980). By 1980, it was el iminated from the Coachella and Imperial Valleys of California (USFWS 1990a). In its desert habitat it feeds on cactus, annual forbs, grasses, and fiowers. Ten to 20 years is required to reach breeding age and rate of reproduction is low. Young are soft-shelled and heavily preyed upon, especially by ravens. The species forages from March to June, estivates during the sumer in burrows, may emerge in the fall, and hibernates from October to March (Karl 1984).

The total number of individuals is unknown, but estimates are that 100,000 tortoises survive in the Mojave and Sonoran deserts (Lowe et al. 1990). Reasons for the continuing decline include urbanization, off-road vehicle use, mining, energy development, upper respiratory di-sease (URDS) that has resulted in an estimated $50 \%$ of present mortality, losses to pets. vandalism, and the population explosion of ravens (Berry 1984).

The Beaver Das Slope population of this species, located in southwestern Hashington County, Utah, was listed as a threatened species with 309 square wiles of critical habitat on August 20, 1980. Subsequently, the entire Mojave population of the desert tortoise (including the Beaver Dam Slope population) was listed as threatened on Apr 7 22, 1990. The Mojave population includes all desert tortoises north and west of the Colorado River in California, southern Nevada, southwestern Utah, and Northwestern Arizona. The March 15, 1990 Biological Evaluation of the ADC Program only included the Beaver Dam Slope population, so the majority of the tortoise population and its habitat were not covered in the evaluation. 


\section{Effects of the Proposed Action}

As stated in the Biological Eraiuation. EPA label restrictions preclude the use of gas cartridges and aluminum pnosphide in designaced critical habitat of the desert tortoise. However. sritical habitat has been designated only for the Beaver Dam Slope population.

Gas cartridges made up of potassium and sodium nitrate and the use of aluminum phosphide in predator dens and rodent burrows in the remaining habitat of the Mojave population in Utah, California, Nevada, and Arizona would kill non-target animals including desert tortoises. Additionally, tortoises could be inadvertently crushed in burrows by ADC vehicles.

\section{BIOLOGICAL OPINION}

There is potential for exposure from the registered application of aluminum phosphide, and from the use of potassium and sodium nitrate because tortoise burrows may be accidentally treated. This impact would be extremely rare because tortoise burrows are much larger than those of the target species, therefore, it is my biological opinion that ADC Program use of aluminum phosphide, as well as the use of potassium and sodium nitrate, is not likely to jeopardize the continued existence of this species, or adversely modify its critical habitat.

\section{INCIDENTAL TAKE STATEMENT}

The Service anticipates that one desert tortoise could be taken as a result of the proposed action. The incidental take is expected to be in the form of kill because of the possibility of crushing a tortoise in burrows located under roads or trails while conducting a control program. These burrows may collapse under the weight of an all terrain vehicle (ATV) or standard-sized vehicle. The Service also anticipates that one tortoise could be taken by burrow fumigants.

The Service has determined that this level of impact is not likely to result in jeopardy to the species.

\section{REASOHABLE AMD PRUDENT MEASURES}

The Service believes that the following reasonable and prudent measures are necessary and appropriate to minimize take of the desert tortoise:

1. Measures shall be -implemented to prevent desert tortoises from being killed by any project-related activity.

2. Measures shall be implemented to minimize loss and degradation of desert tortoise habitat by ATVs. 
Terms and Conditions

In order to be exempt from the prohibitions of Section 9 of the Endangered Species Act. ADC personnel must comply with the following terms and conditions which implement the reasonable and prudent measures described above:

1. Discovery of one dead or sublethally taken tortoise caused by any of the chemicals, requires imediate cessation of its use within the species range and reinitiation of consultation on that chemical for the tortoise.

2. Aluminum and magnesium phosphide, and sodium and potassium nitrate shall be used within the desert tortoise range only by qualified individuals. Such persons shall be limited to qualified wildife biologists, or to agents of county agricultural commissioner offices, university extension offices, or representatives of state or Federal wildife agencies.

3. The size of all access and right-of-way roads associated with $A D C$ Program activities shall be minimized.

4. All vehicle traffic during control activities shall be restricted to roadways and areas that have been cleared of tortoises. The agency requesting control shall provide information to ADC personnel prior to undertaking the proposed action regarding areas where vehicular traffic is not allowed.

\section{GOPHER TORTOISE (Gopherus polyohems) - T}

\section{BIOLOGICAL OPINION}

\section{Status of the Species}

The gopher toptoise is a large 5.9 to 14.6 inches long, dark-brown to grayish-black terrestrial turtle with elephantine hind feet, shovel-like forefeet, and a gular projection beneath the head on the yellowish plastron or undershell.

This tortoise feeds primarily on grasses, grass-like plants, and legumes. Its diet may also include cushrooms, fleshy fruits, and possibly some animal matter. Sometime between late April and mid-July, the female digs a nest in sandy soil, lays a clutch of 4 to 12 eggs, and after refilling the hole leaves the eggs for incubation by the sun's heat. Hatching occurs in August and September. The juvenile tortoises suffer a heavy natural predation loss of almost 97 percent through the first 2 years of 1 ife. Those that survive grow to sexual maturity slowly over a period of 13 to 21 years, depending on the portion of the range and the sex of the turtles. Females usually reach reproductive maturity at 19 to 21 years old. The low reproductive rate is accentuated by the fact that there is some evidence to indicate that not all females nest every year. The juveniles that are 
born and survive may live an average of 40 to 60 years, somerimes 80 to :00 (USFWS 1990C).

The gopher tortoise most often lives on well-drained sanay soils in transitionai (forest ano grassy) areas. It is commonly associated with a pine overstory and an open understory with a grass and forb groundcover and sunny areas for nesting. Most of the gopher tortoise's iffe is spent in and around the burrow. The burrow becomes a more or less permanent home although there may be alternate burrows in the area. Several other species also may share gopher tortoise burrows. Some comonly known burrow associates include the eastern indigo snake, the eastern diamondback rattlesnake, and the gopher frog. This species occurs in sandy coastal plain areas from extreme southern South Carolina to the southeastern corner of Louisiana, and throughout most of Florida (USFWS 1990C).

Less than 20 percent of the historically available habitat remains for the western population of the gopher tortoise. The population segment from the Tombigbee and Mobile Rivers in Alabama. westward, is classified as threatened, and for convenience is termed the western population. The entire western population is within the original range of the longleaf pine. Using statistics of the U.S. Department of Agriculture, the Fish and Widlife Service estimates that present ownership distribution of gopher tortoise habitat is approximately 20 percent in the National Forest, 10 percent in other public ownership, 30 percent in forest industry and 40 percent in other private ownership. No estimate is available for the gopher tortoise's total population size. Biologists were able to document only 11 active burrows in Louisiana in 1981, with only one remaining in 1984 . There is an indicated decline in population densities ranging from 67 percent in Alabama to 91 percent in Louisiana (USFWS 1991a).

Conversion of gopher tortoise habitat to urban areas, croplands, and pasturelands along with adverse forest management practices has reduced the western portion of the historic range. Taking gopher tortoises for sale or use as food or pets also has had a serious effect on some populations. The seriousness of the loss of adult tortoises is magnified by the length of time required for tortoises to reach maturity and their low reproductive rate. Current estimates of human predation and road mortality alone are at levels that could offset any annual addition to the population. A number of other species also prey upon gopher tortoises including the raccoon, the primary egg and hatchling predator; gray foxes; striped skunks; armadillo; dogs; snakes; and raptors. Imported fire ants also have been known to prey on hatchilings. Reported clutch and hatchling losses often approach 90 percent (Landers et al. 1980).

\section{Effects of the Proposed Action}

Toxic baits used in the ADC Program for rodent or predator control could potentially be consumed by the tortoise, but this is considered extremely unlikely in view of their normal diet. In addition, the burrows of the gopher tortoise are commonly utilized by a wide variety of other wildiife, including such potential target species of the ADC Program as fox, skunk, 
armadillo, opossum, raccoon. and rabbit. Use of aluminum phosphide, gas cartridges, and other fumigants within gopher tortoise habitat could result in harm or killing of the species, nowever, woodchucks are the only species treated with fumigants within the species range.

\section{BIOLOGICAL OPINION}

It is the my biological opinion that the ADC Program is not likely to jeopardize the continued existence of the gopher tortoise because of restrictions on virtually all fumigants.

\section{INCIDENTAL TAKE STATEMENT}

The Service anticipates that one tortoise may be taken by use of fumigants. The Service has determined that this level of impact is not likely to result in jeopardy to the species.

\section{REASOMLABLE AND PRUDEMT MEASURES}

The Service believes the following reasonable and prudent measure is necessary and appropriate to minimize incidental take:

1. Use of toxic baits (including zinc phosphide, diaphacinone strychnine, and any anticoagulants) and use of fumigants (including aluminum phosphide, gas cartridges, or other burrow fumigants) shall be prohibited within or in close proximity to potential gopher tortoise habitat in Louisiana, Mississippi, and Alabama, unless the following terms and conditions are met:

\section{Terms and Conditions}

In order to be exempt from the prohibitions of section 9 of the Act, the USDA must comply with the following terms and conditions, which implement the reasonable and prudent measures described above.

1. Habitat must be adequàtely surveyed by qualified personnel who have determined that the habitat does not contain active tortoise burrows. This restriction should also apply to potential gopher tortoise habitat that has recently been converted to other uses but has not been completely destroyed. The Service's Jackson Field office (see address below) can assist ADC personnel in identifying areas of potential tortoise habitat, providing names of qualified personnel for conducting surveys, providing survey techniques, etc.

2. If any incidental take does occur, consultation must be reinitiated with the Jackson Field Office and use of the of the responsible method must cease immediately. 
U.S. Fish and Wildlife Service

Enhancement - Suite $A$

6578 Dogwood View Parkway

Jackson. Mississippi 39213

$601 / 965-4900$

\section{BLUNT-NOSED LEOPARD LIZARD (Gambelia silus) - E}

BIOLOGICAL OPINION

\section{Status of the Species}

The blunt-nosed leopard lizard is a large, robust, lizard that may exceed 15 inches in length (Montanucci et al. 1975). This species was distributed historically throughout the San Joaquin Valley and adjacent interior foothills and plains, extending from central Stanislaus County south to extreme northeastern Santa Barbara County (Montanucci 1965). The lizard prefers open, sparsely vegetated areas of low relief and inhabits valley sink scrub and valley saltbush scrub vegetational commities. The area occupied by this species has been significantly reduced and fragmented by agricultural development, petroleum and mineral extraction, livestock grazing, pesticide application, and off-road vehicle use. Today its distribution is limited to scattered parcels of undeveloped land, with the greatest concentrations occurring on the west side of the Valley floor and in the foothills of the coast Range. The population is declining (USFWS 1985b).

Farming began in the San Joaquin Valley with the advent of the gold rush and the need to supply the new settlers with food. It accelerated in the 1920's when development of electricity made feasible the use of electrical pumps to tap groundwater supplies. In response to declining groundwater supplies, Federal and State water projects were developed to sustain agriculture. Petroleum and mineral development also occurred resulting in the continuing loss of blunt-nosed leopard lizard habitat. Cumulatively, agricuiture, oil and gas development, induced urban growth and_the attendant loss of more habitat have contributed to the species' decline. Today urban expansion continued because of the relatively inexpensive land prices in the San Joaquin Valley compared to coastal real estate costs. Improved transportation corridors have facilitate this development. Although these and other factors have el iminated over 90 percent of the native habitats throughout the San Joaquin Valley, irrigated agriculture has had the most profound effect on the blunt-nosed leopard lizard's decline.

The 1980 blunt-nosed leopard lizard Recovery Plan identified habitat essential for the survival and recovery of the species; essential habitat consists of highest quality wildlands currently remaining. The plan, revised in 1988, is being updated again to reflect continuing habitat loss. Between 1983 and 1985, the California Department of Fish and Game documented a reduction from 439,670 acres to 415,350 acres of unidentified essential 
habitat for the lizard. a ioss of 24.320. Unpublished information. subsequently ootained from ine Depariment of Energy indicates that as much as 80 percent of the identifieo essential haortat has been lost (USFis $1985 b)$.

Effects of the Proposed Action

Blunt-nosed leopard lizards typicaily utilize the San Joaquin kit fox dens and small mammal burrows for shelter. Therefore, some preator or rodent control methods used underground, especially fumigants, could inadvertently harm or kill leopard lizaros.

\section{BIOLOGICAL OPINION}

It is my biological opinion that use of fumigants in the ADC Program will not jeopardize the continued existence of the blunt-nosed leopard lizard because existing label restrictions preclude use of gas cartridges and that is the major toxicant used. Mortality from other toxicants is far less likely.

\section{INCIDENTAL TAKE STATEMENT}

The Service anticipates that one lizard may be taken by underground control methods. The Service has determined that this level of impact is not likely to result in jeopardy to the species.

\section{REASONABLE AND PRUDENT MEASURES}

The Service believes the following reasonable and prudent measures are necessary and appropriate to minimize incidental take of the blunt-nosed leopard lizard:

1. Continue to restrict use of fumigants within the range of the bluntnosed leopard lizard.

\section{Terms and Conditions}

In order to be exempt from the prohibitions of section 9 of the Act, the USDA must comply with the following terms and conditions, which implement the reasonable and prudent measure described above.

1. Existing label restrictions prohibiting use of gas cartridges manufactured and distributed by ADC personnel within the range of the San Joaquin kit fox and blunt-nosed leopard lizard shall be continued and adhered to. Fumigants used by $A D C$ personnel for predator control also shall not be used within the range of the blunt-nosed leopard lizard.

2. No rodent control method or agent not discussed or restricted above shall be used within areas likely to be inhabited by blunt-nosed leopard 
lizards uniess further consultation with the service is conoucteo and Service concurrence in any oroposed activities is ootained.

3. If one dead or sublethaily affecteo soec:men is discovered. use of that pesticide must cease ano consultaion on that chemical for that species must be reinitiated. Any incicental take snall be reported immediately to the Sacramento Field Office.

U.S. Fish and Wildi ife Service

2800 Cottage Way, Room E-1803

Sacramento, CA 95825

(916) $978-4613$

\section{EASTERN INDIGO SHAKE (Drymarchon corias couperi) - T}

BIOLOGICAL OPINION

\section{Status of the Species}

The eastern indigo snake is a large, docile, non-poisonous snake growing to a maximum length of about 8 feet. The color in both young and adults is shiny bluish-black, including the belly, with some red or cream coloring about. the chin and sides of the head. Indigo snakes probably reach sexual maturity at 3 to 4 years of age. Based on observations of captive indigos at Auburn University, mating begins in November, peaks in December, and continues in March. Clutches averaging eight to nine eggs laid in late spring hatch approximately 3 months later. The snakes remain active to some degree throughout the winter, often emerging from their own dens whenever air temperatures exceed 50 degrees Fahrenheit (Odum et al. 1977).

This species is currently known to occur throughout florida and in the coastal plain of Georgia. Historically the range also included southern Alabana, southern Mississippi. and the extreme southeastern portion of South Carolina. The indigo snakes seems to be strongly associated with high, dry, well-drained sandy soils, closely paralleling the sandhill habitat preferred by the gopher tortoise. During warmer months, indigos also frequent streams and swamps, and individuals are occasionally found in fiat woods. Gopher tortoise burrows and other subterranean cayities are commonly used as dens and for egg laying. The howe range of indigos varies considerably according to season. Based on a study conducted in southwest Georgia, an average seasonal range of 4.8 hectares during the winter (December through April), 42.9 hectares during late spring or early summer (May through July), and 97.4 hectares during late summer and fall (August through November) (Speake et al 1978). The most extensive monthly movements occurred during August. Of a total of 108 dens sites located. 77 percent were in gopher tortoise burrows, 18 percent were in or under decayed stumps and logs, and 5 percent were under plant debris. The study area included windrows of debris piled up in the $1960^{\circ}$ s during site preparation for a slash pine plantation. The snakes showed some tendency 
:o prowi ano iocate their cens near inese windrows. This same study also inoicaled inat during May-july inat at East 0 percent. and in August.

vovemoer at least 5 percent, ji ai indigo snake activity occurreowithin i50 feet of iortorses. The haigo sudoues is prey linciuding venomous snakes) througn the use of : ss soweriu! ;aws. swailowing the prey usually still aijue.

The eastern indigo snake poduiation is aeclining (USFWS i982b). The decline is attributed to a loss of naoltat cue to such uses as farming, construction, forestry, pasture. etc.. and to over-collecting for the pet trade. The snake's large size and docile nature have made it much sought after as a pet. The effect of Rattlesnake Roundups on the indigo snakes are speculative. Both indigos and rattlers utilize the burrows of gopher tortoises at certain times. Rattlesnake hunters often pour gasoline down these burrows to drive out the snakes. While some indigos may be killed by this practice, the actuai degree of impact on the population is unknown (USFWS 1978). Recovery tasks currently being implemented include habitat management through controlled burning, testing experimental miniature radio transmitters for tracking of juvenile indigo snakes. maintenance of a captive breeaing colony at Auourn University, a recapture of formerly released snakes to confirm survival in the wild, presentation of education lectures and field trips, and efforts to obtain landowner cooperation in indigo snake conservation efforts.

\section{Effects of the Proposed Action}

Chemical rodent and/or predator control efforts in habitat utilized by the eastern indigo snake may result in incidental take of the indigo snake. The species is not a carrion eater and therefore is not expected to be affected by use of baits for rodent control. However, use of burrow fumigants within areas occupied by the eastern indigo snake could likely result in direct mortality to individuals of the species. Gas cartridges are the only burrow fumigant currently used in the region.

\section{BIOLOGICAL OPINION}

It is my biological opinion that the use of fumigants in the ADC Program is not likely to jeopardize the continued existence of the eastern indigo snake because most den sites are in gopher tortoise burrows and these burrows are easily distinguished from those of other species.

\section{INCIOENTAL TAKE STATEMENT}

The Service anticipates one indigo snake may be taken by fumigants. The Service has deterwined that this level of impact is not likely to result in jeopardy to the species. 


\section{REASOHABLE AND PRUDENT MEASURES}

The Service believes that the following reasonable and prugent measure is necessary and appropriate to minimize incidentai :ake:

1. Use of fumigants within the range of the Eastern indigo snake must be strictiy controlied.

\section{Terms and Conditions}

In order to be exempt from the prohibitions of section 9 of the Act, the USDA must comply with the following terms and conditions, which implement the reasonable and prudent measures described above.

1. Use of aluminum phosphide, gas cartridges, or other burrow fumigants in or adjacent to areas containing active or inactive gopher tortoise burrows (potential habitat of the eastern indigo snake) is prohibited in the states of Florida and Georgia without prior approval from the Service's Jacksonville Fieid Office (see address Delow), and in the state of Alabama without prior approval from the Service's Jackson Field office (see address below).

2. If incidental take does occur, the USDA must cease using the responsibie method and reinitiate consultation with the appropriate fieid office (see address beiow).

U.S. Fish and Wild ife Service

3100 University Blvd., S., Suite 120

Jacksonville, Florida 32216

904/791-2580

U.S. Fish and Wildiffe Service

Enhancement - Suite $A$

6578 Dogwood View Parkway

Jackson, Mississippi 39213

$601 / 965-4900$

\section{SAN FRAKCISCO GARTER SNAKE (Thamophis sirtalis tetrataenia) - E}

\section{BIOLOGICAL OPINION}

\section{Status of the Species}

The San Francisco garter snake is a slender serpent of the family Colubridae (Fitch 1965). Historically, San Francisco garter snakes occurred in scattered freshwater wetland and pond areas on the San Francisco Peninsula from approximately the San Francisco County line south along the eastern and western bases of the Santa Cruz Mountains, at least to the Upper Crystal Springs Reservoir, and along the coast south to Año Nuevo Point, San Mateo County, and Haddell Creek, Santa Cruz County, California (Barry 1978). 
Recent studies have documented garter snake movement over several hundred yards away from wetlanos inco upiano nioernation naditats in smail mamal burrows.

Recently confirmed populations of the San Francisco garter snake occur at Año Nuevo State Reserve, Pescadero Marsh Matural Preserve, San Francisco State Fish and Game Refuge (including both lower and upper Crystal Springs Reservoirs), Sharp Park Golf Course (Laguna Salada). Mori Point, Cascade Ranch, and Millibrae (San Francisco Airport). The following reporied locations and/or "popuiations" have not deen confirmed as extant by the Service or the California Department of Fish and Game: San Bruno Mountain, Whitehouse Creek, Denniston Creek, La Honda Creek, Colma Creek. San Gregorio Creek, San Mateo Creek. Sanchez Creek, and near Edgewood and Canada Roads. Additional San francisco garter snakes have been reported from agricultural ponds situated along the immediate coast between Pescadero Point and the Cascade Ranch (USFWS 1985a).

Urban development and road construction, especially in wetlands and adjacent uplands, pose serious threats to the San Francisco garter snake.

Channelization of creeks and removal of streamside vegetation by grazing cattle deprive garter snakes of the frogs they prey upon. Five state parks are the only publicly managed areas that today harbor San Francisco garter snakes. None of the two dozen privately owned habitats where they occur is secure (USFWS 1985a).

The recovery plan sets a goal of six populations, each with two hundred adult snakes, surviving for five consecutive years before the species can be reclassified as threatened.

\section{Effects of the Proposed Action}

This garter snake uses rodent burrows on a seasonal basis. This subspecies could be harmed if aluminum phosphide, gas captridges, or other fumigants were used in rodent burrows containing one or more snakes. Its limited geographic distribution suggests the likelihood of exposure to these chemicals may be remote, although some populations occur in and around agricultural lands, notably vegetable truck farms and-livestock grazing lands.

\section{BIOLOGICAL OPIMIOH}

It is my biological opinion that the ADC Program will not jeopardize the continued existence of the San Francisco garter snake.

\section{INCIDENTAL TAKE STATEMENT}

The Service anticipates that one San Francisco garter snake may be taken by fumigants. The Service has determined that this level of impact is not likely to result in jeopardy to the species. 


\section{REASORABLE AND PRUDENT MEASURES}

The Service believes the following reasonable and frudent measure is necessary and appropriale to minimize incidental take of the San Francisco garter snake.

1. Fumigant use should be strictly controlled within the known range of the garter snake.

\section{Terms and Conditions}

In order to be exempt from the prohibitions of section 9 of the Act, the $A D C$ must comply with the following terms and conditions, which implement the reasonable and prudent measures described above.

1. Aluminum phosphide, gas cartridges, and other fumigants shall not be used in San Mateo County, Californa, uniess proposals for use are first reviewed and approved by the Fish and Wildifife Service, Office of Fish and Wildife Enhancement, Sacramento. California.

\section{U.S. Fish and Wildife Service}

2800 Cottage Way, Room E-1803

Sacramento, CA 95825

(916) $978-4613$

2. Discovery of one dead or sublethally taken garter snake caused by any of the chemicals requires immediate cessation of its use and reinitiation of consultation on that chemical for the garter snake.

\section{WYAIIMG TOAD (Bufo he}

\section{BIOLOGICAL OPINION}

\section{Status of the Species}

A glacial relic, the Hyoming toad was separated from its closest relative during the last Ice Age. Historically, the Wyoming toad was restricted to within 30 miles of the city of Laramie, but currently it is known only to inhabit floodplains, ponds, and seepage lakes in the shortgrass communities of the Laramie Basin of Wyoming. Larvae of the toads feed primarily on algae while the adults are primarily insectivorous and opportunistic in their selection of food. It is believed that toads hibernate in rodent burrows. The adult toads emerge from winter dormancy in late May or early June, after dafly air temperatures approäch 80 degrees fahrenheit. Breeding then begins in warm. shallow floodplain ponds where the eggs are laid. Tadpoles normally complete their transformation to adults by early August.

From the 1940's through the early $1970^{\prime} \mathrm{s}$, the Hyoming toad was abundant throughout its limited range. Rapid declines were observed in the mid$1970^{\prime} \mathrm{s}$; by the late $1970^{\prime} \mathrm{s}$, the Wyoming toad had become rare; and in the 
early $80^{\prime}$ s, only a few individuals were found (Baxter and Stromberg, 1980. stromberg, 1981. Vankirk. 1980. Baxter et ai. 1982. Baxter and Stone, 1985. Lewis et al. 1985). A single heaithy fopuiation was locared in :987, souchwest of Laramie. A total of 7 bads were first discovered and during a second survey in late summer, 57 toaos were located. Reasons for the decline of the wyoming coad are uncertain. Theories include predation, disease, changes in agricultural practices. pesticide usage including baytex (fenthion) for mosquito conerol, and climatic changes (USF́WS 1991c). Since 1988, surveys have revealed that this popuiation appears to de stade. There are no known non-Federal actions that are expected to impact species in the future.

\section{Effects of the Proposed Action}

$A D C$ personnel provided no information to the Service on effects to amphibians by the pesticides used by the ADC Program. The Service presently lacks adequate information on the feeding habitats of the Wyoming toad to determine if the aboveground use of these pesticides in the Laramie Basin will affect the survival and recovery of this species. The possibility of toads ingesting or absorbing pesticide baits or residues and being affected or killed is unknown. Toads may nibernate in rodent burrows and could contact strychnine or zinc phosphide-contaminated dead rodents in these burrows. Applicators may inadvertently or intentionaliy apply-baits into rodent burrows, increasing the likelihood of strychnine or zinc phosphide/toad contact. Gas cartridges and aluminu phosphide used to control ground squirrels and other burrowing animals would be likely to kill any Wyoming toads in the burrow.

\section{BIOLOGICAL OPINION}

Because this species consists of very few individuals in a very localized population, and because little is known about the effects of grain bait, or the iikelihood of mortality from gas cartridges or aluminum phosphide, it is my biological opinion that the use of these materials by the ADC Program is likely to jeopardize the continued existence of the Wyoming toad.

\section{REASOMABLE AND PRUDEMT ALTERHATIVES}

The Section 7 regulations have defined reasonable and prudent alternatives as alternative actions, identified during formal consultation, that can be implemented in a manner consistent with intended purpose of the action, that can be implemented consistent with the scope of the Federal agency's legal authority and jurisdiction, that are economically and technologically feasible, and that the Service believes would avoid the likelihood of jeopardizing the continued existence of 1 isted species or result in the destruction or adverse modification of critical habitat.

As a reasonable and prudent alternative, the Service shall be contacted prior to any $A D C$ work involving toxicants in the Laramie River Basin in Albany County, Wyoming. Strychnine, zinc phosphide, aluminum phosphide, 
or gas cartridges shall not be used in areas of the Basin where it is determined by the Service that the Wyoming toad may occur.

Because this biological ooinion has found jeodaray, the USDA is reauired to notify the Service of its final decision on the implementation of the reasonable and prudent alternatives.

\section{INCIDENTAL TAKE STATEMENT}

Assuming the implementation of the reasonable and prudent alternative described above, the Service anticipates that the proposed action will not result in any incidental of the Wyoming toad.

\section{Summary Comments}

The dynamic nature of the ADC Program demands close coordination with the Service at field, Regional and Central office levels to assure that any incidental take is reported and steps are taken to correct the circumstances that caused it. The Service suggests that annual coordination meetings, involving appropriate Washington staff from the Fish and Wildlife Service and $A D C$, will serve this purpose.

Further, the Service's central office should receive the annual reports of target and non-target species taken during all operations.

Reinitiation

This concludes formal consultation on the Animal Damage Control Program. Reinitiation of formal consultation is required if the amount or extent of incidental take is exceeded, if new information reveais effects of the action that may impact listed species or critical habitat in a manner or to an extent not considered in this opinion, if the action is subsequently modified in a manner that caused an effect to the listed species or critical habitat that was not considered in this opinion, or if a new species is listed or critical hatitat designated that may be-affected by the action. If reinitiation is required, the responsible ADC office must immediately reinitiate with the appropriate Fish and Wildlife Service office.

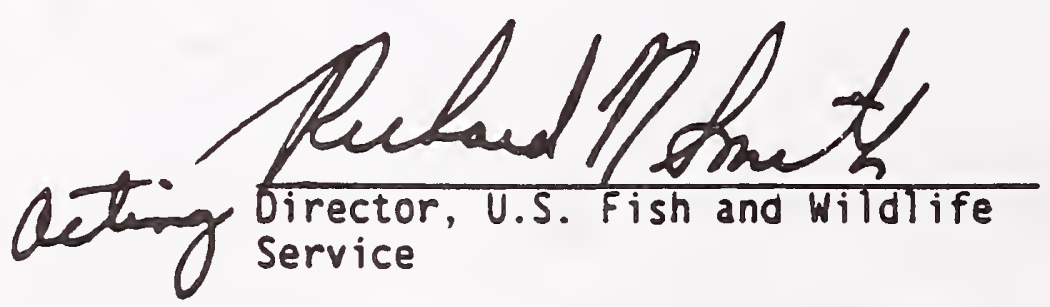




\section{Enclosure 1 \\ SPECIES WITH "MAY AFFECT" DETERMIMATIONS SUBMITTED BY USDA}

Mammals (27)

1. Alabama beach mouse (Peromyscus polionotus ammobates)

2. Biack-footed ferret (Mustela niarioes)

3. Brown/grizzly bear (Ursus arctos pruinosus)

4. Carolina northern flying squirrel (Glaucorays sabrinus coloratus)

5. Choctawhachee beach mouse (Peromyscus polionotus alloorys)

6. Columbian white-tailed deer (Odocoileus virainianus leucurus)

7. Delmarva fox squirrel (Sciurus niger cinereus)

8. Eastern cougar (Felis concolor cougar)

9. Florida panther (Felis concolor coryi)

10. Gray bat (Myotis arisescens)

11. Gray wolf (Canis lupis monstrabilis)

12. Indiana bat (Myot is sodalis)

13. Jagarundi (Felis yagouaroundi cacomitli)

14. Morro bay kangaroo rat (Dipodomys heermanni morroensis)

15. Mount Graham red squirrel (Tamiasciurus hudsonicus grahamensis)

16. Ocelot (Felis pardalis)

17. Ozark big-eared bat (Plecotus townsendii ingens)

18. Perdido Key beach mouse (Peromyscus polionotus trissyllepsis)

19. Red wolf (Canis lupus)

20. Salt marsh harvest mouse (Reithrodontomys raviventris)

21. San Joaquin kit fox (Vulpes macrotis nereis)

22. Sonoran pronghorn (Antilocaora americana sonoriensis)

23. Utah prairie dog (Cynomys parvidens)

24. Virginia big-eared bat (Plecotus pownsendi virqinianus)

25. Virginia northern flying squirrel (Glaucomys sabrinus fuscus)

26. Hualapai Mexican vole (Microtus mexicanus hualpaiensis)

27. Woodland caribou (Ranaifer terandus caribou)

Birds (37)

28. Aleutian Canada goose (Granta canadensis leucopareia)

29. American peregrine falcon (Falco pereorinus anatum)

30. Arctic peregrine falcon (Falco peregrinus tundrius)

31. Attwater's greater prairie chicken (Iympanuchus cupido attwateri)

32. Bald eagle (Hal iaeetus leucocephalus)

33. Black-capped vireo (Vireo atricapillus)

34. Brown pelican (Pelecanus occidentalis)

35. California clapper rail (Rallus Longerostris obsoletus)

36. Cal ifornia condor (Gymnogyos cal ifornianus)

37. California least tern (Sterna albifrons browni)

38. Eskimo curlew (Numenius boralis)

39. Hawai ian comon moorhen (Gallinula chloroous sandvicensis)

40. Hawaiian coot (Fulica americana alai)

41. Hawaiian duck (Anas wyvilliana) 
42. Hawai ian goose (Nesochen sandvicensis)

43. Hawaiian silit (Himantopus mexicanus knuaseni)

44. Large Kauai thrusn (Myadestes myadestinus)

45. Laysan duck (Anas iaysanensis)

46. Laysan finch (Telespyza cancans)

47. Least tern (Sterna ancillarum)

48. Light-footed clapper rail (Rallus longirostris ievices)

49. Masked bobwhite (Colinus virainianus ridqways)

50. Mississippi sandhill crane (Grus canadensis qulla)

51. Molokai thrush (Myadestes lanaiensis rutha)

52. Newell's Townsend's shearwater (Puffinus auricularis newelli)

53. Nihoa fincha (Telespyza ultima)

54. Nihoa millerbird (Acrocephalus familiaris kinai)

55. Northern Aplomado falcon (Falco femoralis septentrional is)

56. Piping plover (Charadrius melodus)

57. Puerto Rican nightjar (Caprimulqus noctitherus)

58. Puerto Rican parrot (Amazona vittata)

59. Puerto Rican plain pigeon (Columoa inornata wetmorei)

60. Roseate tern (Sterna dougallii)

61. Small Kauai thrush (Myadestes paimeri)

62. Whooping crane (Grus americana)

63. Wood stork (Mvcteria americana)

64. Yellow-shouldered blackbird (Agelaius xanthomus)

Reptiles (14)

65. Alabama red-bellied turtie (Pseudemys alabemensis)

66. American alligator (Alliqator mississippiensis)

67. American crocodile (Crocodulus acutus)

68. Desert tortoise (Gopherus agassizii)

69. Eastern indigo snake (Drymarchon corais couperi)

70. Flattened musk turtle (Sternotherus depressus)

71. Green sea turtle (Chelonia mydas)

72. Hawksbill sea turtle (Eretmochelys imbricata)

73. Kemps's Ridley sea turtle (Lepidochelys kempii)

74. Leatherback sea turtie (Dermocnelys coriacea)

75. Loggerhead sea turtle (Caretta caretta)

76. Mona boa (Evicrates monensis monensis)

77. Mona ground iguana (cyclura stejnegeri)

78. Monito gecko (Sohaerodactylus micropithecus)

\section{Amphibians (1)}

79. Hyoming toad (Bufo hemiophrys bax̄eri)

Fishes (17)

80. Alabama cavefish (Speoplatyrhinus poulsoni)

81. Amber darter (Percina antesella)

82. Bayou darter (Etiostoma rubrum) 


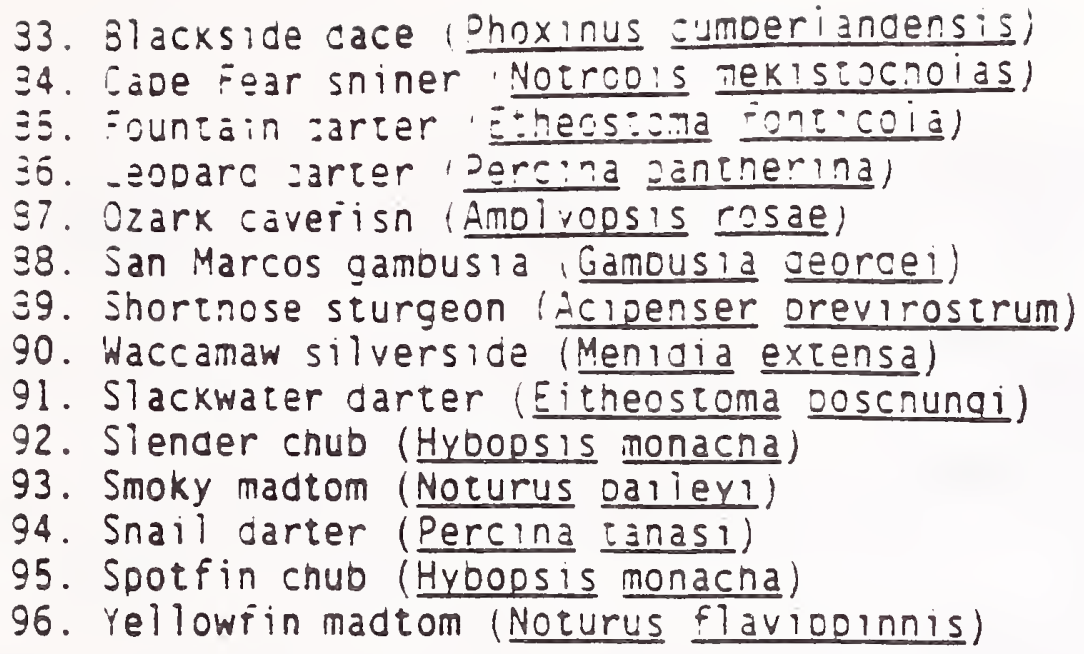

Clams (25)

97. Alabama lamo peariy musse! (Lampsilis virescens)

98. Aopalachian monkeyface vearly mussei (Quadrula sparsa)

99. Birdwing pearly mussei (Conradilla caelata)

100. Cumberiano Dean pearly mussei (Villasa leMicromyal trabilio)

101. Cumberland monkeyface pearly nussel (Quadrula intermedia)

102. Curtis' pearly mussel (Epioblasma l=oysnomial florentine curtisi)

103. Curtus' mussel (Pleurodema curtum)

104. Oromedary peariy mussel (Dromus dromus)

105. Fat pocketbook (Potamilus [=Proptera] capax)

106. Fine-rayed pigtoe pearly mussei (Fusconaia coneolus)

107. Green-blossom pearly mussel (Epiodiasma [0isnomial torulosa qubernacuium)

108. Judge Tait's mussel (Pleurobema taitianum)

109. Louisiana pearlshell (Marqaritifera hembeli)

110. Orange footed pimpleback pearly mussel (Plethobasis cooperianus)

111. Pale lilliput pearly mussel (Toxolasma scrunculina cylindrella)

112. Pink mucket pearly mussei (Lampsillis oroiculata orbiculata)

113. Rough pigtoe (Pleurooema plenum)

114. Shiny pigtoe peariy mussel (Fusconoin edaariana)

115. Stirrup shell (Quadrula stapes)

116. Tan riffle shell (Eoiobiasma walkeri)

117. Tar River spinymussel (Elliptio steinstansana)

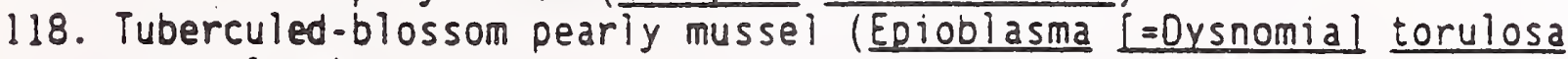
torulose)

119. Turgid blossom pearly mussel (Eoioblasma [=0ysnomia] turaidula)

120. White warty-back pearly mussel (Plethobasis cicatricosus)

121. Yellow-blossom pearly mussel (Epioblasma $[=0 y s n o m i a]$ florentina florentina)

Crustaceans (2)

122. Cave crayfish (Cambarus zophonastes)

123. Nashville crayfish (Orconectes shoupi) 
124. Aconitum novedoracense

125. Arenaria cumberiandensis

126. Baptisia aracnnifera

127. Betula uber

128. Echinacea tennesseensis

i29. Isotria medeoloides

130. Lindera melissifolia

131. Lysimachia asperulaefolia

132. Oxyoolis canbyi

133. Penstemon haydenii

134. Pityopsis ruthii

135. Sagittaria fasciculata

136. Sarracenia oreopnila

137. Sarracenia rubra

138. Sarracenia al abamenes is

139. Scutellaria montana

140. Solidago albopilosa

141. Solidago snortii

142. Solidago spithamaea

143. Trifolium stoloniferum

144. Zizania texana 
Anderson, E.A... S.C. Forrest. T.W. Clark and L. Richardson. 1986.

Paleobiology, biogeograpny, and systematics of the olack-footed ferret, Mustela nigripes (Audubon and Bacnman), i851. Great Basin Nat. Men. $8: 11-62$.

Bailey, E.P. and J.L. Trapp. 1984. A second wild breeding popuiation of the Aleutian Canada goose. Am. Biros 38:284-286.

Barry, S.J. 1978. Status of the San Francisco garter snake. Special Publ. 78-2, Inland Fisheries Endangered Species Program, Calif. Dept. Fish and Game.

Barry, K.H. (Ed.). 1984. The status of the desert tortoise (Gopherus agassizii) in the United States. Report from the Desert Tortoise Council to the U.S. Fish and Wildlife Service, Sacramento, California. Order No. 1130-0083-81.

Bartonek, J.C. U.S. Fish and Wildlife Service Region 1. July 1990. Memorandum to the Chief, Office of Migratory Bird Management. Forecast population of Aleutian Canada Goose in Hinter of 1990-91 and likely areas of range expansion.

Baxter, G.T.. and M.D. Stone. 1985. Amphibians and reptiles of Wyoming. Wyoming Game and Fish Department, Cheyenne, Wyoming. 137 pp.

Baxter, G.T., and M. Stromberg. 1980. Status report. Report to U.S. Fish and Wildife Service, Denver, Colorado. 5 pp.

Baxter, G.T., and M.R. Stromberg, and C.K. Dodd, Jr. 1982. The status of the Hyoming toad, Bufo hemioohrys baxteri. Environ. Conservation $9(4): 348,338$.

Biggins, D.E., M.H. Schroeder, S.C. Forrest, and L. Richardson. 1985. Movements and habitat relationships of radio-tagged biack-footed ferrets. Pp. 11.1-11.17 in Proceedings of Black-footed Ferret Workshop, Sept. 18-19, 1984 (S.H. Anderson and D.B. Inkley, eds.). Wyoming Game and Fish Dept., Cheyenne. 228 pp.

Burnham, W.A. and T.J. Cade. 1992. Peregrine falcon recovery program: Status and recommendations. The Peregrine Fund. Boise, Idaho. 9 pp.

Byrd, G.Y. and D.W. Hoolington. 1983. Ecology of Aleutian Canada geese at Buldir Island, Alaska. U.S. Fish and Wildlife Service, Special Scientific Report - Wildlife No. 253.

Choate, J.R., E.K. Boggess, and F.R. Henderson. 1982. History and status of the biack-footed ferret in Kansas. Trans. Kansas Acad. Sci. 85:121. 132. 
Fitch. H.S.:965. An ecological study of the garter snake, Thamnopnis sirtalis. Univ. Kansas Mus. Nat. Hist. Misc. Publ. No. 52.

Flath. D.L. and M. Stromber. 1986. Historic status of black-footed ferret habitat in Montana. Great Basin Nat. Mem. 8:53.71.

Hall, E.R. and K.R. Kelson. 1959. Mammals of North America. Ronald Press, New York.

Hatch, S.A. and M.A. Hatch. 1983. An isolated population of small Canada geese on Kiliktagik Island, Alaska. Wildfowl 34:130-136.

Heggen, A.W., and R.H. Hasenyager. 1977. Annuai Utah prairie dog progress report to U.S. Fish and Wildlife Service by the Utah Division of Wild ife Resources. Unpubl. Rep., Salt Lake City, UT. \& Pp.

Karl, A.E. 1983. The distribution, relative densities, and habitat associations of the desert tortoise, Gopherus agassizii, in Nevada. MS Thesis, California State University, Nortnridge. 111 PP.

Kjos, C. 1992. Bald eagle numbers continue to rise. Endangered Species Technical Bulletin. 17(1-2): 3-4.

Koford, C.B. 1953. The California condor. National Audubon Society, Research Report No. 4.

Landers, J.L. 1980. Recent Research on the Gopher Tortoise and Its Implications. Pages 8-14 in R. Franz and R.J. Bryant (eds.). Proc. Ist Ann. Mtg., Gopher Tortoise Council. 80 pp.

Lewis, D.L., G.T. Baxter, K.M. Johnson, and M.D. Stone. 1985. Possible extinction of the Wyoming toad, Bufo hemiophrys baxteri. J. Herpetology $19(1): 166-168$.

Lewis, J.C. 1986. The Whooping crane: Audubon Wildlife Report, 1986. National Audubon Society, New York. pp. 659-676.

Lowe, D.H., Matthews, J.R. and C.J. Moseley. 1990. The official World Hildife Fund Guide to Endangered Species of North America. Beacham Publishing, Wastington, D.C. PP 1180.

Montanucci, R.R. 1965. Observations on the San Joaquin leopard lizard, Crotzohytus wislizenii silus Stejneger. Herp. $21(4): 270-283$.

Montanucci, R.R., R.H. Axtell, and H.C. Dessauer. 1975. Evolutionary divergence among collared lizards (Crotaphytus), with coments on the status of Gambelia. Herp 31(3):336-347.

Morrell, S.H. 1972. Life history of the San Joaquin kit fox. California Fish and Game. 58:162-174. 
Odum, R.R., J.R. McCollum, M.A. Neville, and D.R. Ettman. 1977. Georgia's Protected Wildlife. Georgia Department of Natural Resources. Game and Fish Division. Social Circle, Georgia p. 51.

O'Farrell, T.P. 1983. San Joaquin kit fox recovery pian. Prepared for the U.S. Fish and Wild ife Service, Portland, Oregon. EG\&G Energy Measurements, Inc., Goleta. California. 84 pp.

Refuge Manager, Mississippi Sandhill Crane National Wildiife Refuge. 1992. Personal Communication by letter to Region 4 Regional Office, U.S. Fish and Wildi ife Service.

Richardson, L., T.W. Clark, S.C. Forrest, and T.M. Campbell III. 1985. Snow-tracking as a method to search for and study the black-footed ferret. Pp. 25.1-25.11 in Proceedings of the Black-footed Ferret Workshop, Sept. 18-19, 1984 (S.H. Anderson and D.B. Inkley, eds.). Wyoming Game and Fish Dept., Cheyenne, Wyoming. 229 pp.

Snyder N.F.R. 1983. California condor reproduction, past and present. Bird Conservation $1: 67-85$.

Speake, D.H., J.A. MeGlincy, and T.R. Colvin. 1978. Ecology and Management of the Eastern Indigo Snake in Georgia: A Progress Report. PP. 6473. In R.R Odum and L. Landers, Eds. Proceedings of Rare and Endangered Symposium., Georgia Department of Natural Resources., Game and Fish Division., Technical Bulletin. Wh 4.

Stromberg, M. 1981. Wyoming toad (Bufo hemiophrys baxteri) endangered. J. Colorado-Wyoming Acad. Sci. 13(1):47.

Turner, B. 1979. An evaluation of the Utah prairie dog (Cynomys parvidens). Unpubl. Rep., Salt Lake City, UT. 4 pp.

U.S. Fish and Wildlife Service. 1978. Part 17 . Endangered and Threatened Wildlife and Plants: Listing of the Eastern Indigo Snake as a Threatened Species. Federal Reqister, 43(21):4026-4028.

- 1980. Endangered and threatened wildiife and plants: Listing as threatened with critical habitat for the Beaver Dam slope population of the desert tortoise in Utah. Federal Register $45(163): 55654-55666$.

1982a. Grizzly bear recovery plan. U.S. Fish and Wildife Service. Denver, Colorado. January 29, 1982. 195 pp. 1982b. Eastern indigo snake recovery plan. U.S. Fish and Wild ife Service. Atlanta, Georgia. April 22 , 1982. 23 PP. 
U.S. Fish and Wildife Service. :982c. Bald eagle recovery plan (southwestern population) U.S. Fisn and Wildife Service. ilbucuerque. New Mexico. jeptemoer 3. i982. j̄j pp.

1983. Littwater's prairie cnicken recovery pian. U.S. Fisn ano Wiidife Service. Albuquerque. New Mexico. $48 \mathrm{pp}$.

1985a. Recovery pian for the San Francisco garter snake (Thamnopnis sirtalis tetrataenia). U.S. Fish and Wildi ife Service, Portiand, Oregon. September 11, 1985. 77 pp.

1985b. Blunt-nosed leopard lizard revised recovery plan. Portland, Oregon. December 26, 1985. 85 pp.

1986. Whooping crane recovery plan. U.S. Fish and Wildifie Service. Aibuquerque, New Mexico. 28 pp.

1987. Northern Rocky Mountain woif recovery plan. U.S. Fisn and Wildi ife Service, Denver, Colorado. August 3, 1987. 119 $\mathrm{pP}$.

- 1988. Black-footed ferret recovery plan. U.S. Fish and Hildlife Service, Denver, Colorado. August 8, 1988. $154 \mathrm{pp}$.

1990a. Endangered and threatened wildlife and plants: Determination of threatened species for the Mojave population of desert tortoise. Federal Register 55(63):12178-12191. April 2, 1990.

1990. Northern Aplomado falcon recovery plan. U.S. Fish and Wildi ife Service. Albuquerque, New Mexico. June 8, 1990. $56 \mathrm{pp}$.

- 1990c. Gopher tortoise (Gopherus

polyohemus) recovery plan. U.S. Fish and Wildlife Service. U.S. Fish and Wildlife Service, Jackson, Mississippi. December 26, 1990. 28 pp.

. 1991a. "The Red Book," Endangered and Threatened Species of the Southeastern United States, Region 4, U.S. Fish and Wildife Service, Atlanta, Georgia. February 1991.

1991b. Mississippi sandhill crane Grus

canadensis pulla recovery plan. U.S. Fish and Wildlife Service, Atlanta Georgia. September 6, 1991. 42 pp.-

- 1991C. Wyoming toad recovery plan. U.S.

Fish and Wildlife Service, Denver, Colorado. September 11, 1991. 22 pp. 
U.S. Fish and Wildlife Service. 199ld. First update of peregrine falcon (Falco peregrinus), Eastern population recovery plan. Newton Corner, Massachusetts. September 27, 1991. 35 pp.

- 1991e. Aleutian Canada goose revised recovery pian. Anchorage, Alaska. September 30, 1991. 55 pp.

- 1991f. Utah prairie dog recovery plan. U.S. Fish and Wildlife Service, Denver, Colorado. September 30, 1991. $41 \mathrm{pp}$.

199lg. Biological opinion for the friant Division Water Contract Renewals. U.S. Fish and Wildlife Service, Sacramento, California. October 15, 1991. 47 pp. and appendices. wolf. Twin Cities, Minnesota. 1992 . Recovery plan for the eastern timber

Vankirk, E.A. 1980. Report of population of Bufo hemiophrys on Laramie Plain, Albany County, Wyoming. Report to Wyoming Natural Heritage Program. The Nature Conservancy, Cheyenne, Wyoming. 6 pp.

Wilbur, S.R. 1980. Estimating the size and trend of the California condor population, 1965-1978. California Fish and Game 66:40-48.

Young, S.P. and E.A. Goldman. 1944. The wolves of North America. Am. Wildl. Mgt. Inst., Washington, O.C. $636 \mathrm{pp}$. 
decora. Bobby. :991. SSDA comments on Jrait opinion. Letter so Regionai Jirector. Region 5. Secemoer !9. :e?!. Eeviseo Oraft. Só dages.

Acting Assistant Regionai Director. Region 5. 1991. -etter and draft opinion to james Glosser.

Assistant Regional Director. Region 5. :992. Partial drait AOC Opinion memorandum to all Regions. March 17, 1992. 46 pages.

Assistant Regional Director, Region ó. 1991. Review of ADC draft opinion. Memorandum to Assistant Regional Director, Region 5. iune 3, 1991. 8 pages.

Assistant Regional Director, Region 6. 1992. Review of ADC ODinion. Memorandum to Assistant Regional Director, Region इ. April 20. 1992. 4 pages.

Chief, Endangered Species. Region 4. 1992. Mississippi sandhill cranes. Memorandum to Chief, Endangereo Species, Region 5. 4 pages.

Chief, Endangered Species, Region 5. 1991. Note and draft opinion to consultation team members.

Corr, Odon. March 1990. Letter explaining incidental take of gray wolf in North Dakota. USDA-ADC. 2 pages.

Deputy Director, Region 5, 1990. U.S. Fish and Wildlife Service, Formal Consultation. USDA-ADC. Memorandum to Regional Director, Region 5. January 4, 1990.

Deputy Director, Region 5. 1991. Memorandum to all Regions requesting comments on USDA revised draft. December 31, 1991. 46 pages.

- 1990. Letter to James Glosser acknowledging consultation request. April $27,1990$.

Field Supervisor, Reno, Nevada; Region 1, 1990. ADC desert tortoise information. Memorandum to Paul Nickerson, Region 5. December 19 , 1990. 3 pages.

Field Supervisor, Sacramento, California; Region 1, 1991. Aphis consultation-species accounts. Memorandum to ARO-FWE, Portland, Oregon. January 2, 1991.5 pages.

Field Supervisor, Sacramento Field Office. 1991. Animal Damage Control consultations. Memorandum to Assistant Regional Director, Region 5. June 6, 1991. 2 pages. 
Field Supervisor. Ashevilie. North Caroiira. 1991. Jpecies accounts and opinion. Region 4 species. Faxeo co Paui Nickerson May 23, 1991.

Glosser, james. 1990a. JSDA ietter to john Turner requesting formal consuitation on the Nationai ADC Program. March 15, i990.

- i990b. USDA letter to John Turner responding to extension request. October $26,1990$.

Thompson, Ronald. April 10, 1991. Letter to MA. Bill Lehman, U.S. Fish and Wildife Service explaining incidental take of a San Joaquin kit fox. USDA-ADC. 2 pages.

Regional Director, Region 2. 1990a. Memorandum to Regional Director, Region 5 requesting an extension of the consultation time frame. September 11 , 1990.

1990b. Species information on Attwater's

prairie chicken, masked bobwhite, Northern aplomado falcon, whooping crane, Sonoran pronghorn, jagarundi and ocelot. November 23, 1990.

1991. Comments on draft opinion. Memorandum to Regional Director, Region 5. May 17, 1991. 2 pages.

1992. Section 7 Consultation; Oraft opinion on Animal Damage Control nationwide program. Memorandum to Regional Director, Region 5. January 20, 1992.

Regional Director, Region 3. 1990. Oraft writeup for bald eagle section of opinion. August 9, 1990.

1992. Oraft biological opinion on the Animal Damage Control program. Memorandum to Regional Director, Region 5. January 20, 1992. 2 pages.

Regional Director, Region 6. 1990. Memorandum to Regional Director, Region 5 providing species information on ferret, walf, grizzly. Wyoming toad, Utah prairie dog and desert tortoise.

1992. Review of ADC draft opinion.

Memorandu to Regional Director, Region 5. January 17, 1992. 7 pages. 
:E: $\quad 3012-M I B-F W S / D i r e c t c r a t e$ RF 3012-MIB-FiWS/DD Chron

3012 -MIB-FWS/CCU

3024-MIB-FWS/AFWE RF

434-ARSLQ-FWS/DAFWE RF

452-ARLSQ-FWS/DES (CEnright)

452-ARLSQ-FWSIOES RF

FWS/DES:CEnright: jma:358-21?!:7/28/92:adC42.rec (Disk: Enrights Storage Alerts/Briefings) 


\title{
APPENDIX 5 M-44 CYANIDE CAPSULE USE RESTRICTIONS
}

\author{
M-44 Cyanide Capsules \\ M-44 Use Restrictions \\ EPA Registration No. 56288-15
}

1. Use of the M-44 device shall conform to all applicable federal, state, and local laws and regulations.

2. Applicators shall be subject to such other regulations and restrictions as may be prescribed from time-to-time by the U.S. Environmental Protection Agency (EPA).

3. Each applicator of the $\mathrm{M}-44$ device shall be trained in: (1) safe handling of the capsules and device, (2) proper use of the antidote kit, (3) proper placement of the device, and (4) necessary recordkeeping.

4. M-44 deviccs and sodium cyanide capsules shall not be sold or transferred to, or entrusted to the care of any person not supervised or monitored, by the Animal and Plant Health Inspection Service (APHIS), Animal Damage Control (ADC) program or any agency not working under an ADC cooperative agreement.

5. The M-44 device shall only be used to take wild canids suspected of preying on livestock, poultry, or federally designated threatened or endangered species.

6. The M-44 device shall not be used solely to take animals for the value of their fur.

7. The M-44 device shall only be used on or with 7 miles of a ranch unit or allotment where losses due to predation by wild canids are occurring or where losses can be reasonably expected to occur based upon recurrent prior experience of predation on the ranch unit or allotment. Full documentation of livestock depredation, including evidence that such losses were caused by wild canids, will be required before applications of the M-44 is undertaken.

8. The M-44 device shall not be used: (1) In areas within national forests or other federal lands set aside for recreational uses, (2) areas where exposure to the public and family and pets is probable, (3) in prairie dog towns, or, (4) except for the protection of federally designated threatened or endangered species, in national and state parks; national or state monuments; federally designated wilderness areas; and wildlife refuge areas.
9. The M-44 device shall not be used in areas where federally listed threatened or endangered animal species might be adversely affected. Each applicator shall be used a map, prepared by or in consultation with the U.S. Fish and Wildlife Service, which clearly indicates such areas.

10. One person other than the individual applicator shall have knowledge of the exact placement location of all M44 devices in the field.

11. In areas where more than one governmental agency is authorized to place M-44 devices, the agencies shall exchange placement information and other relevant facts to ensure that the maximum number of M-44's allowed is not exceeded.

12. The M-44 device shall not be placed within 200 feet of any lake, stream, or other body of water, provided that natural depression areas which catch and hold rainfall only for short periods of time shall not be considered "bodies of water" for purposes of this restriction.

13. The M-44 device shall not be placed in areas where food crops are planted.

14. The M-44 device shall be placed at least a 50-foot distance or at such a greater distance from any public road or pathway as may be necessary to remove it from the sight of persons and domestic animals using any such public road or pathway.

15. The maximum density of M-44's placed in any 100acre pastureland area shall not exceed 10; and the density in any 1 square mile of open range shall not exceed 12 .

16. No M-44 device shall be placed within 30 feet of a livestock carcass used as a draw station. No more than four M-44 devices shall be placed per draw station and no more than five draw stations shall be operated per square mile.

17. Supervisors of applicators shall check the records, warning signs, and M-44 devices of each applicator at lease once a year to verify that all applicable laws, regulations, and restrictions are being strictly followed. 
18. Each M-44 device shall be inspected by the applicator at least once every week, weather permitting access, to check for interference or unusual conditions and shall be serviced as required.

19. Damaged or nonfunctional M-44 devices shall be removed from the field.

20. An M-44 device shall be removed from an area if, after 30 days, there is no sign that a target predator has visited the site.

21. All persons authorized to possess and use sodium cyanide capsules and M-44 devices shall store such capsules and devices under lock and key.

22. Used sodium cyanide capsules shall be disposed of by deep burial or at a proper landfill site.

23. Bilingual warning signs in English and Spanish shall be used in all areas containing M-44 devices. All such signs shall be removed when M-44 devices are removed.

a. Main entrances or commonly used access points to areas in which M-44 devices are set shall be posted with warning signs to alert the public to the toxic nature of the cyanide and to the danger to pets. Signs shall be inspected weekly to ensure their continued presence and ensure that they are conspicuous and legible.

b. An elevated sign shall be placed with 25 feet of each individual M-44 device warning persons not to handle the device.
24. Each authorized or licensed applicator shall carry an antidote kit on his person when placing and/or inspecting M-44 devices. The kit shall contain at least six pearls of amyl nitrite and instructions on their use. Each authorized or licensed applicator shall also carry on his person instructions for obtaining medical assistance in the event of accidental exposure to sodium cyanide.

25. In all areas where the use of the M- 44 device is anticipated, local medical people shall be notified of the intended use. This notification may be through a poison control center, local medical society, the public health service, or directly to a doctor or hospital. They shall be advised of the antidotal and first-aid measures required for treatment of cyanide poisoning. It shall be the responsibility of the supervisor to perform this function.

26. Each authorized M-44 applicator shall keep records dealing with the placement of the device and the results of each placement. Such records shall include, but need not be limited to:
a. The number of devices placed.
b. The location of each device placed.
c. The date of each placement, as well as the date of each inspection.

d. The number and location of devices which have been discharged and the apparent reason for each discharge.
e. Species of animals taken.
f. All accidents or injuries to humans or domes- tic animals.

\author{
U.S. Department of Agriculture \\ Animal and Plant Health Inspection Service \\ Animal Damage Control \\ National Technical Support Staff \\ Hyattsville, MD 20782 \\ May 13, 1988
}




\section{APPENDIX 6 TRAPPING REGULATIONS 1992 STATE OF MONTANA}

\section{DEFINITIONS}

Furbearing animals as defined by the law are marten or sable, otter, muskrat, fisher, mink, bobcat, lynx, wolverine, northern swift fox, and beaver. ONLY RESIDENTS MAY TRAP FURBEARERS. LICENSE REQUIRED.

Predatory animals are coyote, weasel, skunk and civet cat. LICENSE REQUIRED FOR NONRESIDENT TRAPPERS.

Nongame wildlife means any wild animal not otherwise legally classified by statute or regulation in Montana. Examples of nongame wildlife with commercial value are badger, raccoon, and red fox. LICENSE REQUIRED FOR NONRESIDENT TRAPPERS.

Fur dealer defined as any person or persons, firm, company or corporation engaging in carrying on, or conducting wholly or in part the business of buying or selling, trading, or dealing within the State of Montana, in the skins or pelts of any animal or animals, designated by the laws of Montana as furbearing or predatory animals, shall be deemed a fur dealer within the meaning of the act. If such fur dealer resides in or if his or its principal place of business is within the State of Montana, he or it shall be deemed a resident fur dealer. All other fur dealers shall be deemed nonresident fur dealers.

Licenses: Licenses are available from Department of Fish, Wildlife and Parks offices in Kalispell, Missoula, Bozeman, Great Falls, Billings, Glasgow, Miles City, and Helena.

General Trapper: \$20; available only to resident conservation license holders 13 years of age or older.

Youth Trapper: \$3; available only to resident conservation license holders 6 through 12 years of age. Valid for mink and muskrat.

Landowner Trapper: $\$ 1$; applicants must give legal description of land owned or leased, name, address, and resident conservation license number.

Nonresident C2 Predator and Nongame Wildlife Trapper: \$250; available only to nonresidents conservation license holders, 13 years of age or older, whose state of residence has nonresident trapper licenses available to Montana trappers.

Fur Dealer's License: Resident Fur Dealer - \$10; Fur Dealer Agent - \$10; Nonresident Fur Dealer - $\$ 50$.

\section{GENERAL REGULATIONS}

Indian Reservations: Tribal governments may have adopted trapping regulations within the exterior boundaries of their respective reservations. Trappers should be aware that tribal regulations may differ from the statewide trapping regulations adopted by the Montana Department of Fish. Wildlife and Parks Commission. The question of state-tribal jurisdiction has not been resolved.

Permission: Resident trappers must obtain permission of landowners before trapping on private land. Nonresidents must obtain written permission from the landowner, lessee or his agent before trapping or snaring predatory and nongame wildlife on private property.

Hunting: Bobcat, woiverine and lynx may be taken by hunting (M.C.A. Sec. 87-2-601). See regulations for bobcat and lynx for further information on means of taking these species.

Dogs: Dogs may be used to take bobcat, but no other animals defined by law as furbearing animals. 


\section{GENERAL REGULATIONS (cont.)}

Identification: Metal identification tags that bear the name and address of the trapper must be fastened to all traps and snares. Tags should be attached to the end of the snare, chain, or other anchoring material at the end farthest from the portion of the device which grips the animal. Snares must also have telephone numbers included on the tag. Landowners who trap with permit on their own lands and irrigation rights-of-way contiguous to their land do not need to tag traps or snares.

Snares: It is unlawful to set snares on private property without the landowner's consent. Snares must be set in a manner and at a time so as not to duly endanger livestock. A trapper who injures livestock in a snare is liable for damages.

Preserves, Parks Department Lands: All state game preserves are open to trapping. Trapping on Department of Fish, Wildlife and Parks' lands will be allowed by written authorization of the area manager or a department employee on lands not having a resident manager. Beaver Creek Park open to trapping by permission only obtained from Hill County Park Board.

Live Furbearers: Live furbearing animals may not be possessed except under the provisions of the fur farm or roadside zoo permits. It is unlawful to capture wild furbearers for fur farm stock.

Closures: All National Parks, National Wildlife Refuges, and Indian Trust or Tribal Trust lands are closed to trapping except as otherwise specified. Permits to trap on National Wildlife Refuges may be issued by the Refuge Manager.

Pelt Possession: It shall be unlawful for any fur dealer or fur dealer agent to purchase or possess any untagged bobcat, fisher, marten, otter, wolverine or lynx pelt, except those untagged furs originating outside Montana, when accompanied by an export permit or other documentation of lawful acquisition.

Export: A federal export permit is required in addition to a Montana state tag before the pelts of bobcat, lynx, and otter may be exported from the United States. Apply to U.S. Fish and Wildlife Service, 600 Central Plaza, Room 209, Great Falls, MT 59401.

Carcasses (Wolverine, Fisher, and Swift Fox): It is mandatory that the entire and intact carcass (including pelt), of all wolverine and fisher be turned in to the Department of Fish, Wildlife and Parks in good condition, at the time the pelt is presented for tagging. Good condition is defined as fresh or frozen and securely wrapped in such a manner as to have prevented decomposition in order that all tissue samples shall be suitable for lab analysis.

Any wolverine or fisher pelt that is presented for tagging without the carcass in good condition shall be subject to confiscation. Complete carcass (including pelt) of accidentally trapped swift fox must be turned in to Fish, Wildlife and Parks personnel if animal cannot be released alive.

Destroying Muskrat and Beaver Houses: It is unlawful for any person to willfully destroy, open or leave open, a house of muskrat or beaver, except that this shall not prohibit trapping in the house of muskrats when authorized by the Commission.

Checking and Placing Traps: Traps should be checked at least once every 48 hours. It is the trapper's responsibility to check his/her traps regularly. Failure to pick up snares or traps at the end of the trapping season or attending them in a manner that wastes furbearing animals constitutes a misdemeanor.

To prevent accidental trapping of raptors, no trap may be set within 30 feet of an exposed carcass placed in a manner that can be seen by soaring raptors. EXEMPTION: trappers employed or contracted by a government agency in the official performance of their duties. An exposed carcass is defined as the meat or viscera of a mammal, bird or fish, or any part thereof more than one pound in weight. Bleached bones are excluded.

It is unlawful to disturb traps or trapped animals belonging to another trapper without permission. Penalties are the same as set forth below. 


\section{GENERAL REGULATIONS (cont。)}

Penalties: Persons convicted of knowingly taking, possessing or transporting furbearers or pelts in violation of the rules or laws, shall be fined not less than $\$ 50$ or more than $\$ 1,000$, imprisoned in the county jail for not more than 6 months, or both. In addition, such person shall forfeit his privilege to hunt, fish or trap for not less than 24 months. Civil restitution from $\$ 100$ to $\$ 500$ may be assessed for each illegal animal or pelt.

Taking of fur animals during the open season by any means other than trapping or snaring is prohibited, unless otherwise stated.

Tagged Furbearers: A number of furbearing animals have been ear tagged for scientific study. If one of these animals is captured, please notify the nearest game warden or regional office of the tag number or numbers and the locality of the capture.

Recorded or Electronic Devices: It is unlawful to use any recorded or electrically amplified bird or animal calls or sounds or imitations of bird or animal calls or sounds to assist in the hunting, taking, killing or capturing of any wildlife except predatory animals. (M.C.A., Sec. 87-3-108.)

Criminal Trespass to Property: Montana law states that lands can be closed to the public either by posting the land or through verbal communication by landowners or their agents. However, even if lands are not posted, trappers are advised to seek landowner permission before pursuing any activities on private lands. If permission is granted, the landowner may revoke the permission by personal communication at any time.

Disposal of Trapped Non-Target Species: Protected birds or animals found alive in traps, and minimally injured shall be released on site. Trapped species in need of rehabilitation shall be removed and immediately reported to a Fish, Wildlife and Parks office, local warden, or biologist for disposition. Dead raptors, big game species, and furbearing animals during closed season should be left at the trapping site and shall be immediately reported to a Fish. Wildlife and Parks office or field personnel for disposition. When either a Fish, Wildlife and Parks office or field personnel cannot be reached, trappers may report the above information by calling 1-800-332-6117.

\section{QUOTAS/SEASON CLOSURES}

Trappers may call toll free 1-800-332-6117 during the trapping season to obtain current information on districts which have reached the quotas. Current harvest information may be obtained by calling the appropriate Fish, Wildlife and Parks Regional headquarters during normal business hours.

\section{PELT TAGGING}

Beaver pelts taken within Trapping Districts 1,2, and 3 must be tagged by Fish, Wildlife and Parks personnel residing in the district where taken prior to sale or transfer, or within 10 days following the closure of the applicable season. Untagged pelts will be subject to confiscation. Beaver pelts taken in Trapping Districts 4, 5, 6 and 7 do not require tagging.

Otter, marten and wolverine pelts, must be tagged by the Fish, Wildlife and Parks personnel residing in the district where pelts were taken no later than 10 days after close of the open season.

Bobcat, lynx, and fisher pelts must be tagged by Fish, Wildlife and Parks personnel residing in the trapping district where killed, within 72 hours of taking. The species, trapping district, date and tag number will be permanently recorded on the back of the trapper's license when pelts are tagged. Trappers or hunters unable to comply with the tagging requirements due to special or unique circumstances must report their harvest to the proper regional office or by calling 1-800-332-6117 during office hours ( 8 a.m. to 5 p.m.) within 72 hours of taking. Pelts not registered or presented to department personnel within 72 hours are subject to confiscation. 



\section{APPENDIX 7}

Uniled Slates Department of Agriculture

Animal and Plani Heath inspection Service

ADC Directive 2.050 o $320,0,3$

\section{TRAPS AND TRAPPING DEVICES}

1. PURPOSE

To establish guidelines for ADC personnel for using traps and other capture devices in managing wildlife damage.

2. REPLACEMENT HIGHLIGHTS

This Directive replaces ADC Directive 4.095 dated 11/29/90.

3. POLICY

The use of all traps and trapping devices by ADC employees will comply with applicable Federal, State, and local laws and regulations, except where specific exemptions or permits from State or local wildife management authorities are obtained. All traps and trapping devices are to be checked as frequently as possible and no less frequently than required by State law, unless ADC acquires specific written exemptions from the regulating State agency. All traps used by ADC will be labeled (e.g., Property of U.S. Government, Pfoperty of USDA, Property of Texas, etc.) either with an attached tag or 'stamped directly on the trap. Other trapping devices will be identified as required by state law.

Al1 traps and trapping devices will be set in a manner which minimizes the chances of capturing nontarget species. Nontarget animals captured will be released alive if it is determined that they are physically able to survive. Target animals captured will be dispatched immediately, removed from the capture device, and disposed of properly.

Appropriate warning signs will be posted on main entrances or commonly used access points to areas where foot-hold traps, snares, or conibear traps are in use. Signs will be routinely checked to assure they are present, obvious, and readable. Signs must be removed when equipment is no longer in use.

a. Foot-hold traps and snares. Foot-hold traps or snares are not to be set closer than 30 feet from any exposed animal carcass or part thereof, having meat or viscera attached, including remains of animals previnusly removed from traps or snares that may attract raptors or other nontarget animals. If an animal carcass can be clragged or moved by scavengers to within 30 feet of set foot-hold traps or snares, the carcass should be secured to restrict movement. These restrictions do not apply to animal carcasses used to attract 
bear or mountain lion to any approved capture devices or to foot-hold traps set for the purpose of live-capturing raptors.

The use of foot-hold traps on land must incorporate pan-tension devices to prevent or reduce the capture of nontargot animals, unluss such use would preclude capture of the intended target animals.

Foot-hold traps equivalent to size $3 \mathrm{~N}$ Victor or larger are limited to types with smooth, rounded offset steel jaws or padded soft-catch type jaws. This restriction does not apply to drowning sets. Foot-hold traps with teeth or spiked jaws are prohibited unless use is authorized in writing by the Director for the purpose of reducing trap injuries to target animals.

If it is necessary to use foot-hold traps or snares under fence Iines, reasonable efforts should be taken to obtain the approval of adjacent landowners, and judgment should be used to avoid capture of livestock and other domestic animals.

The use of break-away locks is encouraged when livestock, deer, or other large animals may be exposed to snare sets.

When setting traps and snares, caution should be used so that captured animals will not be conspicuous to the public, particularly along public roads and trails.

Appropriate notification signs must be posted near bear and lion foot snare sets.

Foot-hold traps will not be used to take bear.

b. Pole traps. Foot-hold traps, leg snares, or tangle snares may be set on poles or roosting structures to capture raptors causing damage if such devices are authorized by the applicable depredation permit. Appropriace Federal, State, or local special purpose permits shall be obtained and in the possession of the authorized $A D C$ person when performing the capture function.

Traps should not exceed size No. 1-1/2 for most raptors. This limitation does not preclude the use of larger, modified traps to capture eagles. Trap springs should be modified to produce the lightest jaw closure sufficient to catch and hold the target raptor. Trap jaws should be sufficiently padded to reduce the possibility of injuring the raptor's legs.

To reduce unnecessary stress to the captured bird, traps will be checked at least twice daily, but not less than required by perinit, 
and a slide wire, of similar device, shall be used to allow the raptor to rest on the ground.

c. Conibear traps. Conibear type traps equivalent to size 330 , or with a jaw spread exceeding 8 inches, are restricted to water sets.

d. Cage traps. In addition to the above requirements, cage traps loaned to cooperators or the public will be labeled as "Loaned equipment". Cooperators and the public will be responsible for replacing lost. damaged, or stolen equipment. For additional information see ADC Directive 4.165, Loaning Equipment.

\section{REFERENCES}

ADC Directive 4.165, Loaning Equipment (3/26/93)

50 CFR Part 21 - Migratory Bird Permits, Subpart D - Control of Depredating Birds

50 CFR Part 22 - Eagle Permits

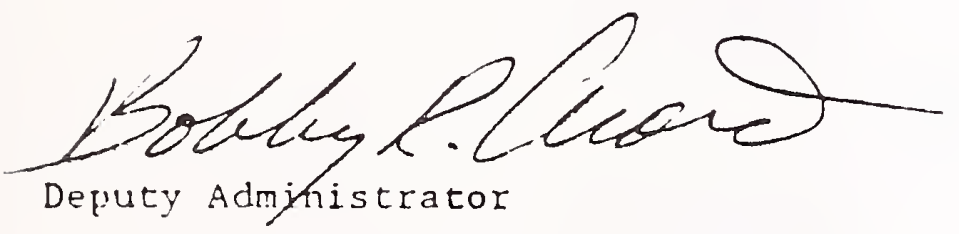





\section{APPENDIX 8}

MONTANA SHEEP AND LAMB LOSSES, 1987 - 1992 SOURCE: MONTANA AGRICULTURAL STATISTICS SERVICE

1992

Total Lamb Losses:
Total Sheep Losses:
TOTAL LOSSES:

Total Lamb Losses:

Total Sheep Losses:

TOTAL LOSSES:

Total Sheep Losses:

TOTAL LOSSES:

Total Lamb Losses:

Total Sheep Losses:

TOTAL LOSSES:

1988

Total Lamb Losses:

Total sheep Losses:

TOTAL LOSSES:

Total Lamb Losses:

Total Sheep Losses:

TOTAL LOSSES:
1989

1987

32,900

8,300

41,200

1991

34,500

10,400

44,900

1990

31,500

7,600

39,100

28,200

7,700

35,900

33,600

9,500

43,100

30,500

6,400

36,900

CATTLE AND CALVE DEATH LOSSES FOR 1991

SOURCE: NATIONAL AGRICULTURAL STATISTICS SERVICE, 1992

Montana Cattle Losses by all predators: 300

Montana Calf Losses by all predators: 1,800

TOTAL CALF/CATTLE LOSSES IN MT: 2,100 



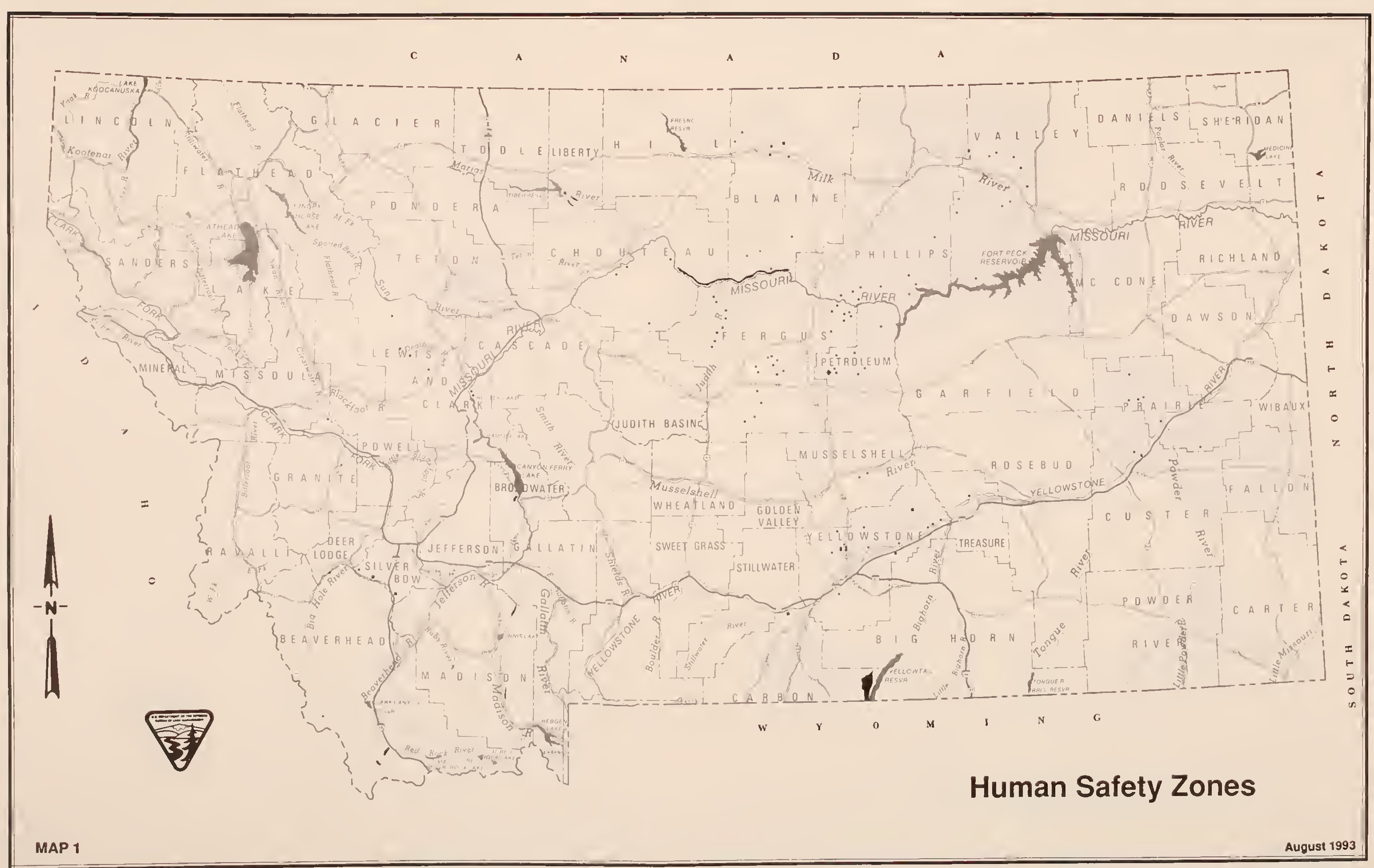





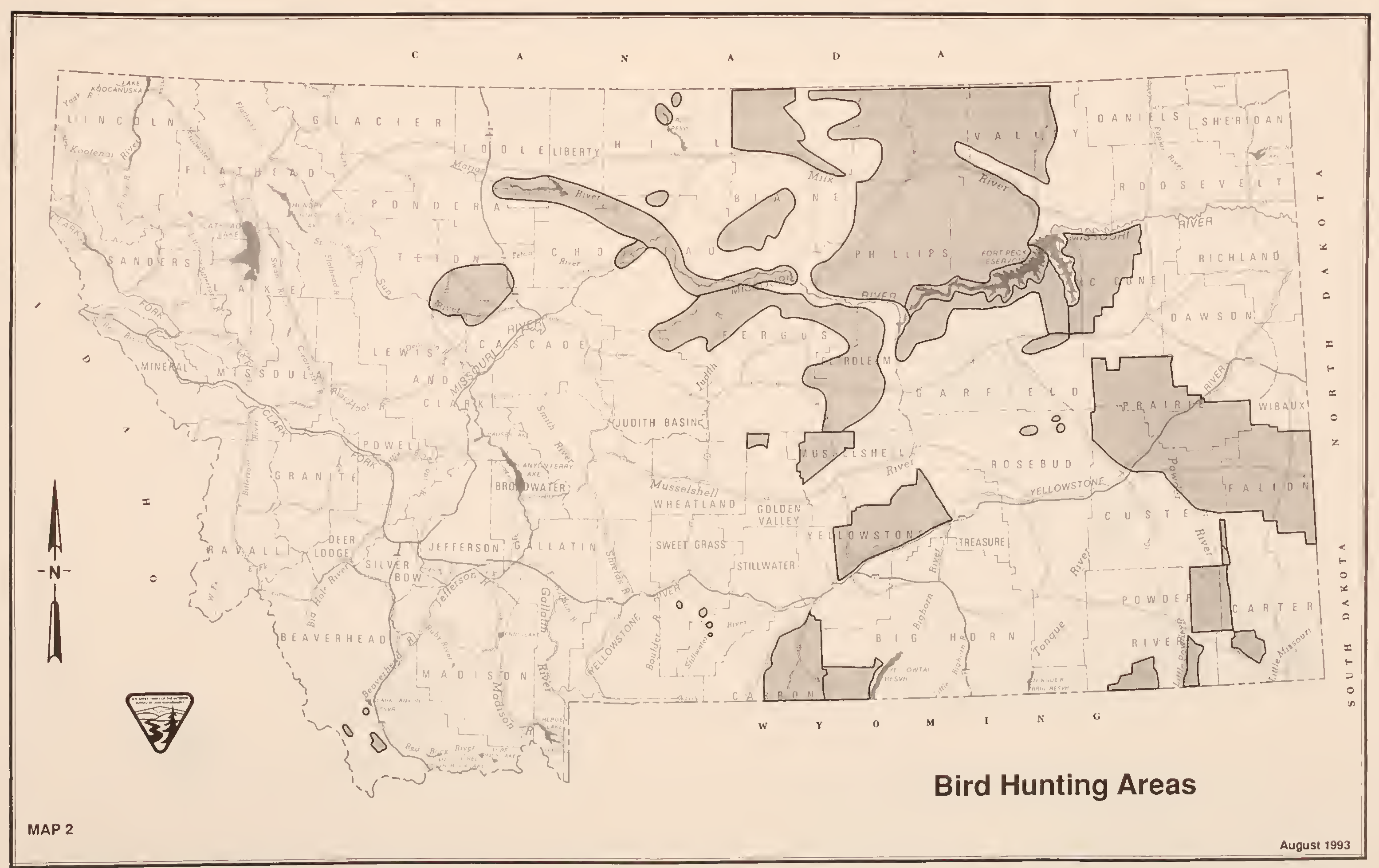





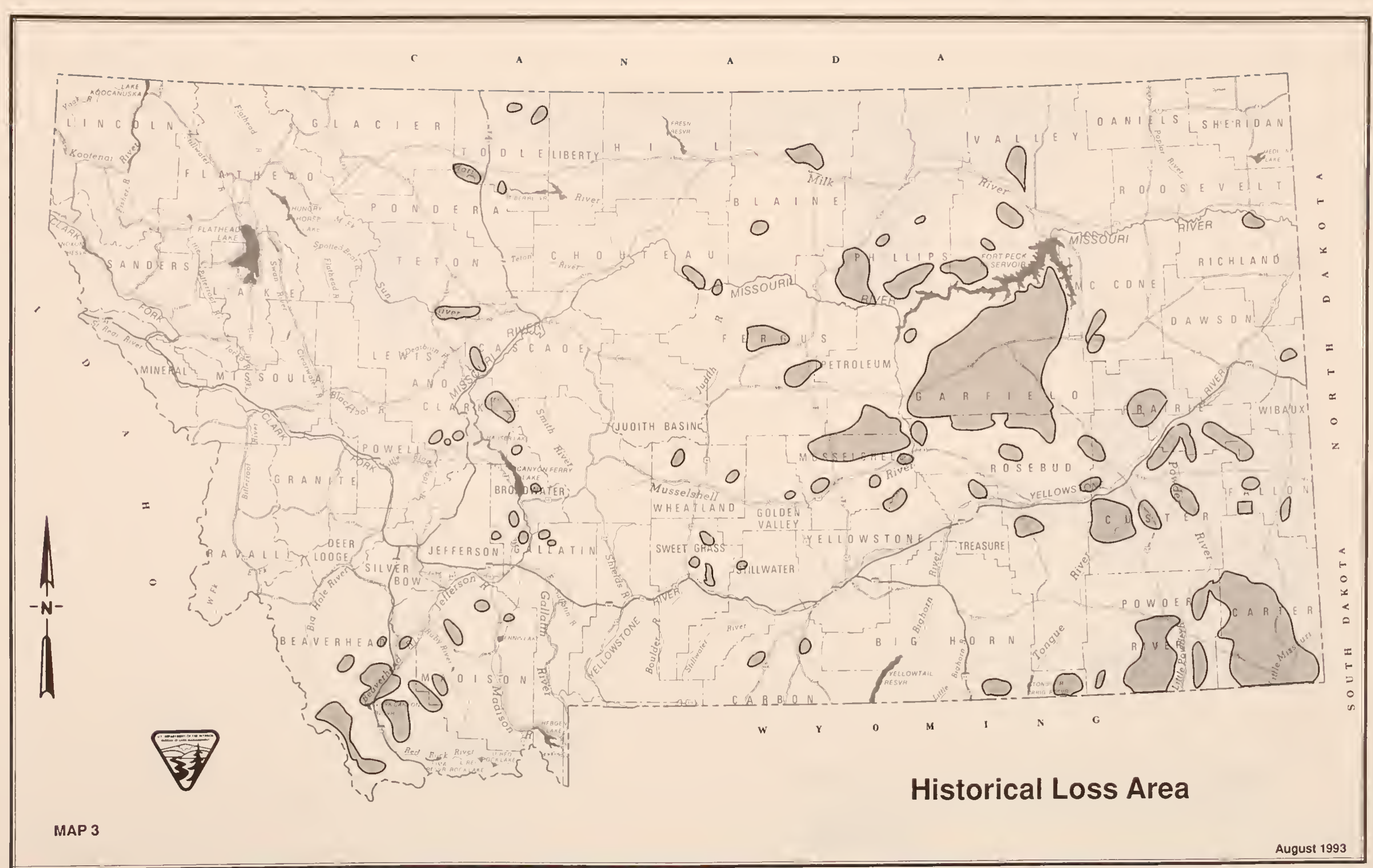





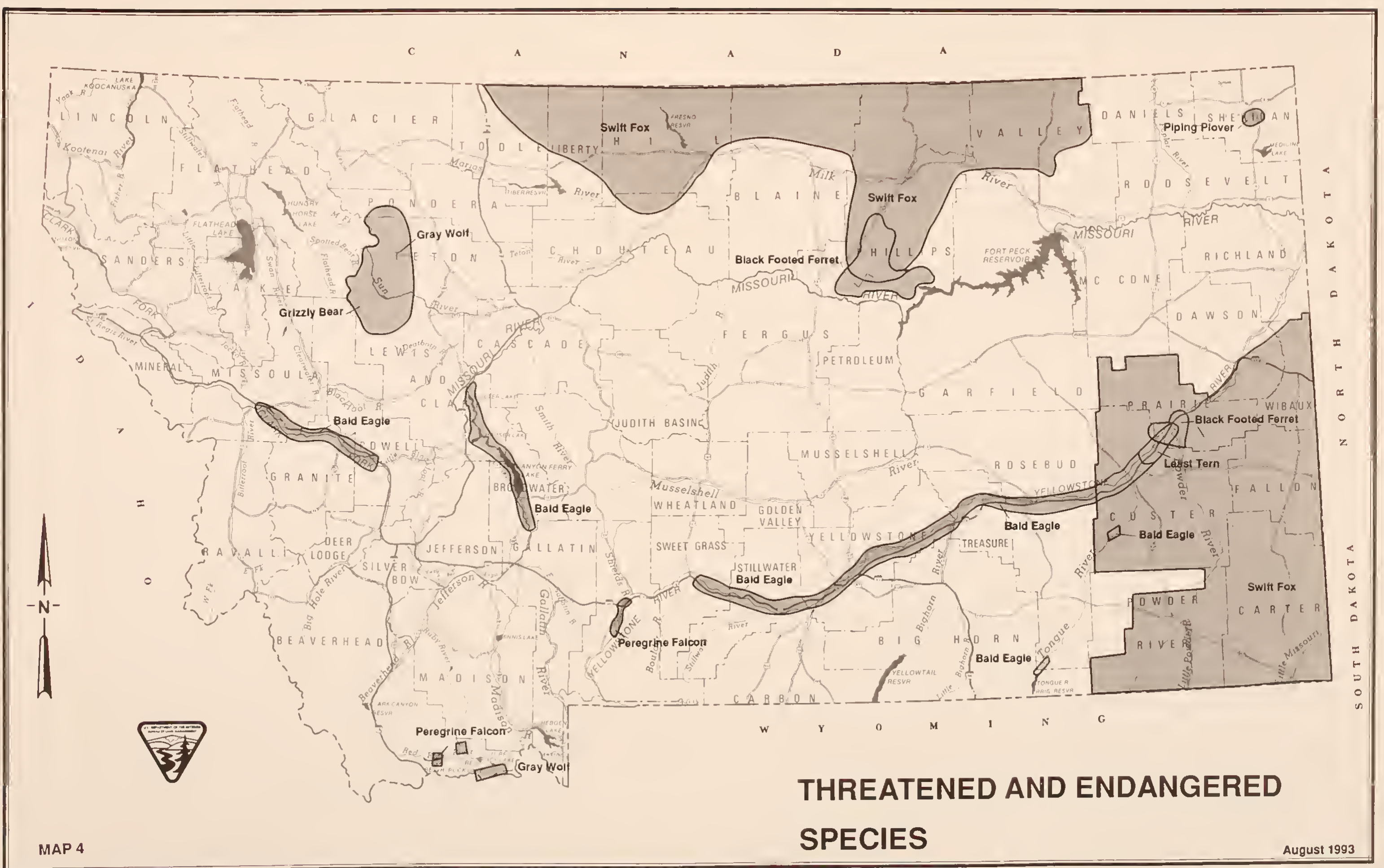




